UNIVERSIDADE DE SÃO PAULO

INSTITUTO DE QUÍMICA DE SÃO CARLOS

\title{
REDUÇÃO DE DERIVADOS DE ACETOFENONAS COM FUNGOS \\ DE ORIGEM MARINHA
}

Lenilson Coutinho da Rocha

Dissertação apresentada ao Instituto de Química de São Carlos, da Universidade de São Paulo para obtenção do Título de Mestre em Ciências área de concentração Físico-Química

Orientador: Prof. Dr. André Luiz Meleiro Porto

São Carlos

2008 
Dedico este trabalho a minha mãe pelo apoio incondicional em todos os momentos da minha vida. 
Este trabalho foi desenvolvido sob orientação do Professor Dr. André Luiz Meleiro Porto. 
"Viva para amar, ame sempre" Phob's 


\section{O cientista}

Se os objetos racionalizassem sozínhos o mundo

a gente viraria vagabundo. o melhor e mais dedicado vagabundo tornar-se-ia o mais completo cientista. Também, convenhamos, sería o máximo se os bichos aprendessem utílidades de bicho homem...

$\mathcal{A}$ braçar formigas, excelente. Já falar inglês e informatar o mundo todo constituiría um despropósito sem tamanho, posto que Baratas falariam inglês...

Cabería ao homem executar o esforço inusitado, tipo o de coçar a cabeça e descobrir a cor de cada sorriso feminino. À mulher caberia a rara disfunção de aproveitar restos de frases para deflorar linguagens. Se quisesse também se ocupava de transgredir a gargalhada de cada cheiro.

Os loucos me abençoarão de idolatría. Os mendigos rezarão por mim. Os bêbados se deleitarão de ter um representante seu no caminho mais prodigo do lirismo. Os objetos serão muito orgulhosos que nem os vegetais e os insetos. Sabem que atingirão o ponto de raciocinar com lógica certa e curta.

Eu estarei, livrinho da sílva. 


\section{AGRADECIMENTOS}

- A Deus, por tudo que tem me proporcionado até hoje;

- À minha namorada amada Josiane Gutierrez Correia pelo apoio e amor a mim dedicado ao longo desses últimos anos;

- À minha mãe (Ana) por ter me ensinado tudo e pelo seu amor;

- Ao meu pai (Laércio) pelo apoio, companheirismo e por me ensinar a amar as pessoas;

- Ao meu amado e querido irmão (Leno) por tudo que vivemos até hoje juntos a distância renovou ainda mais o amor que sinto por você;

- À minha cunhada Luciana pelo apoio de sempre;

- À minha querida e amada tia Carolina por tudo e principalmente pelo amor a min dedicado;

- Aos amigos da época de cursinho que me apóiam até hoje André e Eder vocês são demais;

- Aos amigos da graduação Universidade Estadual de Maringá que estão espalhados, mas que fazem parte do ciclo de amizade Leandro Piovan, Rudolf, Adriano (Neguin), Hercules, Franciele (Fran), Alexandra, Roberta, Sivia, Thiago (Backs), Débora e aos outros que fizeram a graduação comigo;

- Ao Professor André por me dar a oportunidade de trabalhar em seu Grupo, pela orientação e por sempre ser exigente com os dados científicos;

- Ao Professor Roberto Berlinck pela brilhante colaboração nas discussões e contribuições para desenvolvimento desse trabalho; 
- À profa. Dra. Mirna Seleghim e técnica Darci pela colaboração e pelo treinamento no laboratório de microbiologia;

- Aos colaboradores e amigos Eli Pimenta, Mirian, Raquel, Simone, Fabio, Michele pelas dicas e pelas boas discussões;

- Aos grandes amigos do laboratório de inorgânica meus irmãos José Luiz (Zé) e Valdemiro (Magão), Evânia (Ebania), Baiano e André (Candango) pelo momentos inesquecíveis e por todas as nossas discussões;

- Aos amigos do Instituto: Bruno (Palmito), Flavio (Baxinho), Jairo (Tipão), Adriano (Manchinha), Orlando, Rommel, Sabrina;

- À rapaziada do laboratório da cachaça Wendel, Itapira, Carlão, Duzão;

- Ao Professor Benedito por sempre me receber bem, dando-me maior conceito que o merecido e pelo empréstimos de matérias e a disponibilização do cromatógrafo a gás;

- Aos professores Antonio e Daniel (IQSC);

- Ao prof. Dr. Alcindos A. dos Santos pelas analises no (CG ) e pelas demais contribuições (UFSCar);

- Ao Instituto de Química de São Carlos/USP, pelo apoio institucional;

- Aos amigos da toka do kastor Renato e Matheus;

- Aos amigos de laboratório Eduardo, Scarlet, Mariana, e Ana Maria;

- Aos técnicos do (CAQI), Mauro (IV), Paulo (CG) e Silvana (RMN);

- Altair, técnico do nosso laboratório;

- Romano (Financeiro); 
- E em especial ao meu grande amigo e companheiro Hercules por esses últimos anos pela lealdade e principalmente pela amizade;

- À Richele pela grandiosa e valiosa contribuição para que este trabalho pudesse ser realizado;

- Aos professores do exame de qualificação Profa. Dr. Márcia e ao Prof. Dr. Arthur;

- Ao profa. Dra. Maria Olímpia de Oliveira pela disponibilização do equipamento cromatógrafo a gás acoplado ao massas (CG-EM);

- À técnica Maria Diva pelas analises de CG-EM;

- As faxineiras Cleusa e Eva;

- Ao Prof. Dr. Camilo La Rotta pelo fungo Caldariomyces fumago;

- Ao IQSC pela oportunidade;

- À CAPES pela bolsa de mestrado;

- À FAPESP pelo financiamento do projeto;

- À Silvia e Andréia por tudo que fizeram por mim ao longo desses anos;

- À bibliotecária Eliana pela revisão bibliográfica. 


\section{SUMÁRIO}

LISTA DE FIGURAS

LISTA DE ESQUEMAS

LISTA DE TABELAS

LISTA DE ABREVIATURAS

RESUMO

ABSTRACT

$1 \quad$ INTRODUÇÃ

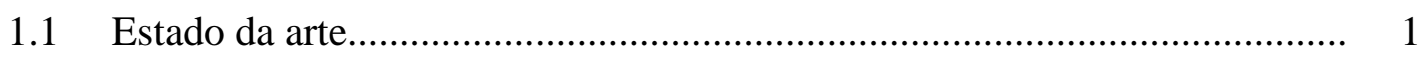

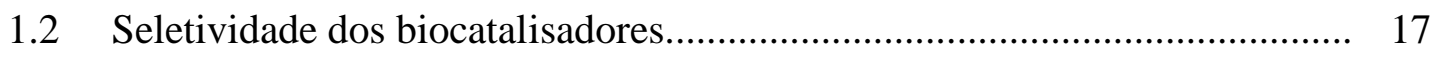

1.3 Sínteses assimétricas de alcoóis (via química)........................................ 18

1.4 Métodos analíticos para determinação da seletividade................................ 19

2 PROCEDIMENTOS EXPERIMENTAIS....................................... 23

2.1 Método para obtenção de alcoóis e haloidrinas......................................... 23

2.2 Cultivo dos microrganismos de origem marinha................................... 24

2.2.1 Repique das culturas puras e crescimento das células totais....................... 25

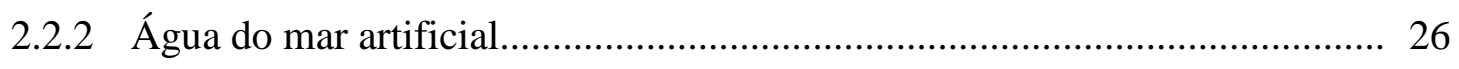

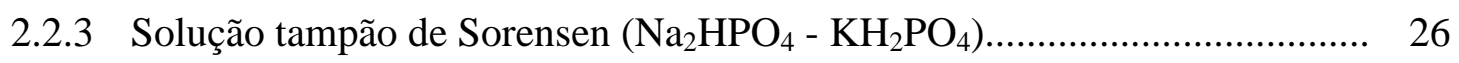

2.2.4 Cultivo do fungo Penicillium scleroirum ............................................ 26

2.2.5 Cultivo do fungo Caldariomyces fumago.............................................. 26 
2.2.6 Procedimento para preparar o meio de cultivo para o fungo Caldariomyces fumago.....

2.2.7 Repique das culturas puras.

2.3 Reações de biocatálise

2.3.1 Síntese das haloidrinas e alcoóis por biocatálise.

2.3.2 Reações de redução das cetonas com as células totais.

2.3.3 Reações de redução das halocetonas com o caldo enzimático (meio de cultura filtrado).

2.3.4 Biotransformações no agitador rotativo.

2.3.5 Extração das reações.

2.3.6 Separação enantiomérica das haloidrinas (1-4) e alcoóis (5-7) por colunas quirais

2.4 Identificação dos fungos de origem marinha.

2.4.1 Identificação taxonômica.

2.5 Materiais

2.5.1 Reagentes e solventes

2.5.2 Cromatografia em coluna.

2.5.3 Espectroscopia de infravermelho (IV).

2.5.4 Espectroscopia de ressonância magnética nuclear (RMN).

2.5.5 Espectrometria de massas (EM)

2.5.6 Polarímetro.

2.5.7 Cromatografia a gás (CG). 


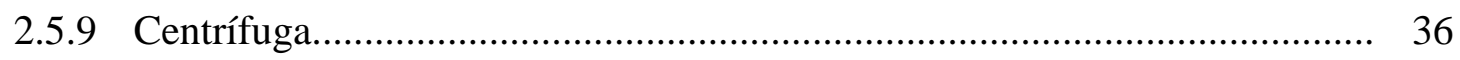

2.5.10 Agitador orbital rotativo termostatizado........................................... 36

2.5.11 Outros equipamentos utilizados................................................... 36

$3 \quad$ Resultados e Discussão.......................................................... 38

3.1 Fungos de origem marinha.......................................................... 38

3.2 Biorredução de cetonas com fungos de origem marinha...................................... 41

3.2.1 Cetonas comerciais utilizadas na triagem............................................. 41

3.2.2 Síntese das haloidrinas (1a-3a) racêmicas utilizadas como padrões............ 41

3.2.3. Redução da $\alpha$-cloroacetofenona (1) com fungos de origem marinha.......... 42

3.2.4 Estudo do efeito do $\mathrm{pH}$ na redução da $\alpha$-cloroacetofenona (1) com células totais do fungo Penicillium miczynskii Gc5 na ausência de glicose............ 48

3.2.5 Estudo do efeito do $\mathrm{pH}$ na redução da $\alpha$-cloroacetofenona (1) com células totais do fungo Penicillium miczynskii Gc5 na presença de glicose.

3.2.6 Redução da $\alpha$-bromoacetofenona (2) com fungo de origem marinha Aspergillus sydowii Ce19

3.2.7 Reação da $\alpha$-bromoacetofenona (2) com caldo enzimático do fungo Aspergillus sydowii Ce19 e reação da $\alpha$-bromoacetofenona (2) somente com água do mar artificial (branco).

3.2.8 Influência da produção enzimática do fungo Aspergillus sydowii Ce19 no meio de cultura com extrato de malte $3 \%$ com ou sem a água do mar artificial na reação de redução. 
3.2.9 Biotransformação da $p$-bromo- $\alpha$-bromoacetofenona (3) e da $p$-nitro- $\alpha$ bromoacetofenona (3) com fungo de origem marinha Aspergillus sydowii Ce19

3.2.10 Redução de orto-, meta- e para-iodoacetofenonas (5-7) com os fungos de origem marinha Trichoderma sp Gc1 e Penicillium. miczynskii Gc5

3.2.11 Caracterização dos compostos.

3.3. Analises de espectros de massas (EM)

4 Conclusão.

$5 \quad$ Referências bibliográficas.

\section{Anexos}




\section{LISTA DE FIGURAS}

Figura 1. Setores da indústria que mais utilizam processos enzimáticos.............. 04

Figura 2. Modelo da chave-fechadura............................................................ 06

Figura 3. Mecanismo ilustrado do encaixe induzido......................................... 07

Figura 4. Gráfico da energia livre para uma reação............................................ 07

Figura 5. Regra de Prelog para predizer o curso estereoquímico de alcoóis obtidos a partir da redução assimétrica de cetonas proquirais com ADH (álcool desidrogenases)

Figura 6. Fotos de alguns fungos utilizados nas biorreduções das cetonas.

Figura 7. Cromatogramas obtidos por CG em coluna quiral de $\beta$-ciclodextrina para as reações com $100 \mathrm{~mL}$ de tampão fosfato em $\mathrm{pH}=7,0 ; 50 \mathrm{mg}$ de $\alpha$-cloroacetofenona (2); $200 \mu \mathrm{L}$ DMSO; $150 \mathrm{rpm} ; 32{ }^{\circ} \mathrm{C} ; 5 \mathrm{~g}$ de células totais dos fungos; (A) P. miczynskii Gc5; (B) A. sydowii Ce19; (C) P. sclerotiorum - fungo terrestre; (D) A. sydowii Ce15; (E) Trichoderma sp Gc1; (F) Bionectria sp Ce5; (G) A. sydowii Gc12; (H) P. raistrichii Ce16.

Figura 8. Cromatogramas obtidos por CG: (A) Padrão da $\alpha$-cloroacetofenona (1); (B) Padrão do (RS)-2-cloro-1-feniletanol (1a); (C) Reação com o P. miczynskii Gc 5 ( 5 g células, 48 h)

Figura 9. Gráfico das reações da $\alpha$-cloroacetofenona (1) com o fungo Penicillium miczynskii Gc 5 com diferentes valores de $\mathrm{pH}$ e na ausência de glicose.

Figura 10. Cromatogramas obtidos em coluna quiral de $\beta$-ciclodextrina: (A) padrão $\alpha$-bromoacetofenona 2; (B) Padrão da (RS)-2-bromo-1feniletanol (2a); (C) Reação com o caldo enzimático do fungo $A$. sydowii Ce19 com 24 h; (D) Reação com células totais do fungo A. 
sydowii Ce19 com 24 h; (E) Reação com o caldo enzimático do fungo A. sydowii Ce19 com 120 h. (F) Reação com células totais do fungo A. sydowii Ce19 com $120 \mathrm{~h}$ As reações foram realizadas com $100 \mathrm{~mL}$ de caldo enzimático ou com $5 \mathrm{~g}$ de células totais; $100 \mathrm{mg}$ de $\alpha$ bromoacetofenona (2); $200 \mu \mathrm{L}$ DMSO; $150 \mathrm{rpm} ; 32{ }^{\circ} \mathrm{C}, 100 \mathrm{~mL}$ tampão fosfato $\mathrm{pH}=7,0$.

Figura 11. Cromatogramas obtidos em CG-EM. (A) Reação com caldo enzimático do fungo A. sydowii Ce19 com $\alpha$-bromoacetofenona (2) (B) Reação das células totais do fungo A. sydowii Ce19 com $\alpha$ bromoacetofenona (2). Condições de reação: $5 \mathrm{~g}$ de células totais do fungo; $50 \mathrm{mg}$ de $\alpha$-bromoacetofenona (2); $100 \mu \mathrm{L}$ de DMSO; 150 $\mathrm{rpm} ; 32{ }^{\circ} \mathrm{C}$; extrato de malte $3 \%, 50 \mathrm{~mL}$ de tampão fosfato $\mathrm{pH}=7 \ldots .$.

Figura 12. Cromatogramas obtidos em coluna quiral de $\beta$-ciclodextrina. (A) Cromatograma da $\alpha$-bromoacetofenona (2). (B) Cromatograma da bromoidrina racêmica, $(R S)$-2a. (C) Reação da $\alpha$-bromoacetofenona (2) com o fungo A. sydowii Ce19. Condições de reação: $5 \mathrm{~g}$ de massa celular úmida de fungo; $50 \mathrm{mg}$ de $\alpha$-bromoacetofenona (2); $100 \mu \mathrm{L}$ de DMSO; $150 \mathrm{rpm} ; 32{ }^{\circ} \mathrm{C}$; extrato de malte $3 \%, 50 \mathrm{~mL}$ de tampão fosfato $\mathrm{pH}=7$

Figura 13. Cromatogramas obtido por CG: (A) padrão $\alpha$-cloroacetofenona (1); (B) reação da $\alpha$-bromoacetofenona (2) com caldo do fungo A. sydovii Ce19.......

Figura 14. Cromatogramas obtidos em coluna quiral de $\beta$-ciclodextrina. (A) Cromatograma da $\alpha$-bromoacetofenona (2). (B) Cromatograma do álcool (RS)-2a. (C, D, E). Reações da $\alpha$-bromoacetofenona (2) com o fungo A. sydowii Ce19. Condições da reação: $5 \mathrm{~g}$ de massa celular úmida de fungo; $50 \mathrm{mg}$ de $\alpha$-bromoacetofenona $(2) ; 100 \mu \mathrm{L}$ de DMSO; $150 \mathrm{rpm} ; 32^{\circ} \mathrm{C}$; extrato de malte $3 \%, 50 \mathrm{~mL}$ de tampão fosfato em $\mathrm{pH}=7$. 
Figura 15. Cromatogramas obtidos em coluna quiral de $\beta$-ciclodextrina. (A) Cromatograma da p-nitro- $\alpha$-bromoacetofenona (4). (B) Cromatograma do álcool $(R S)-4 a$. $(\mathrm{C}, \mathrm{D}, \mathrm{E})$. Reações da $p$-nitro- $\alpha$ bromoacetofenona (4) com o fungo A. sydowii Ce19. Condições da reação: $5 \mathrm{~g}$ de massa celular úmida de fungo; $50 \mathrm{mg}$ de $p$-nitro- $\alpha$ bromoacetofenona (2); $100 \mu \mathrm{L}$ de DMSO; $150 \mathrm{rpm} ; 32{ }^{\circ} \mathrm{C}$; extrato de malte $3 \%, 50 \mathrm{~mL}$ de tampão fosfato em $\mathrm{pH}=7$

Figura 16. Cromatogramas: (A) Padrão da (RS)-o-iodo-1-fenil-etanol (5a); (B) Reação com 48 h com o fungo Trichoderma sp Gc1; (C) Reação com reação 96 h com o fungo Trichoderma sp Gc1 (D) Reação com 168 h com o fungo Trichoderma sp Gc1.

Figura 17. Cromatogramas: (A) Padrão da $(R S)$ - $m$-iodo-1-fenil-etanol (6a); (B) Reação com 48 h com o fungo Trichoderma sp Gc1; (C) Reação com 96 h com o fungo Trichoderma sp Gc1 (D) Reação com 168 h com o fungo Trichoderma $\mathrm{sp} \mathrm{Gc1...........................................}$

Figura 18. Cromatogramas: (A) Padrão da (RS)-p-iodo-1-fenil-etanol (7a); (B) piodo-acetofenona (7) e p-iodo-1-fenil-etanol (7a), com reação 48h; (C) ) $p$-iodo-acetofenona (7) e $p$-iodo-1-fenil-etanol (7a), com reação $96 \mathrm{~h}$ (D) $p$-iodo-acetofenona (7) e $p$-iodo-1-fenil-etanol (7a), com reação $168 \mathrm{~h}$ 


\section{LISTA DE ESQUEMA}

Esquema 1. Hidroxilação enzimática do deoxicortisol em hidrocortisol............ 02

Esquema 2. Representação da catálise enzimática............................................ 05

Esquema 3. Redução assimétrica da $\alpha$-clorocetona com $S$. nodosus................. 09

Esquema 4. Sistemas de reciclagem dos cofatores NADH/NAD ${ }^{+} \ldots \ldots \ldots \ldots \ldots \ldots \ldots . . . . . . . .10$

Esquema 5. Redução catalisada por S. cerevisiae ............................................. 10

Esquema 6. Redução de $\alpha$-acetofenonas por Rhodotorula sp. AS2.2241.......... 11

Esquema 7. Redução esterosseltetiva da $o$-cloroacetofenona............................. 12

Esquema 8. Redução das acetofenonas nitro-substituídas (orto, meta e para) e desracemização dos alcoóis $(R S)$-1-(nitrofenil)etanol mediadas por Aspergillus terreus

Esquema 9. Redução quimiosseletiva da benzoilacetato de etila por $S$. cerevisiae

Esquema 10. Redução seletiva da 4-cloroacetoacetato de octila................ 14

Esquema 11. Redução de cetona meso por D. carota ......................................... 15

Esquema 12. Síntese de alcoóis e haloidrinas quirais........................................ 22

Esquema 13. (A) Redução da $\alpha$-bromoacetofenona (2) com o fungo A. sydowii Ce19. (B) Reação da $\alpha$-bromoacetofenona (2) com o caldo enzimático do fungo A. sydowii Ce19 e com a água do mar $\operatorname{artificial}(A S W)$ 


\section{LISTA DE TABELAS}

Tabela 1. Distribuição dos grupos de pesquisas em Biocatálise/ Biotransformação no Brasil............................................................... 16

Tabela 2. Relação entre número de mols e massas utilizados para as reações de redução.

Tabela 3. Espécies mais próximas aos fungos derivados de ambiente marinho baseado nas análises do BLAST e dados de identificação morfológica.

Tabela 4. Programas utilizados no cromatógrafo a gás utilizando-se coluna quiral de ciclodextrinas.

Tabela 5. Triagem da $\alpha$-cloroacetofenona (1) com fungos de origem marinha..

Tabela 6. Redução da $\alpha$-cloroacetofenona (1) com o fungo Penicillium miczynskii Gc5 na ausência de glicose e em diferentes valores de $\mathrm{pH}$

Tabela 7. Redução da $\alpha$-cloroacetofenona (1) com o fungo Penicillium miczynskii Gc5 na ausência de glicose e em diferentes valores de $\mathrm{pH}$

Tabela 8. Redução de $\alpha$-bromo-cetofenona (3) com o fungo de origem marinha Aspergillus sydowii Ce19.

Tabela 9. Redução de iodoacetofenonas (5-7) com o fungo de origem marinha Trichoderma sp Gc1

Tabela 10. Redução de iodoacetofenonas (5-7) com o fungo de origem marinha Penicillium miczynskii Gc5..... 


\section{LISTA DE ABREVIATURAS}

$\mathrm{CG}=$ cromatografia gás

CG-EM = cromatografia a gás acoplado ao espectrômetro de massas

$\mathrm{d}=$ dupleto

DMSO = dimetil sulfóxido

$\mathrm{EM}=$ espectrometria de massas

IV = infravermelho

$\mathrm{J}=$ constante de acoplamento

$\mathrm{m}=$ multipleto

$\mathrm{sl}=$ singleto largo

$\mathrm{t}=$ tripleto

$\mathrm{UV}=$ ultravioleta

$\mathrm{RMN}{ }^{13} \mathrm{C}=$ ressonância magnética nuclear de carbono

RMN ${ }^{1} \mathrm{H}=$ ressonância magnética nuclear de hidrogênio

$\delta=$ deslocamento químico 


\section{RESUMO}

Neste trabalho realizou-se o primeiro estudo biocatalítico envolvendo reações de redução de cetonas com fungos de origem marinha. Foram utilizadas 7 cetonas comerciais como substratos e 8 fungos derivados marinhos como biocatalisadores. Os fungos foram isolados das esponjas marinhas Geodia corticostylifera (Trichoderma sp Gc1, Penicillium miczynskii Gc5, Aspergillus sydowii Gc12) e Chelonaplysylla erecta (Bionectria sp Ce5, Aspergillus sydowii Ce15, Penicillium raistrickii Ce16 e Aspergillus sydowii Ce19). A redução $\alpha$-cloroacetofenona foi estudada sob várias condições de reação (mudanças de $\mathrm{pH}$, adição ou ausência de glicose) e o melhor resultado foi com fungo $P$. miczynskii Gc5, pois se obteve um rendimento isolado de 60 $\%$ e excesso enantiomérico de $50 \%$ para a $(S)$-(+)-2-cloro-1-feniletanol . O interessante nestes estudos foi que todos os fungos utilizados na triagem com a $\alpha$-cloroacetofenona apresentaram seletividade anti-Prelog. Na literatura é comum obter redução enzimática com seletividade Prelog. A $\alpha$-bromoacetofenona foi biotransformada pelo fungo $A$. sydowii Ce19 nos correspondentes compostos: (S)-2-bromo-1-feniletanol, (S)-2-cloro-1feniletanol, enquanto que a $\alpha$-hidroxiacetofenona, $\alpha$-clorocetofenona e o epóxidoestireno foram obtidos por reações não enzimáticas. A $p$-bromo- $\alpha$-bromoacetofenona e a $p$-nitro- $\alpha$-bromoacetofenona foram totalmente biodegradadas pelo fungo A. sydowii Ce19. A redução biocatalítica da orto-iodoacetofenona e meta-iodoacetofenona com o fungo Trichoderma sp Gc1 forneceu o orto-iodo-1-feniletanol e o meta-iodo-1feniletanol com excelentes excessos enantioméricos (e.e. > $99 \%$ ). Ficou comprovado também que os fungos derivados marinhos para promover as reações de redução por biocatálise precisam ser cultivados em água do mar artificial. 


\begin{abstract}
This work carried out the first biocatalytic study involving reactions of reduction of ketones with marine-derived fungi. In this study were utilized 7 commercial ketones as substrates and 8 marine-derived fungi as biocatalysts. The fungi were isolated from the marine sponges Geodia corticostylifera (Trichoderma sp Gc1, Penicillium miczynskii Gc5, Aspergillus sydowii Gc12) and Chelonaplysylla erecta (Bionectria sp Ce5, Aspergillus sydowii Ce15, Penicillium raistrickii Ce16 and Aspergillus sydowii Ce19). The reduction of 2-chloro-1-phenylethanone was studied under several conditions of reaction (changes of $\mathrm{pH}$, addition or absence of glucose) and the best result was with fungus $P$. miczynskii Gc5, therefore it was isolated in modest yield of $60 \%$ and enantiomeric excess of $50 \%$ for the $(S)-(+)-2$-chloro-1-phenylethanol. The interesting in these studies was that all the fungi utilized in the screening with the 2-chloro-1phenylethanone presented selectivity anti-Prelog. In the literature is common to obtain enzymatic reduction with Prelog selectivity. The 2-bromo-1-phenylethanone was biotransformated by the fungus A. sydowii Ce19 in the (S)-2-bromo-1-phenylethanol, (S)-2-cloro-1-phenylethanol, whereas the $\alpha$-hydroxy-acetophenone, 2-chloro-1phenylethanone and the 2-phenyloxirane were obtained by no enzymatic reactions. The 2-bromo-1-(4-bromophenyl)ethanone and the 2-bromo-1-(4-nitrophenyl)ethanone were biodegraded by the fungus $A$. sydowii Ce19. The biocatalytic reduction of 1-(2iodophenyl)ethanol and 1-(3-iodophenyl)ethanol with the fungus Trichoderma sp Gc1 afforded the 1-(2-iodophenyl)ethanol and the 1-(3-iodophenyl)ethanol in excellent enantiomeric excesses (e.e. $>99 \%$ ). It was verified that the marine-derived fungi must grow in artificial sea water to catalyze the reduction reactions.
\end{abstract}




\section{Introdução}

\subsection{Estado da arte}

Neste trabalho realizaram-se reações de biocatálise envolvendo fungos de origem marinha. $\mathrm{Na}$ introdução serão abordados assuntos envolvendo o tema central do trabalho como o estado da arte (biocatálise) e as reações de redução.

O grande potencial de aplicação das enzimas no desenvolvimento de processos de síntese é hoje uma realidade irrefutável. As biotransformações têm sido investigadas desde os tempos de Pasteur e foram impulsionadas por grandes químicos e bioquímicos do século XIX. Pode se observar que, nessa época, era comum um mesmo cientista pesquisar temas inerentes à química e a bioquímica sem nenhuma distinção. Um exemplo dessa afirmação é a lista de processos catalíticos feita por Berzelius em 1838 (ROBERTS et al., 1995). Essas duas áreas da ciência percorreram juntas um longo caminho e em algum momento no início do século XX elas se tornaram independentes. Hoje, após quase um século, os cientistas tomaram consciência de que existe na interface destas ciências, um mundo a ser ainda descoberto (MARSAIOLI et al., 2002). O progresso no uso de enzimas e células totais na Química Orgânica Sintética foi relativamente lento até os anos 50, quando o uso de microrganismos para modificar núcleos esteroidais foi estudado em laboratórios de indústriais e academias Universidades e Institutos (HOLLAND, 1992). Conversões, tal como a transformação de 17$\alpha$-acetóxi-11-deoxicortisol em hidrocortisol (Esquema 1) usando o fungo Curvularia lunata para introduzir diretamente o grupo 11- $\beta$-hidróxi, ajudou a despertar novamente o interesse na aplicação desses catalisadores biológicos para solucionar problemas da Química Orgânica Sintética (HOLLAND, 1992). 


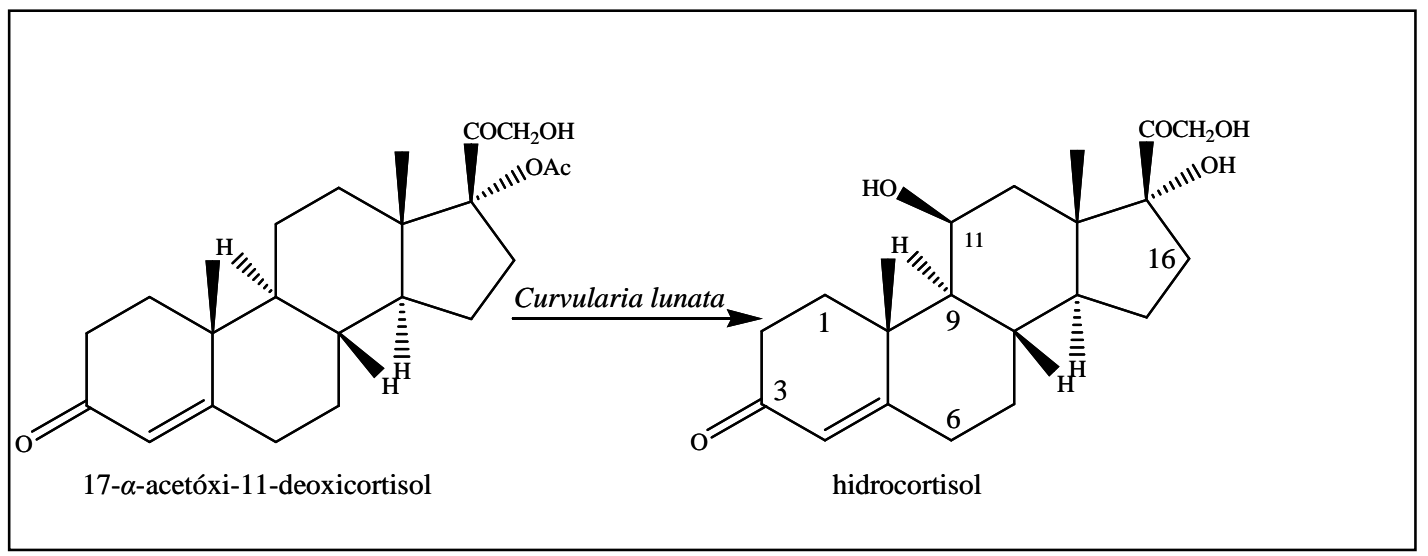

Esquema 1: Hidroxilação enzimática do deoxicortisol em hidrocortisol

No entanto, foi apenas na década de 80 que a biocatálise sofreu o seu maior impulso, através da quebra do dogma de que as enzimas só poderiam funcionar em meios aquosos. A utilização de enzimas em meios não convencionais (e.g. solventes orgânicos) permitiu aplicar estes biocatalisadores em reações de síntese química. O potencial desta utilização foi incrementado pelo fato de que em meios não aquosos as enzimas exibem seletividade, não só ao nível da quimiosseletividade, mas especialmente ao nível da enantiosseletividade. O fato das enzimas poderem resolver misturas racêmicas foi de encontro as necessidades da indústria farmacêutica por compostos enantiomericamente puros (FABER, 2004). No entanto, a aplicação imediata desta tecnologia ficou condicionada pelos elevados custos associados. Deste modo, a biocatálise nos últimos 20 anos tem sido direcionada para áreas como a biologia molecular e as ciências dos materiais, com o intuito de desenvolver biocatalisadores mais ativos, estáveis e seletivos, passíveis de serem utilizados pela indústria a um custo mais acessível. O emprego de células totais de microrganismos nos processos de biotransformações é bem conhecido. Apresentam uma diversidade de enzimas capazes de catalisar um grande número de reações químicas (BARBIERI et al., 2001). O futuro da indústria de síntese química, essencialmente devido às crescentes exigências ao nível da qualidade e meio ambiente, passará em muitos casos pela utilização de processos biocatalíticos. 
Os termos biocatálise ou biotransformação referem-se aos processos em que um catalisador biológico é utilizado para a conversão de um substrato (composto orgânico) por um número limitado de etapas enzimáticas, sendo o biocatalisador a enzima, o principal agente dessas reações (DEMIRJIAN, 1999). A biocatálise é hoje um dos campos mais promissores dentro das novas tecnologias para síntese de compostos de alto valor agregado. A exploração da biodiversidade na busca de novos catalisadores por técnicas de seleção de microrganismos, de plantas ou células animais representam os métodos tradicionais de descoberta de novas enzimas para o desenvolvimento da biocatálise em escala industrial (DEMIRJIAN, 1999). Os microrganismos, neste caso, são de particular interesse, devido ao curto período de geração, à grande diversidade de processos metabólicos e enzimas envolvidas e, há um número ilimitado de microrganismos na natureza que podem ser avaliados, os quais são bastante diferentes entre si. Microrganismos isolados em território brasileiro têm demonstrado excelente potencial biocatalítico frente a diferentes substratos orgânicos de interesse, como por exemplo na hidrólise de óleos marinhos para síntese de ésteres de ácidos graxos poliinsaturados e de ésteres aromáticos (CARVALHO et al., 2005). Ainda, para ter acesso ao potencial enzimático é necessário que os organismos apresentem algumas vantagens, neste caso destacam-se os microrganismos, pois esses são robustos, apresentam crescimento rápido fornecendo elevadas quantidades de massas celulares e produzem todas as enzimas necessárias para catalisar as mais diversas reações químicas (DEMIRJIAN, 2000). Deve-se destacar que embora muitos avanços sejam realizados na área de biocatálise, há ainda desafios em desenvolver as reações enzimáticas utilizando-se compostos xenobióticos, como por exemplo, realizar reações em escala de g/L.

A indústria de química fina vem utilizando os biocatalisadores há algum tempo graças à extraordinária capacidade de reconhecimento quiral estereosseletivo das enzimas (ISHIGE E SHIMIZU, 2005). Atualmente sabe-se que substâncias biologicamente ativas usadas como 
fármacos não devem ser empregadas na forma de racematos, já que as diferenças existentes entre as formas espaciais de cada enantiômero significam diferenças entre suas propriedades químicas, físicas e principalmente biológicas, influenciando diretamente na atividade do fármaco (PILLI, 2001). Em uma pesquisa recente, das 128 sínteses realizadas por três grandes indústrias farmacêuticas, 69 consistiram na preparação de compostos quirais. Para um fármaco quiral ser aprovado por uma agência regulatória, é preciso que haja um excesso enantiomérico (e.e.) de no mínimo 99,5\%. Essa alta seletividade pode facilmente ser alcançada através de processos biocatalíticos. Para isso, naturalmente há a necessidade de que sejam realizados estudos a fim de selecionar o agente biológico (a enzima) e as condições adequadas para que a transformação de um determinado substrato forneça a seletividade desejada. A obtenção destes compostos em suas formas enantiomericamente puras é, sem dúvida, uma das principais aplicações da biocatálise na indústria de química fina e farmacêutica (FABER, 2000). A indústria de uma forma geral vem utilizando os processos de biotransformação destacando-se o ramo farmacêutico (STRAATHOLF et al., 2002), como demonstrado na Figura 1.

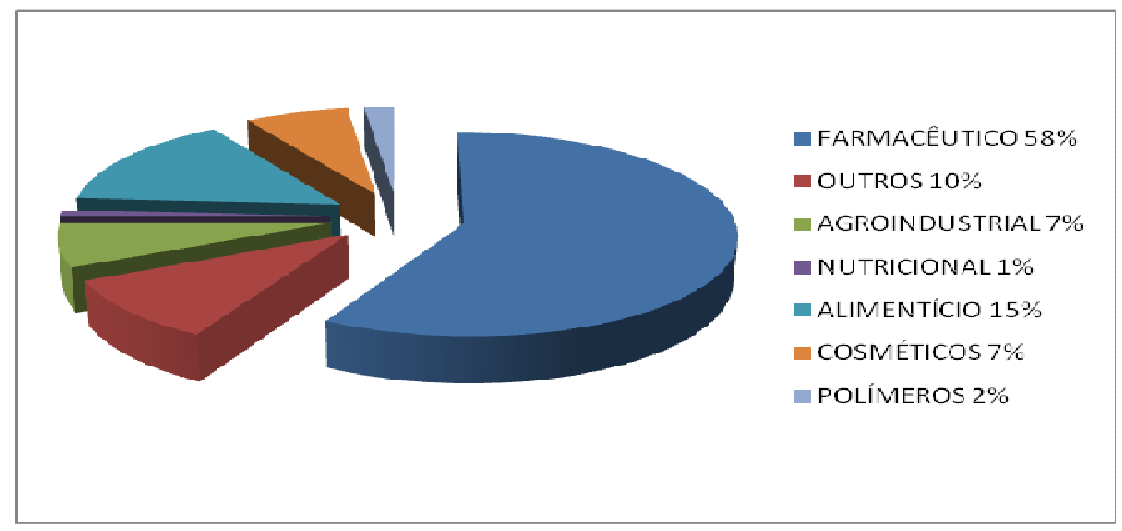

Figura 1. Setores da indústria que mais utilizam processos enzimáticos

As enzimas são, em geral, proteínas de grande complexidade estrutural que atuam como catalisadores na maioria das reações químicas do metabolismo celular. São constituídas 
por resíduos de aminoácidos, unidos através de ligações peptídicas e possuem massa molar que pode variar de milhares a milhões de Daltons (g/mol). Estas macromoléculas altamente especializadas exercem funções vitais nos organismos vivos e dependendo de sua atividade biológica e do organismo que as sintetizou, apresentam características bastante peculiares (SILVERMAM, 2000).

As enzimas aproximam os substratos com orientação espacial favorável dentro de uma cavidade, denominada sítio ativo, formando um complexo enzima substrato (En-S). O sítio ativo é uma cavidade com forma definida, aberta na superfície da molécula globular da enzima, constituídas por grupos $\mathrm{R}$ de aminoácidos. Esta forma do sítio ativo confere especificidade à catálise enzimática: para ser reconhecida como substrato uma molécula deve ter a forma adequada para acomodar-se no sítio ativo e os grupos químicos capazes de estabelecer ligações com os grupos R presentes nos aminoácidos (Esquema 2) (NELSON E COX, 2000).

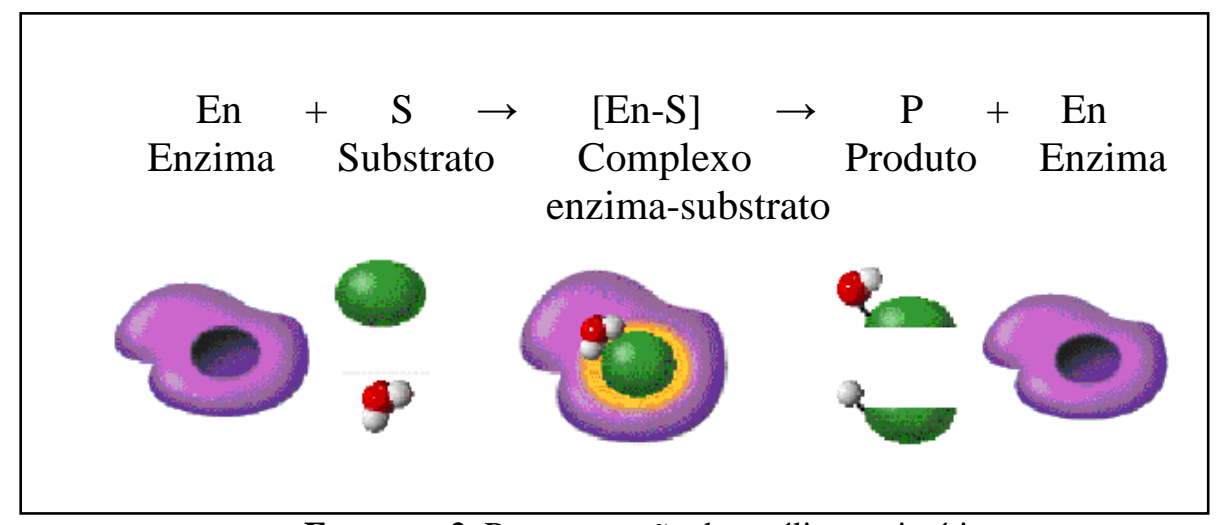

Esquema 2. Representação da catálise enzimática

Existem algumas propostas mecanísticas a respeito das especificidades das reações promovidas pelas enzimas, conhecidas como modelos enzima-substrato. Emil Fisher propôs, em 1894, que as enzimas se ajustavam perfeitamente como uma chave-fechadura o qual denominou "modelo chave e fechadura" Neste modelo o substrato e o sítio ativo catalítico da 
enzima eram estruturalmente complementares em tamanho, forma e natureza química, portanto um sistema altamente rígido e definido. (Figura 2)

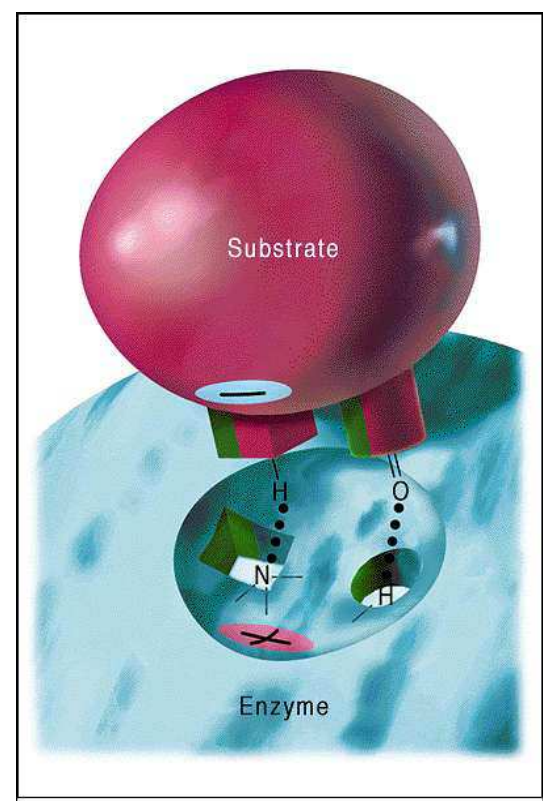

Figura 2. Modelo da chave-fechadura

Um sítio catalítico da enzima estruturalmente complementar ao seu substrato seria pouco eficiente, pois a aproximação e a ligação do substrato ao sítio ativo da enzima alteram o balanço de forças responsáveis pela manutenção da estrutura tridimensional da enzima, alterando sua forma e a do substrato, fazendo a enzima adquirir uma nova conformação, a que se torna ideal para a catálise. Este mecanismo foi proposto por Koshland em 1958 conhecido como "modelo do encaixe induzido". A conformação dos substratos também é tencionada e distorcida, aproximando-se do estado de transição. São esses os conjuntos mecanísticos que tornam a catálise enzimática tão eficiente permitindo que uma enzima catalise uma variedade de substratos não naturais (Figura 3) (VERLI E BARREIRO, 2005). 


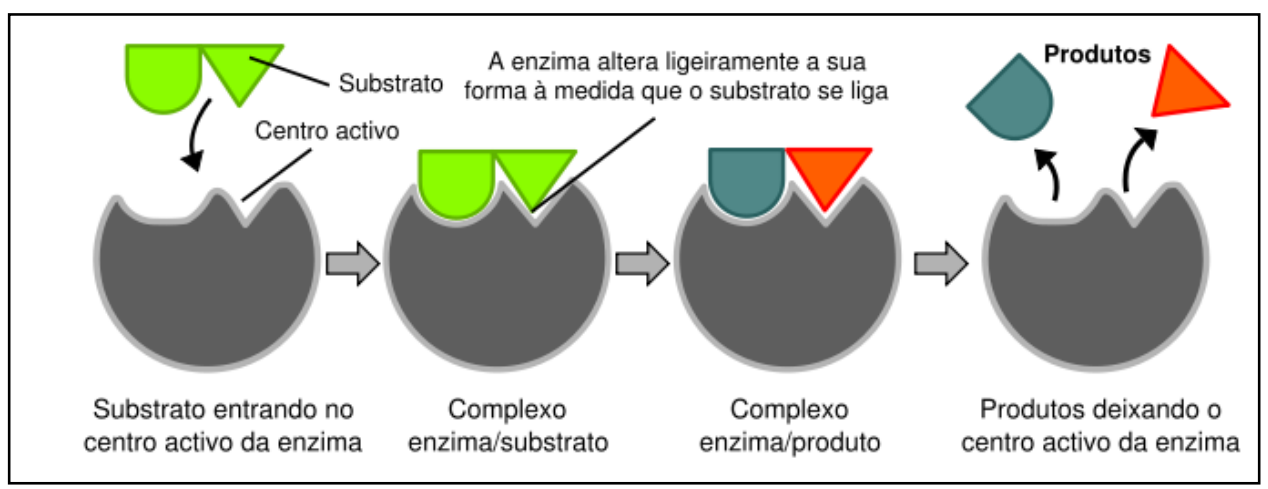

Figura 3. Mecanismo ilustrado do encaixe induzido

A utilização de microrganismos (enzimas) como biocatalisadores é muito vantajosa, pois são aceitáveis ambientalmente (biodegradáveis), trabalham em condições brandas, possuem alta tolerância aos substratos e catalisam diferentes tipos de reações (FABER, 1997), ainda:

- não alteram o estado de equilíbrio da reação

- aceleram a velocidade de reação em pelo menos $10^{6}$ vezes

- diminuem a energia de ativação

- variação de energia livre não é afetada pela enzima $(\Delta \mathrm{G})$

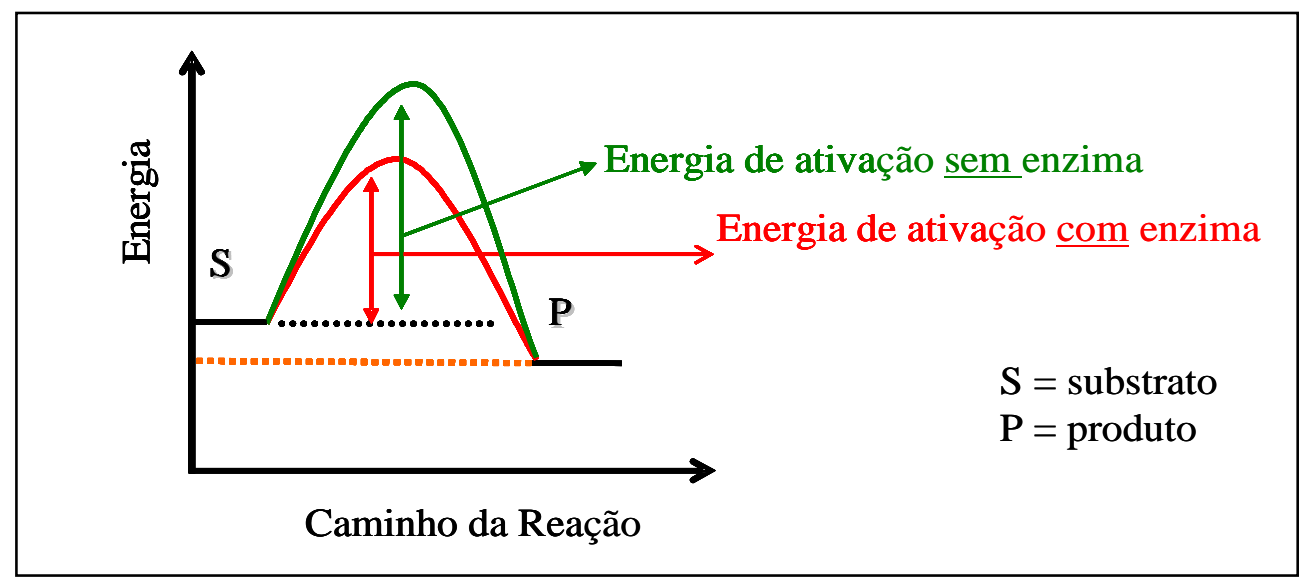

Figura 4. Gráfico da energia livre para uma reação

Uma das metodologias mais comumente empregadas em biocatálise é realizada através da utilização das células totais dos microrganismos cultivados em meios de cultura apropriados, onde toda a maquinaria enzimática está disponível, para catalisar inúmeras 
reações enzimáticas podendo inclusive gerar uma mistura de produtos por biotransformações. O uso de células totais aplica-se principalmente nas reações em que as enzimas para catalisarem as reações químicas requerem cofatores. Na ausência de cofatores determinadas classes de enzima (e.g. oxidorredutases) não promovem as reações químicas (CÁNOAS E IBORRA, 2005). O sistema de biotransformação a ser empregado dependerá do tipo de reação, do uso de cofatores, bem como da escala em que ocorrerá a reação, entre outros parâmetros relevantes ao processo (FABER, 1997). A título de exemplo torna-se economicamente vantajoso o uso de células totais na redução de carbonilas de cetonas, pois fornece alta seletividade e elimina a necessidade de fornecer quantidades equimolares de coenzimas, como NADH/NAD ${ }^{+}$ou NADPH/NADP ${ }^{+}$, ao sistema reacional.

A redução assimétrica de cetonas é uma das reações mais importantes e fundamentais para produção de álcoois quirais, que podem ser transformadas em várias outras funcionalidades com aplicações para a síntese química industrial, tais como, farmacêutica, agroquímica e alimentícia (NAKAMURA, et al., 2003). No (Esquema 3) tem-se um exemplo de redução de cetona catalisada pelo uso de células totais do fungo Streptomyces nodosus SC 13149 cujo produto quiral foi utilizado na síntese do indinavir um inibidor de protease do vírus HIV (PATEL, 2003). 


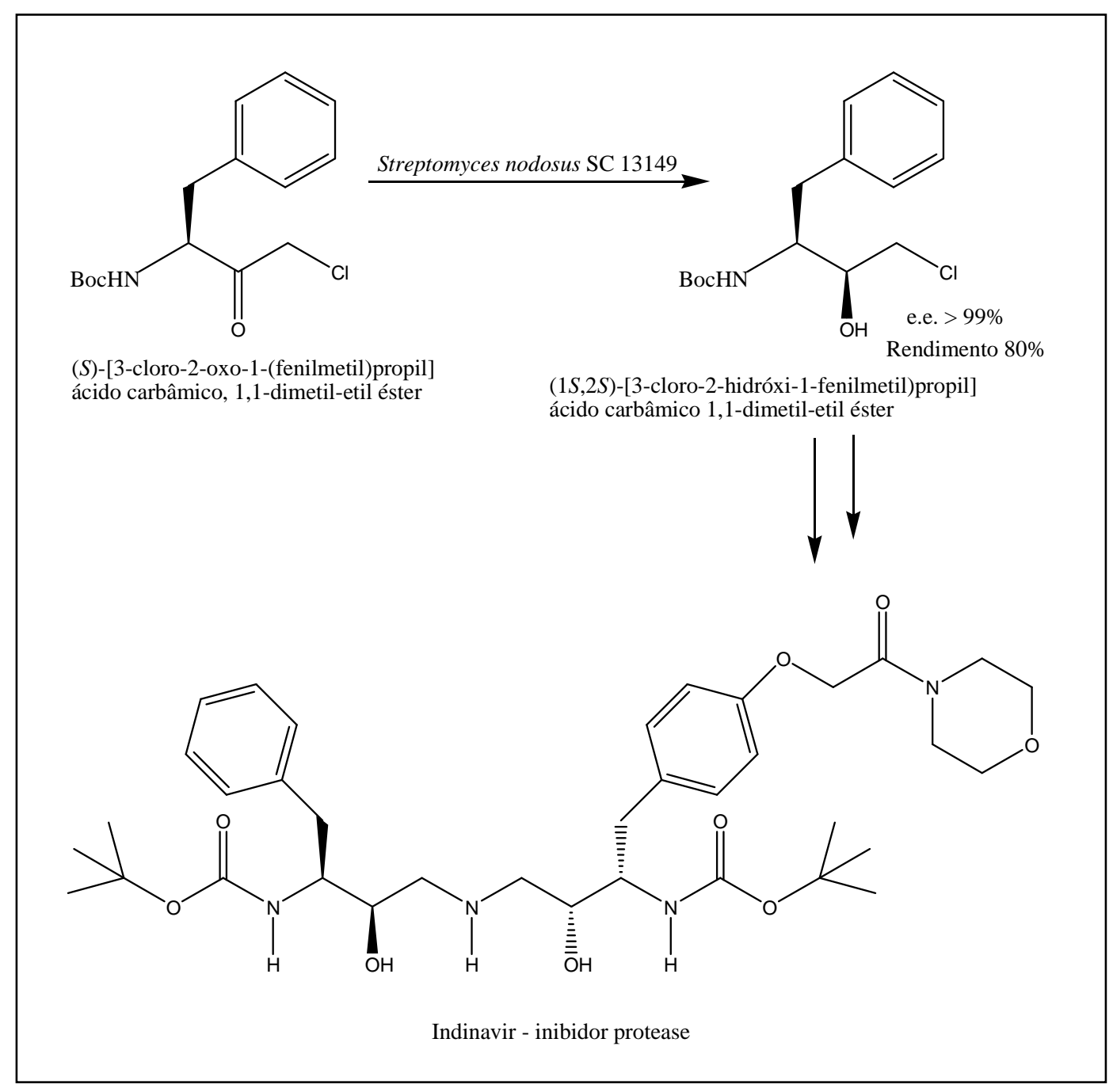

Esquema 3. Redução assimétrica da $\alpha$-clorocetona com $S$. nodosus

Como mencionado anteriormente, o uso de células totais tem sido muito bem empregado na redução seletiva de cetonas proquirais (HOMANN et al., 2004). Sendo particularmente vantajoso para executar a redução desejada e ainda possuem a capacidade de produzir todos os cofatores e os caminhos metabólitos necessários para sua regeneração. Adicionalmente, todas as enzimas e cofatores são bem protegidos dentro de seu ambiente celular natural (MANDAL et al., 2004). No (Esquema 4) tem-se sistemas com diferentes possibilidades de reciclagem de cofatores envolvidos em uma reação de redução com o uso de enzima, células totais e ou substrato auxiliar. 


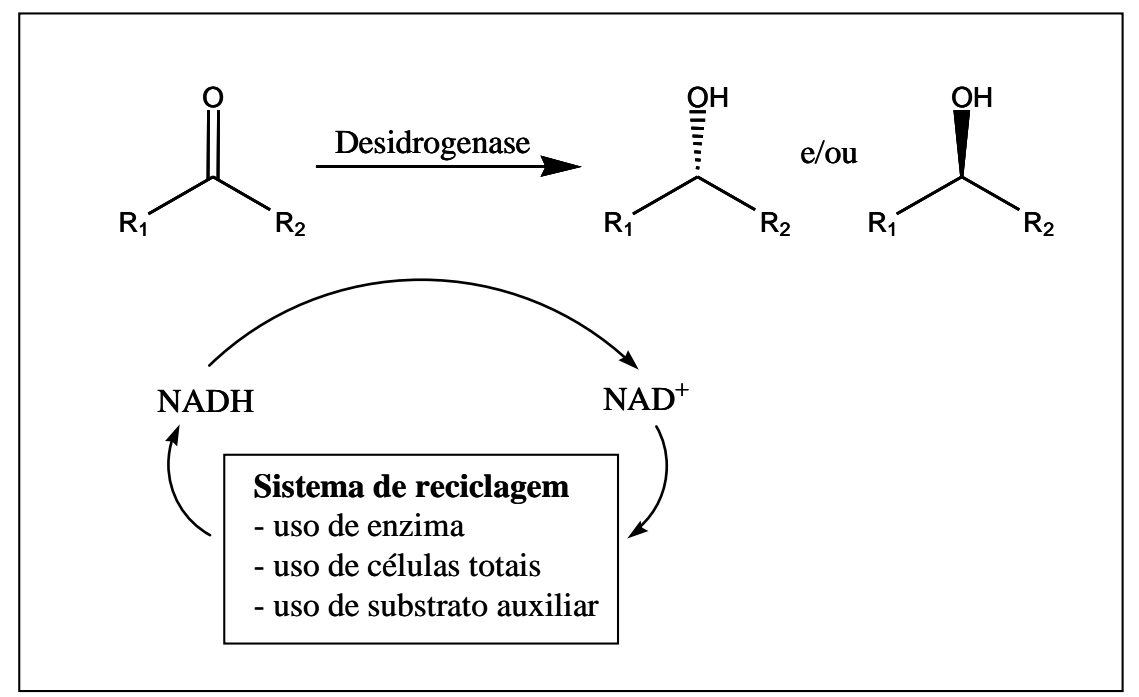

Esquema 4. Sistemas de reciclagem dos cofatores NADH/NAD ${ }^{+}$

Dentre os microrganismos que possuem a capacidade de reciclar seus cofatores encontra-se a levedura Saccharomyces cerevisiae (fermento do padeiro ou fermento do cervejeiro) que é o microrganismo mais largamente usado para a redução assimétrica de compostos carbonílicos, pois é prontamente disponível, de baixo custo e possui uma alta capacidade como biocatalisador redox em uma variedade de reduções estereosseletivas (LACERDA et al., 2006).

No (Esquema 5) tem-se um exemplo de biorredução de um grupo aceto acetato com a utilização do fungo $S$. cerevisiae como um biocatalisador.

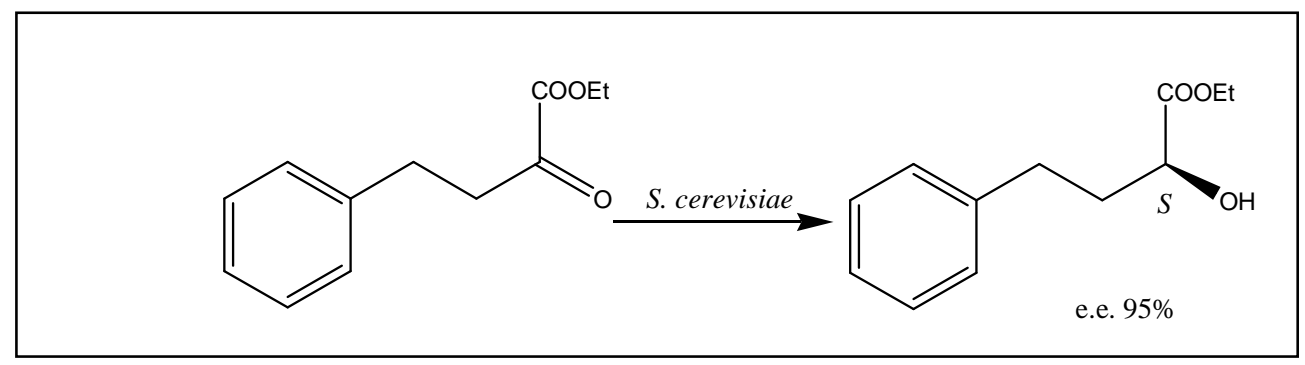

Esquema 5. Redução catalisada por $S$. cerevisiae

Outros microrganismos também apresentam enzimas seletivas na redução de cetonas, levando a produção de álcoois enantiomericamente puros, tais como, Rhizopus arrhizus, 
(SALVI E CHATTOPADHYAY, 2006), Merulius tremellosus, (HAGE et al., 2OO1), Geotrichum candidum (MATSUDA et al., 2000), Rhodococcus rubber (STAMPFER et al., 2002), Trichothecium sp., (MANDAL et al., 2004), Rhizopus oryzae (COMASSETO et al., 2003), etc.

As enzimas desidrogenases e redutases são responsáveis pela redução de grupos carbonílicos de aldeídos e cetonas. Quando o grupo carbonílico de cetonas é reduzido, pode levar a formação de centros estereogênicos de acordo com a estrutura do substrato (ZANG et al., 1999). As acetofenonas e seus derivados são substratos de grande interesse sintético e inúmeros estudos biocatalíticos vêm sendo realizados visando à obtenção de álcoois quirais oticamente puros (BRZEZINSKA-RODAK, et al., 2006).

No (Esquema 6) estão apresentados alguns exemplos de conversões utililizando-se o fungo Rhodotorula sp As 2.2241 (YANG et al., 2006) na redução de $\alpha$-halocetonas produzindo as correspondentes haloidrinas quirais.
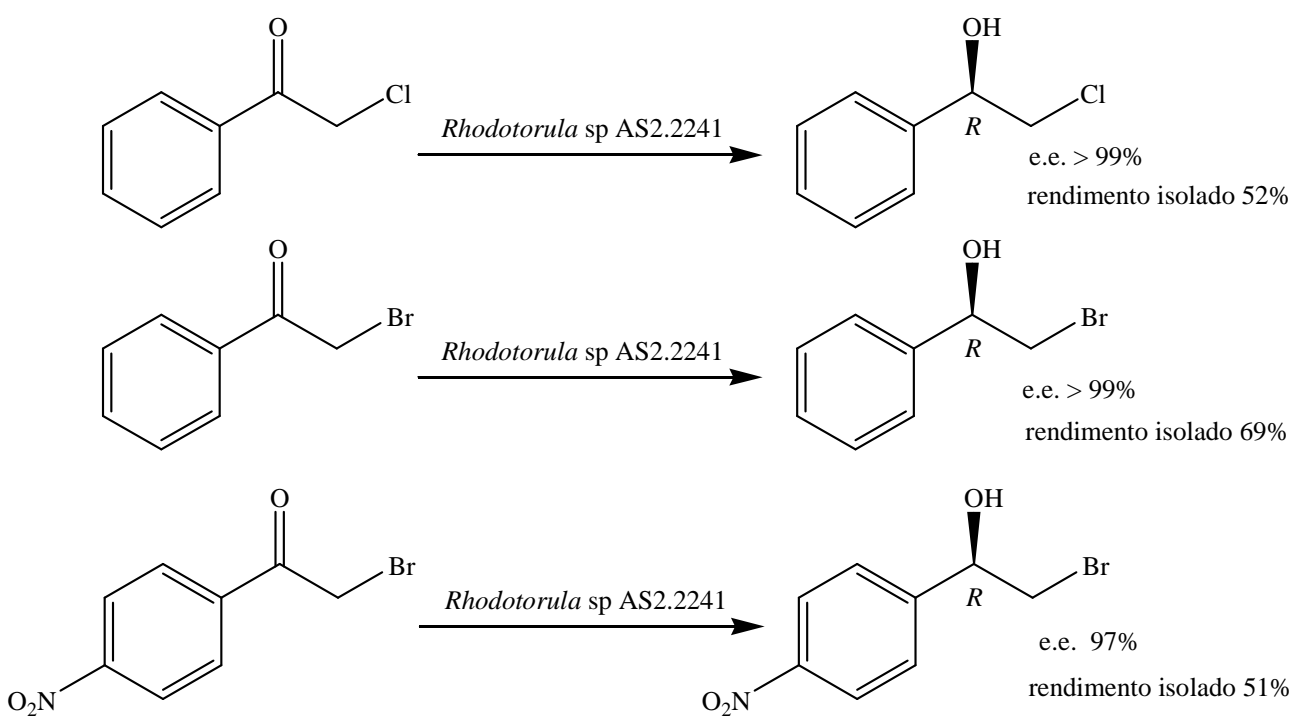

Esquema 6. Redução de $\alpha$-acetofenonas por Rhodotorula sp. AS2.2241

O uso de células totais da levedura Cândida pseudotropicalis em meio aquoso na redução assimétrica da $o$-cloroacetofenona formou o (S)-1-(2-clorofenil)etanol (Esquema 7). 
Apesar da alta toxicidade do substrato para as células, a levedura foi capaz de tolerar até 36 g/L da cetona, e o álcool (S)-1-(2-clorofenil)etanol foi obtido com alta enantiosseletividade e.e. > 99\% (XIE et al., 2006).

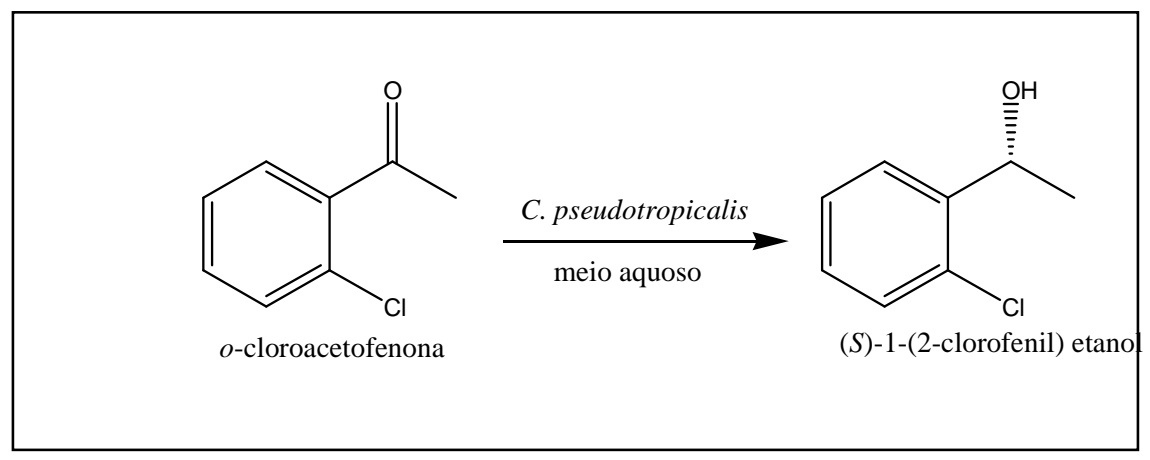

Esquema 7. Redução esterosseltetiva da $o$-cloroacetofenona

Utilizando-se o fungo Aspergillus terreus em meio aquoso, Comasseto e col. obtiveram a partir da redução de acetofenonas nitro-substituídas conversões de $98 \%$ aos álcoois quirais com e.e. > 98\%. Os autores também verificaram estereoinversão dos álcoois racêmicos, na presença das células totais do fungo A. terreus, variando o $\mathrm{pH}$ do meio reacional onde condições ácidas favoreceram o processo de desracemização, e o álcool (S)-(-)-1-(m-nitrofenil)etanol foi obtido com alta enantiosseletividade (e.e. > 98\%) Esquema 8 (COMASSETO, et al., 2004). 


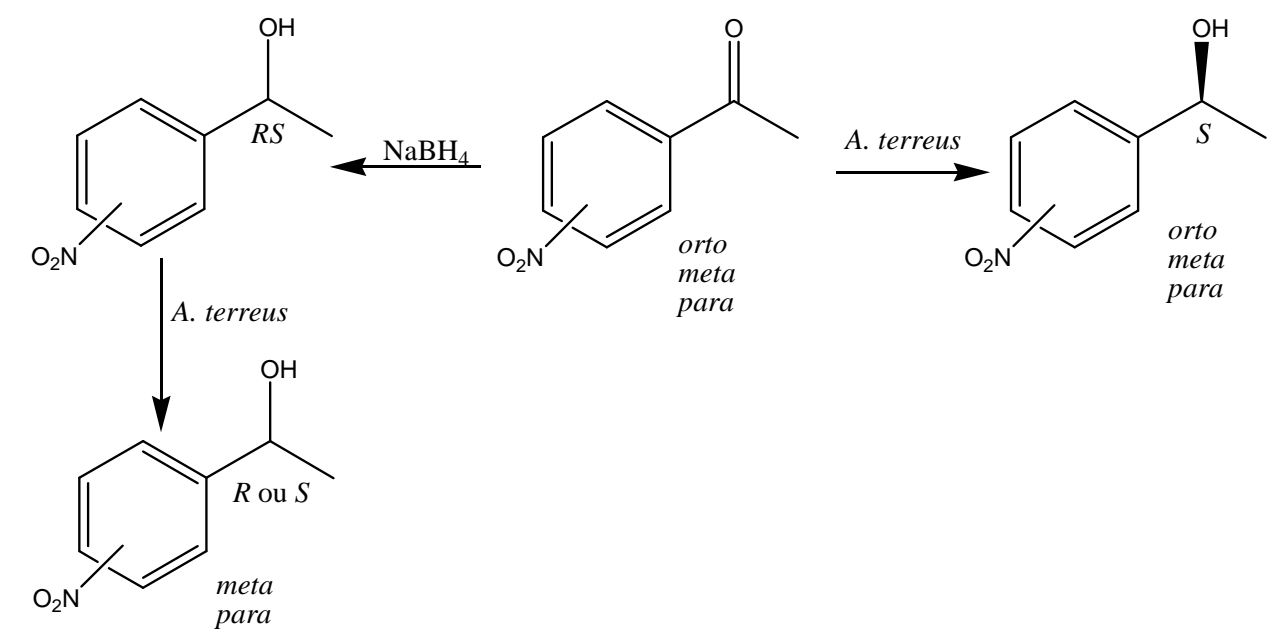

Esquema 8. Redução das acetofenonas nitro-substituídas (orto, meta e para) e desracemização dos álcoois $(R S)$ 1-(nitrofenil)etanol mediadas por Aspergillus terreus

Um exemplo de aplicação industrial encontra-se para a fluoxetina, um fármaco usado como antidepressivo, cujo único centro estereogênico foi obtido através da redução catalisada pela levedura S. cerevisiae (Esquemas 9). O produto quiral obtido pela redução foi utilizado na síntese da fluoxetina após algumas etapas. (PEREIRA, 1997).

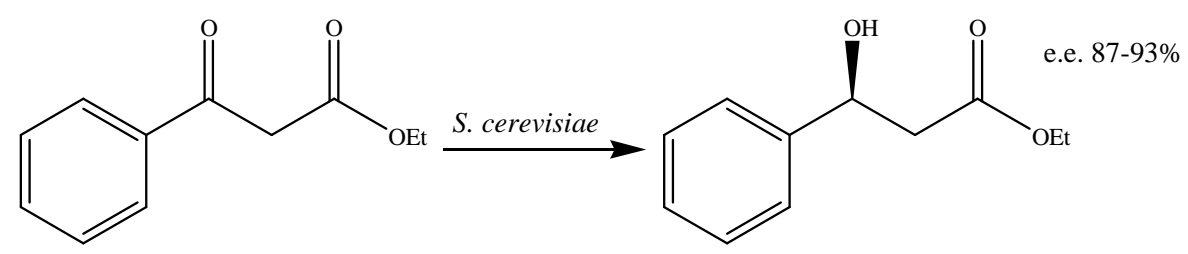

benzoilacetato de etila

(3S)-3-hidróxi-3-fenilpropanoato de etila

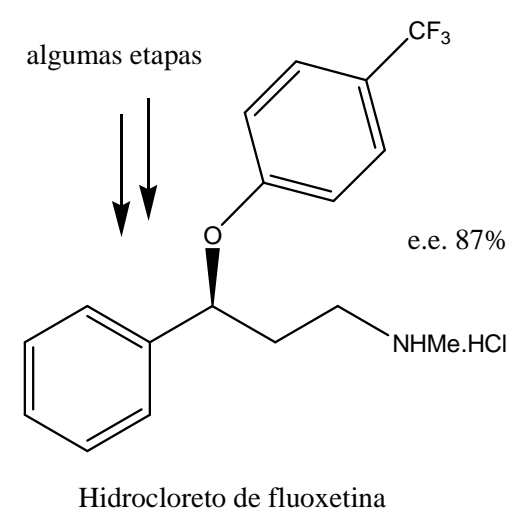

Esquema 9. Redução quimiosseletiva da benzoilacetato de etila por S. cerevisiae 
A L-carnitina, um fármaco usada na prevenção de infarto do miocárdio, pode ser obtido através de duas etapas de reação, sendo que a primeira trata-se de uma redução catalisada pelas células de S. cerevisiae, conforme mostrado no (Esquema 10). A produção seletiva do isômero "L" $(R)$ é essencial, pois a forma isomérica "D" $(S)$ é tóxica para o organismo humano (PEREIRA, 1997).

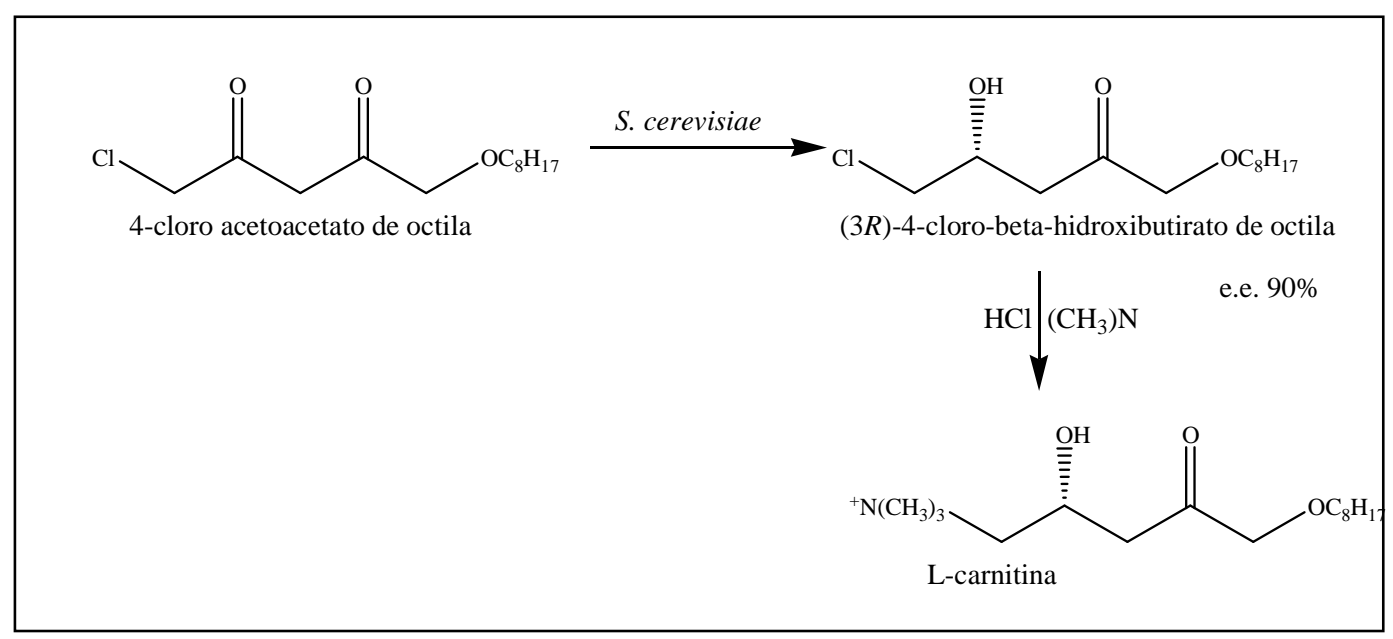

Esquema 10. Redução seletiva da 4-cloroacetoacetato de octila por $S$. cerevisiae

Além dos microrganismos, os vegetais são excelentes fontes de biocatalisadores e ainda são muito úteis para promoverem reações químicas (Apêndice).

O Brasil tem uma grande variedade de vegetais que podem constituir em fontes inesgotáveis de enzimas para serem aplicados aos mais diversos tipos de reações enzimáticas.

Atualmente, vem despertando entre vários pesquisadores o interesse pela redução assimétrica de cetonas utilizando-se catalisadores vegetais que podem também ser empregadas para produzir compostos com alta pureza enantiomérica (SCARPI et al., 2005).

Dentre os catalisadores vegetais destaca-se a Daucus carota (cenoura), para determinados substratos, despontando-se atualmente como o mais promissor biocatalisador vegetal para redução assimétrica de cetonas proquirais. (YADAV et al., 2002).

Um exemplo do uso de Daucus carota é a redução seletiva da nitrocetona proquiral (SCARPI et al., 2005), mostrado no (Esquema 11). 


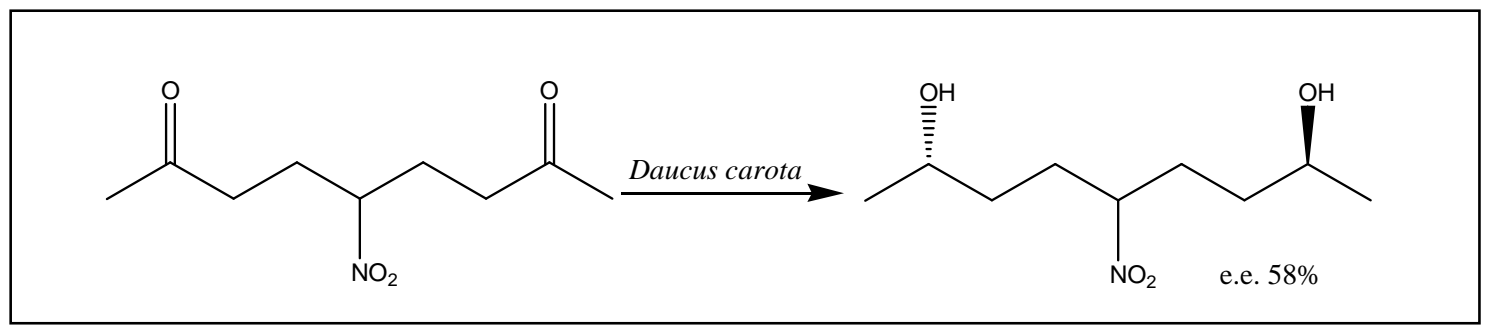

Esquema 11. Redução de cetona meso por D. carota

Dentre essas fontes, a enzima álcool desidrogenase responsável pela redução de aldeídos e cetonas é encontrada em diversos vegetais que se tornam fontes alternativas destas enzimas que podem ser empregadas no desenvolvimento da biocatálise e/ou métodos enzimáticos como as sementes de algodão Gossypium hirsutum cv. Siokra (MILLAR et al., 1994); de girassol, Helianthus annus (TORRES, 1974); soja, Glycine max (TANG E CHANG, 1990); pimentão, Capsicum annuum (SMITH E COBB, 1991); amendoim, Arachis hypogaea (CHUNG et al 1996); tabaco, Nicotiana sylvestris (ZARSKY et al.,1994); tecidos de morango, Fragaria xananassa Duch (MITCHELL E JELENKOVIC, 1995); oliva, Olea europaea (SALAS E SANCHEZ, 1998) e beterraba, Beta vulgaris (KONOVALOV, 1994).

Essas alternativas de emprego desses materiais biológicos são de extrema importância para as indústrias sucro-alcooleiras, uma vez que o monitoramento dos teores de etanol nos processos fermentativos pode levar a maior produtividade dessa substância tão importante para a economia nacional. Estas enzimas naturalmente imobilizadas nas células destes materiais biológicos em seu habitat natural são mais estáveis e geralmente possuem o seu cofator disponível (FILHO E VIEIRA, 2002).

\section{- Grupos de biocatálise no Brasil}

No Brasil existem vários grupos de pesquisas que atuam na área de biocatálise. Como pode ser visto na (Tabela 1), a maior parte desses grupos está no Estado de São Paulo, principalmente nucleados na Universidade de São Paulo (USP) e na Universidade de 
Campinas (UNICAMP), segundo relatório gerado através da Plataforma Lattes (BEATRIZ et al., 2005).

Tabela 1. Distribuição dos grupos de pesquisas em Biocatálise/ Biotransformação no Brasil

\begin{tabular}{lc}
\hline Estado/Região & $\begin{array}{c}\text { Número de grupos de Pesquisa em } \\
\text { biotransformação /Biocatálise }\end{array}$ \\
São Paulo/Sudeste & 08 \\
Rio de Janeiro/Sudeste & 02 \\
Minas Gerais/Sudeste & 01 \\
Paraná/Sul & 04 \\
Santa Catarina/Sul & 02 \\
Rio Grande do Sul/Sul & 01 \\
Goiás/Centro-Oeste & 01 \\
Mato Grosso do Sul/Centro-Oeste & 01 \\
Roraima/Norte & 01 \\
Pará/Norte & 01 \\
Bahia/Nordeste & 01 \\
Ceará/Nordeste & 01 \\
\hline
\end{tabular}

\section{- Reações de biocatálise com microrganismos}

As reações biocatalíticas com microrganismos, por exemplo, as reduções podem ser realizadas por duas metodologias.

a) Com a adição do composto orgânico a ser biotransformado (e.g substrato) durante o crescimento ou inóculo do microrganismo: Neste caso, denomina-se reação biocatalisada com células em crescimento, uma vez que as reações são realizadas na presença de meio de cultura e, portanto os microrganismos podem estar reproduzindo-se continuamente.

b) Reações com as células totais em repouso: Neste procedimento, faz-se o crescimento dos microrganismos, posteriormente remove-se o meio de cultura e ressuspende-se as células totais em água ou em soluções tamponadas e por último adiciona-se o composto orgânico (substrato) para ser biocatalisado.

Ambas as metodologias são interessantes e sempre devem ser utilizadas quando se inicia uma triagem com novos biocatalisadores, pois as respostas dos resultados podem ser 
distintas influenciando diretamente nos resultados obtidos. Destaca-se que a seleção de biocatalisadores é uma das etapas mais tediosas, exaustivas em estudos de biocatálise, mas são fundamentais para selecionar os melhores biocatalisadores. Existem hoje triagens de alto desempenho High Throughput Screening (HTS), contudo também apresentam limitações, principalmente quanto às análises das estereosseletividades, bem como se limita ao biocatalisador a ser utilizado. Por exemplo, fungos filamentosos são difíceis de serem utilizados para triagem com HTS devido à miniaturização dos ensaios.

\subsection{Seletividade dos biocatalisadores}

Os biocatalisadores apresentam os principais tipos de seletividades desejadas (FABER, 1997) tais como quimiosseletividade, pois reage preferencialmente com um tipo de grupo funcional presente no substrato; regiosseletividade, considerando que as enzimas são capazes de distinguir entre grupos funcionais posicionados em diferentes regiões do mesmo substrato; e enantiosseletividade, pois as enzimas podem formar enantiômeros com elevadas purezas óticas (SILVERMAM, 2000). As enzimas mais interessantes para serem utilizadas na química assimétrica são aquelas capazes de catalisar reações seletivas. A seletividade pode ser facilmente alcançada em reações biocatalíticas, pois as enzimas são macromoléculas quirais com propriedades catalíticas (FABER, 2004).

Uma vez atingida a seletividade esperada na redução de cetonas proquirais poderá levar a produção de produtos enantiomericamente puros. Uma das ferramentas mais importantes para determinação da estereoquímica dos compostos biocatalisados via redução é a regra de Prelog. Nas reações de redução o papel das enzimas só se torna relevante se houver a presença do cofator. As redutases do tipo álcoois desidrogenases são dependentes dos cofatores NADH ou NADPH, que são os responsáveis pela transferência de íon hidreto ao 
grupo carbonílico. Foi postulado por Prelog que de acordo com o volume (tamanho) dos grupos substituintes ligados ao carbono carbonílico é possível inferir pela qual face da carbonila ocorre à transferência do íon hidreto (Figura 5). Se a transferência do íon hidreto ocorrer pela face re da carbonila obtém-se $(S)$-álcoois e se ocorrer pela face si obtém-se $(R)$ álcoois considerando-se que os grupos oxigênio $(\mathrm{O})$ o grupo volumoso $(\mathrm{G})$ e o grupo pequeno (P) seguem a mesma prioridade segundo Cahn-Ingold-Prelog para designação da configuração absoluta dos centros estereogênicos, respectivamente (MUSA et al., 2007).

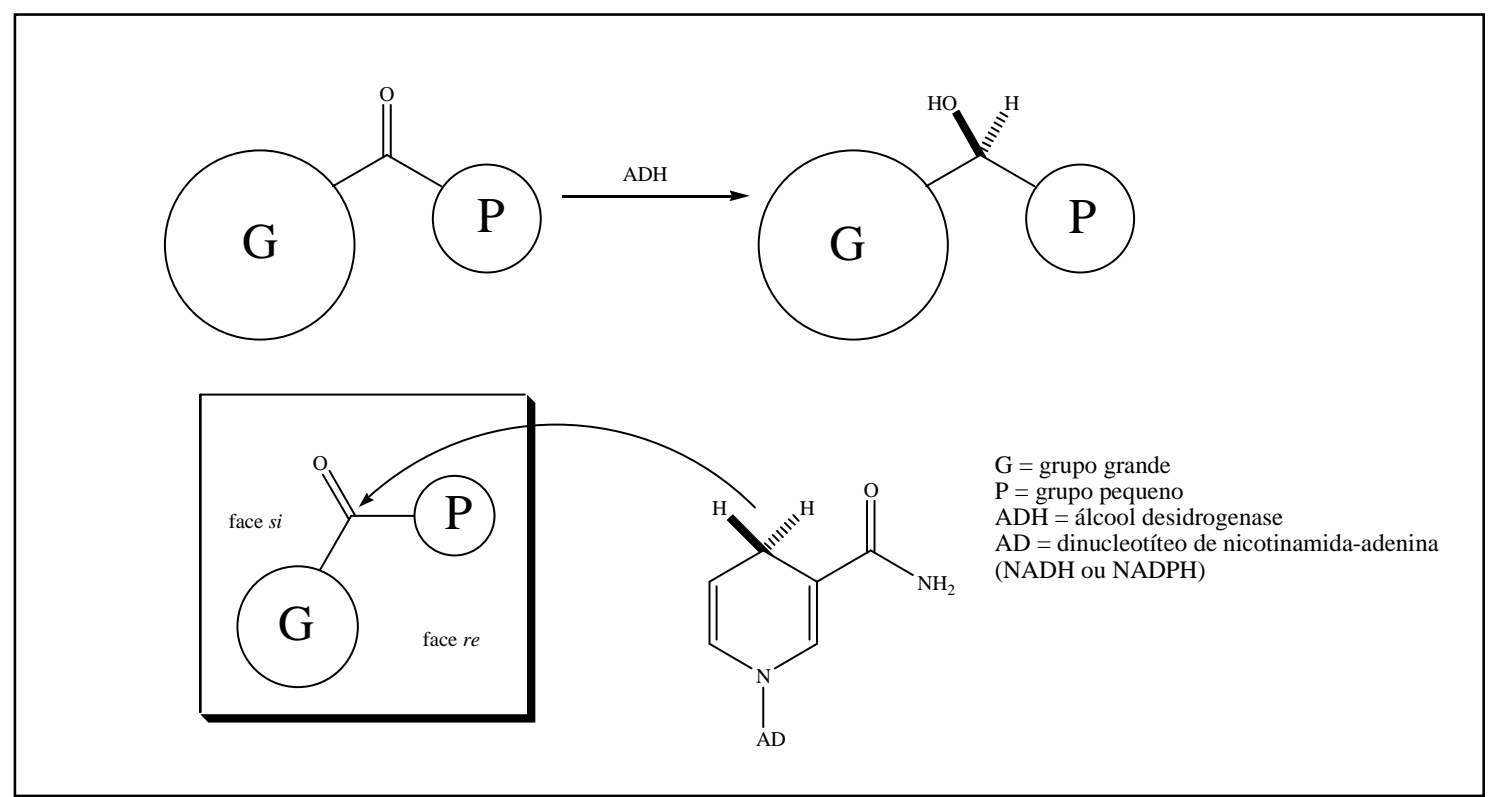

Figura 5. Regra de Prelog para predizer o curso estereoquímico de álcoois obtidos a partir da redução assimétrica de cetonas proquirais com ADH (álcool desidrogenase)

\subsection{Sínteses assimétricas de álcoois (via química)}

Alcoóis podem ser obtidos a partir da redução de compostos carbonílicos. O carbono carbonílico se encontra na forma $s p^{2}$ e possui geometria trigonal plana. A adição de um íon hidreto ao carbono carbonílico leva a formação de um álcool, onde o carbono passa então a ter hibridização $s p^{3}$ e a geometria do carbono torna-se tetraédrica. Os avanços na síntese orgânica vêm possibilitando a preparação de vários compostos quirais enantiomericamente puros ou enriquecidos. Na redução de compostos carbonílicos é comum à utilização de hídretos de boro 
e de alumínio, complexos de ródio, rutênio e outros metais associados a ligantes quirais utilizados para sínteses de álcoois quirais (ALCÂNTRA E BARROSO, 2002).

$\mathrm{O} \mathrm{NaBH}_{4}$ é um agente redutor aquiral, portanto a transferência do hidreto ocorre dos dois lados do plano da carbonila, gerando um produto racêmico. $\mathrm{O}$ uso de reagentes quirais leva à seleção de um dos lados da geometria trigonal plana da carbonila durante a transferência do hidreto, e assim, pode-se obter um único estereocentro. Contudo, essas metodologias de redução de compostos carbonílicos geram custos elevados, utilizam compostos que podem ser tóxicos e necessitam de condições reacionais específicas (atmosfera de argônio, nitrogênio) bem como a síntese dos catalisadores.

Portanto, o uso de enzimas como biocatalisadores na redução de cetonas surge como uma ótima estratégia para obtenção de álcoois enantiomericamente puros, uma vez que os microrganismos (enzimas) podem atuar seletivamente nos substratos.

\subsection{Métodos analíticos para determinação da seletividade}

Enantiômeros são compostos químicos diferentes cujas imagens especulares não são superponíveis, e exibem propriedades físicas, químicas e biológicas diferentes. Entretanto, a maioria das propriedades (ponto de ebulição, solubilidade, índice de refração são idênticas) à exceção de duas, uma física e outra química. A primeira tem a ver com o efeito que cada enantiômero provoca no desvio da luz polarizada no plano: um dos compostos gira a luz polarizada no plano no sentido dos ponteiros do relógio, segundo um dado valor angular, chamado de dextrógiro $(d)$ enquanto que o outro enantiômero roda o plano da luz polarizada segundo o mesmo valor angular absoluto, mas no sentido contrário ao dos ponteiros do relógio, chamado de levógiro $(l)$. 
O método clássico de determinação da pureza enantiomérica de uma amostra é medir sua pureza ótica usando um polarímetro. Determina-se assim o ângulo de rotação ótica experimental da amostra e este é convertido para a rotação ótica específica $[\alpha]^{\mathrm{T}} \mathrm{D}$, grandeza e a característica de cada substância oticamente ativa (MARPLES, 1981).

Equação :

$$
[\alpha]_{\mathrm{D}}^{\mathrm{T}}=\frac{\alpha}{l . c}
$$

onde:

$[\boldsymbol{\alpha}]^{\mathrm{T}}{ }_{\mathrm{D}}=$ rotação ótica específica

$\alpha=$ rotação ótica observada

$l=$ comprimento da cela polarimétrica $(\mathrm{dm})$

$c=$ concentração da solução em $\mathrm{g} / \mathrm{cm}^{3}$ de solvente

$\mathrm{T}=$ temperatura $\mathrm{em}^{\circ} \mathrm{C}$

$\mathrm{D}$ = comprimento de onda de emissão da linha $\mathrm{D}$ do sódio $(\lambda 589 \mathrm{~nm})$

A medida da rotação ótica de uma amostra deve ser realizada sob condições definidas de temperatura, solvente, concentração e em um dado comprimento de onda de incidência da luz polarizada no plano. Estes valores podem ser comparados com rotações conhecidas de amostras enantiomericamente puras de alguns compostos, medidos sob condições idênticas. Se a medida for realizada sob condições rigorosamente controladas e calibrações apropriadas, o valor pode ser igualado com o de pureza enantiomérica (MARPLES, 1981). O excesso enantiomérico pode ser calculado a partir das rotações óticas:

$$
\begin{gathered}
\% \text { do excesso } \\
\text { enantiomérico }
\end{gathered}=\frac{\text { Rotação específica observada }}{\text { Rotação específica do enantiômero puro }} \times 100
$$


Ou ainda pelas áreas obtidas por cromatografia gasosa (CG):

$$
\text { e.e. }(\%)=\frac{P-Q}{P+Q} \times 100
$$

Onde P e Q são as áreas correspondentes aos picos dos enantiômeros. Sendo P corresponde a área maior e Q a área menor (FABER, 2004).

A separação dos enantiômeros nos compostos quirais pode ser realizada por cromatografia gasosa com o uso de colunas quirais. Muitas fases quirais foram desenvolvidas para a separação de enantiômeros por (CG), tais como, as baseadas em derivados de aminoácidos, na complexação com metais, além das fases quirais derivadas de ciclodextrinas (BONATO, 2006). As ciclodextrinas são oligossacarídeos cíclicos contendo 6, 7 ou 8 unidades de glicose, sendo denominadas de $\alpha-\beta-$ e $\gamma$-ciclodextrinas, respectivamente. As unidades de glicose, unidas por ligações $\alpha(1,4)$, estão espacialmente arranjadas na forma de um cone cortado. A cavidade da ciclodextrina é relativamente apolar e a superfície polar, devido aos grupos hidroxilas, os quais podem sofrer reações químicas, formando derivados para a preparação de diferentes tipos de colunas quirais. O mecanismo de separação está baseado na formação de um complexo diastereoisomérico de inclusão entre amostra e a ciclodextrina, devido à inclusão da parte hidrofóbica da molécula quiral na cavidade hidrofóbica da ciclodextrina e interação dos grupos hidrofílicos com as hidroxilas ou com os grupos resultantes da derivação (MACHIDA et al., 1998 ETHUR, 2004). A cromatografia gasosa é uma das técnicas analíticas mais utilizadas, além de possuir um alto poder de resolução, é muito atrativa devido à possibilidade de detecção em escala de nano $\left(10^{-9}\right)$ e pico $\left(10-^{12}\right)$ gramas de amostras. O gás utilizado como fase móvel deve ter alta pureza e ser inerte em relação à fase estacionária. Hidrogênio e hélio são os mais usados. 


\section{Procedimentos experimentais}

\subsection{Método para obtenção de álcoois e haloidrinas}

\section{- $\quad$ Síntese dos álcoois e haloidrinas racêmicas}

Os álcoois e haloidrinas racêmicos foram sintetizados a partir da redução das correspondentes cetonas (1-7) com boroidreto de sódio ((Tabela 2 e Esquema 12).

As sínteses dos álcoois e haloidrinas foram realizadas em balões de $100 \mathrm{~mL}$ sob agitação magnética. Foram adicionados $10 \mathrm{~mL}$ de metanol e $50 \mathrm{mg}$ das cetonas (1-7) e um pequeno excesso de boroidreto de sódio $\left(\mathrm{NaBH}_{4}\right)$. As reações foram monitoradas por cromatografia em camada delgada utilizando-se placas de sílica gel.

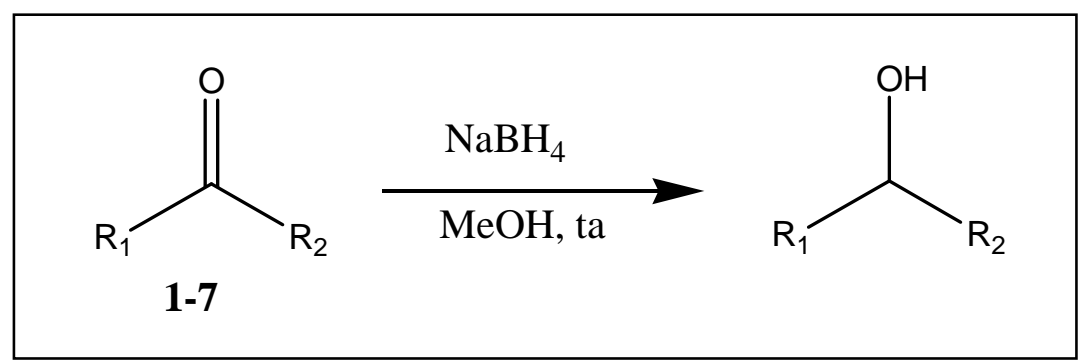

Esquema 12: Síntese de álcoois e haloidrinas quirais

\section{- $\quad$ Extrações das reações}

Após as reações terem sido completadas, adicionou-se na mistura reacional aproximadamente $10 \mathrm{~mL}$ de água destilada. As reações foram extraídas com acetato de etila 3 x $30 \mathrm{~mL}$. À fase orgânica foi adicionado sulfato de magnésio e em seguida realizou-se uma filtração e posteriormente o solvente foi evaporado sob pressão reduzida no rota evaporador. 


\section{- $\quad$ Purificação}

Os resíduos (produtos) obtidos foram purificados por cromatografia em coluna onde utilizou-se sílica flech e após obtenção dos produtos purificados determinou-se o rendimento (Tebela 2). As caracterizações foram realizadas por RMN ${ }^{1} \mathrm{H}$, IV e quando necessárias em CG-EM.

Tabela 2. Relação entre numero de mols e massas utilizados para as reações de redução

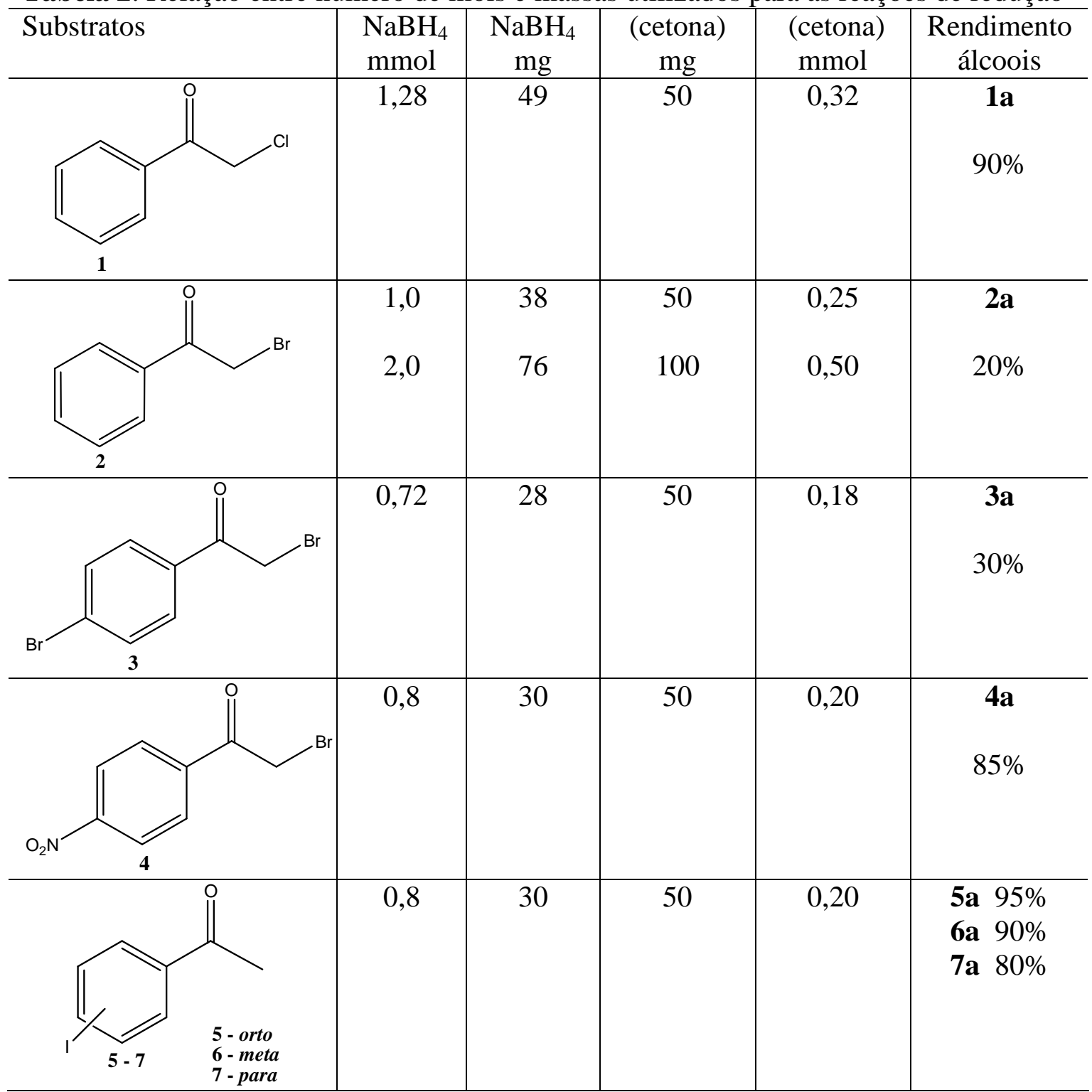




\subsection{Cultivo dos microrganismos de origem marinha}

- Composição dos meios de cultura

Composição do meio de cultura líquido e sólido para crescimento dos fungos de origem marinha (1L).

Meio líquido $\left(\mathrm{M}_{3}\right)$ : extrato de malte (30 g), peptona de farinha de soja (3 g).

Meio sólido ( $\left.\mathrm{MA}_{3}\right)$ : extrato de malte (30 g), peptona de farinha de soja (3 g), agar (15 g).

Meio líquido batata (B): batata (20 g).

Meio sólido batata (BA): batata (20 g) e agar (20 g).

OBS: Para as reações de redução no cultivo dos fungos, utilizou-se água do mar artificial preparada no laboratório. Os fungos foram cultivados em meio de cultura sólidos (em placas de Petri e em tubos de ensaio). Estas culturas foram mantidas sob refrigeração (4 $\left.{ }^{\circ} \mathrm{C}\right)$ para posteriores repiques em meio de cultura líquidos.

- $\quad$ Procedimento para preparar o meio $\left(\mathbf{M}_{3}\right)$

Preparo do meio de cultura líquido $\left(\mathrm{M}_{3}\right)$ : Em um recipiente de $(2 \mathrm{~L})$ foram adicionados (1 L) de água do mar artificial, (30 g) de extrato de malte e (3 g) de peptona de soja. A solução foi agitada e ajustado o $\mathrm{pH}=8,0$ com solução KOH $2 \mathrm{M}$.

- $\quad$ Procedimento para preparar o meio $\left(\mathrm{MA}_{3}\right)$

Preparo do meio de cultura sólido $\left(\mathrm{MA}_{3}\right)$ : Em um recipiente de (2 L) foram adicionados $1 \mathrm{~L}$ de água do mar artificial, 30, g de extrato de malte, 3,0 g de peptona de soja e 15, g de agar. A solução foi agitada e ajustado $\mathrm{pH}=8,0$ com solução $\mathrm{KOH} 2 \mathrm{M}$. 
- $\quad$ Procedimento para preparar o meio (B)

Preparo do meio de cultura líquido (B): Em um recipiente de (2 L) foram adicionados

(1 L) de água do mar artificial, 20, g batata cozida/macerada. A solução foi agitada e ajustado o $\mathrm{pH}=8,0$ com solução $\mathrm{KOH} 2 \mathrm{M}$.

- Procedimento para preparar o meio BA

Preparo do meio de cultura sólido (BA). Em um recipiente de (2 L) foram adicionados (1 L) de água do mar artificial, 20, g batata cozida macerada e 20, g de agar. A solução foi agitada e ajustado o $\mathrm{pH}=8,0$ com solução $\mathrm{KOH} 2 \mathrm{M}$.

Após o ajuste de $\mathrm{pH}$ todos os meios de cultura foram autoclavados por 20 minutos $\left(121^{\circ} \mathrm{C}, 1,5 \mathrm{Kpa}\right)$. Os meios sólidos foram vertidos em placas de Petri ou em tubos de ensaio inclinados. Esses meios foram utilizados para preservação das culturas puras. Todos os meios de cultura utilizados foram da marca (Acumedia $\left.{ }^{\circledR}\right)$.

\subsubsection{Repique das culturas puras e crescimento das células totais}

Os inóculos dos microrganismos em meio líquido foram realizados em erlenmeyer de (2 L) contendo $1000 \mathrm{~mL}$ de meio de cultura $\left(\mathrm{M}_{3}\right)$ ou $(\mathrm{B})$. $\mathrm{O}$ crescimento foi realizado em agitadores rotativos $\left(32^{\circ} \mathrm{C}\right.$ e $\left.150 \mathrm{rpm}\right)$ de acordo com o crescimento mais adequado para cada microrganismo. Após 5 a 8 dias de crescimento dos microrganismos em agitador orbital rotativo as células totais foram filtradas a vácuo em funil de Buchner para posteriores reações de biorredução. As células totais e o caldo resultante da filtração foram utilizados nas reações de biorredução. 


\subsection{2. Água do mar artificial}

A composição da água do mar artificial para $1 \mathrm{~L}$ : $\mathrm{CaCl}_{2} \cdot 2 \mathrm{H}_{2} \mathrm{O}(1,36 \mathrm{~g}), \mathrm{MgCl}_{2} \cdot 6 \mathrm{H}_{2} \mathrm{O}$ $(9,68 \mathrm{~g}), \mathrm{KCl}(0,61 \mathrm{~g}), \mathrm{NaCl}(30,0 \mathrm{~g}), \mathrm{Na}_{2} \mathrm{HPO}_{4}(0,014 \mathrm{mg}), \mathrm{Na}_{2} \mathrm{SO}_{4}(3,47 \mathrm{~g}), \mathrm{NaHCO}_{3}(0,17$ g), $\mathrm{KBr}(0,1 \mathrm{~g}), \mathrm{SrCl}_{2} \cdot 6 \mathrm{H}_{2} \mathrm{O}(0,040 \mathrm{~g}), \mathrm{H}_{3} \mathrm{BO}_{3}(0,030)$.

\subsubsection{Solução tampão de Sorensen $\left(\mathrm{Na}_{2} \mathrm{HPO}_{4}-\mathrm{KH}_{2} \mathrm{PO}_{4}\right)$}

Foram utilizadas soluções tampão fosfato de sódio e potássio. Composição da solução tampão fosfato de sódio (1 L): Dissolveu-se 11,876 g de $\mathrm{Na}_{2} \mathrm{HPO}_{4}$. Composição da solução tampão fosfato de potássio (1 L): Dissolveu-se $9.078 \mathrm{~g}$ de $\mathrm{KH}_{2} \mathrm{PO}_{4}$.

$\mathrm{O}$ pH desejado foi preparado de acordo com uma mistura apropriada de cada uma das soluções de tampão Sorensen (MORITA \& ASSUMPÇÃO,1995).

\subsubsection{Cultivo do fungo Penicillium scleroirum}

O fungo foi cultivado e preservado da mesma forma que os microrganismos de origem marinha apenas a água do mar foi substituída por água destilada, uma vez que este microrganismo não necessita do meio salino para seu cultivo.

\subsubsection{Cultivo do fungo Caldariomyces fumago}

O fungo foi cultivado e preservado em meio de cultura sólido (BA) em placas de Petri e em tubos de ensaio. Estas culturas foram mantidas sob refrigeração $\left(4{ }^{\circ} \mathrm{C}\right)$ para posteriores repiques em meio de cultura líquido. 
Composição do meio de cultura líquido e sólido para crescimento do fungo Caldariomyces fumago $(1 \mathrm{~L})$.

Meio líquido: frutose (40 g), uréia (10 g), $\mathrm{NaNO}_{3}(2 \mathrm{~g}), \mathrm{KCl}(2 \mathrm{~g}), \mathrm{KH}_{2} \mathrm{PO}_{4}(2 \mathrm{~g})$, $\mathrm{MgSO}_{4} \cdot 7 \mathrm{H}_{2} \mathrm{O}(1 \mathrm{~g}), \mathrm{FeSO}_{4} \cdot 7 \mathrm{H}_{2} \mathrm{O}(0,02 \mathrm{~g})$.

Meio sólido batata $\mathrm{BA}_{2}$ : batata $(20 \mathrm{~g})$ e agar $(20 \mathrm{~g})$.

(Observação para o crescimento em meio liquido foi utilizado água destilada).

\subsubsection{Procedimento para preparar o meio de cultivo para o fungo Caldariomyces fumago}

Preparo do meio de cultura líquido: Em um recipiente de (2 L) foram adicionados (1 L) de água destilada e todos os sais descritos na (seção 2.2.5.). A solução foi agitada e ajustado o $\mathrm{pH}=2,75$ com solução de $\mathrm{HCl} 10 \%$.

\subsubsection{Repique das culturas puras}

O inóculo do fungo C. fumago em meio líquido foi realizado em erlenmeyer de (125 $\mathrm{mL}$ ) contendo $50 \mathrm{~mL}$ de meio de cultura. $\mathrm{O}$ crescimento foi realizado em agitador rotativo $\left(27^{\circ} \mathrm{C}\right.$ e $\left.130 \mathrm{rpm}\right)$ por 6 dias. Após o pré-crescimento o conteúdo do erlenmeyer foi vertido para outro erlenmeyer de $(1 \mathrm{~L})$ previamente autoclavado contendo $500 \mathrm{~mL}$ de meio de cultura líquido. E novamente levado ao agitador rotativo onde permaneceu por mais 10 dias $\left(27^{\circ} \mathrm{C}\right.$ e $150 \mathrm{rpm}$ ). Após o crescimento do microrganismo, as células totais foram filtradas a vácuo em funil de Buchner e em seguida ressuspensas em soluções tamponadas para posteriores reações. 


\subsection{Reações de biocatálise}

\subsubsection{Síntese das haloidrinas e álcoois por biocatálise}

Após o crescimento dos microrganismos em meio líquido, as células totais foram filtradas e pesadas. As células e caldo resultantes da filtração foram utilizadas para realizar as reações.

\subsubsection{Reações de redução das cetonas com as células totais}

As reações foram realizadas em erlenmeyer de $250 \mathrm{~mL}$, onde adicionou-se $5 \mathrm{~g}$ de células totais úmidas de fungos suspensas em $100 \mathrm{~mL}$ de solução tampão fosfato $\left(\mathrm{Na}_{2} \mathrm{HPO}_{4} / \mathrm{KH}_{2} \mathrm{PO}_{4}\right) \mathrm{pH}=7$. Em seguida, com o auxílio de uma micropipeta e ou espátula, adicionou-se as $\alpha$-halocetonas $(\mathbf{1}$ - 4) previamente dissolvida com $200 \mu \mathrm{L}$ de DMSO e as cetonas (5 -7), essas foram dissolvidas com $600 \mu \mathrm{L}$ de DMSO. Em todas reações foram utilizadas $50 \mathrm{mg}$ ou $50 \mu \mathrm{L}$ das cetonas (1-7).

(Observação apenas uma reação da $\alpha$-bromoacetofenona (2) foi realizada com 100 mg).

2.3.3. Reação de redução das halocetonas com o caldo enzimático (meio de cultura filtrado)

As reações foram realizadas em erlenmeyer de $250 \mathrm{~mL}$ onde adicionaram-se $100 \mathrm{~mL}$ do filtrado (caldo enzimático) e as $\alpha$-halocetonas (1-4) previamente dissolvidas com $200 \mu \mathrm{L}$ de DMSO. Como o caldo enzimático não levou a redução das cetonas não foram utilizadas as iodoacetofenonas (5-7).

(Observação utilizou-se quando necessária maior quantidade de DMSO). 


\subsubsection{Biotransformações no agitador rotativo}

Após o preparo de todas as reações, com as células e com o caldo, levaram-se os erlenmeyers ao agitador rotativo (150 rpm e $\left.32^{\circ} \mathrm{C}\right)$. Retiraram-se alíquotas em tempos determinados de acordo com cada reação. As alíquotas foram extraídas com acetato de etila e posteriormente foram realizadas as análises por cromatografia gasosa (CG) e/ou em CG-EM.

\subsubsection{Extração das reações}

Os produtos obtidos das reações biocatalisadas foram extraídos com acetato de etila (3 x, $50 \mathrm{~mL}$ ) em funil de separação. À fase orgânica foi adicionado sulfato de magnésio, em seguida realizado uma nova filtração e o solvente removido a vácuo no rotaevaporador. Os produtos foram purificados por cromatografia em coluna (CC), utilizando-se como eluente misturas de éter de petróleo: acetato de etila 9,5:0,5; $9: 1 ; 8: 2$ e 1:1.

\subsubsection{Separação enantiomérica das haloidrinas (1-4) e álcoois (5-7) por colunas quirais}

As análises cromatográficas das haloidrinas (1a-4a) e dos álcoois (5a-7a) foram obtidos por cromatografia gasosa (CG) detector (FID) utilizando as colunas quirais de $\beta$ ciclodextrinas pela injeção de $2 \mu \mathrm{L}$ de amostra. As condições de análise encontram-se na (Tabela 4, página 37). 


\subsection{Identificação dos fungos de origem marinha}

Os fungos utilizados nas biorreduções foram repicados em duplicata em tubos inclinados contendo meio de cultura $\mathrm{MA}_{3}$ e encaminhados para a identificação. $\mathrm{O}$ tempo de crescimento foi de 5 a 8 dias produzindo células suficientes para a identificação.

\subsubsection{Identificação taxonômica}

Identificação taxonômica dos fungos derivados de ambiente marinho foi realizada pelo grupo da Dra. Lara Durães do Centro de Pesquisas Químicas, Biológicas e Agrárias (CPQBA/Unicamp). A identificação baseou-se na utilização de métodos de taxonomia convencional e taxonomia molecular. A morfologia dos isolados de fungos filamentosos foi examinada por meio da observação da colônia em esterioscópio (Leica MZ6, Wetzlar, Germany) e por meio da análise de microscopia ótica das lâminas coradas com lactofenol azul de algodão (Leica DM LS, Wetzlar, Germany). Os fungos foram identificados baseado nas observações macro e microscópicas e seguindo os métodos descritos em literatura (PITT, 1979; SAMSON et al).

Visando a confirmação e identificação taxonômica mais acurada os fungos derivados de ambiente marinho foram submetidos a análises moleculares. A extração de DNA foi realizada de acordo com a metodologia descrita na literatura (RAEDER E BRODA, 1985) com as seguintes modificações: o micélio foi previamente congelado a $80^{\circ} \mathrm{C} \mathrm{em} 50 \mu \mathrm{L}$ de TE (10 mM Tris, $1 \mathrm{mM}$ EDTA, pH 8.0) e gentilmente macerado contra a parede do microtubo utilizando um pequeno bastão de plástico. Para a remoção de RNA foi utilizado $1 \mu \mathrm{L}$ da enzima Rnase $\left(10 \mathrm{mg} \mathrm{mL}^{-1}\right)$ seguido de incubação a $37^{\circ} \mathrm{C}$ por $60 \mathrm{~min}$. O DNA foi estocado a $-20{ }^{\circ} \mathrm{C}$. As regiões D1/D2 do DNAr 28S foram amplificadas e sequenciadas de acordo com o 
protocolo descrito por (SETTE, et al 2006). O par de primers utilizados para a amplificação do DNAr 28S foram NL-1 (5' - GCATATCAATAAGCGGAGGAAAAG-3') e NL-4m (5'GGTCCGTGTTTCAAGACG-3') e para o sequenciamento foram utilizados os primers NL-1 $\left(5^{\prime}-\right.$ GCATATCAATAAGCGGAGGAAAAG-3’), $\quad$ NL-2m (5'CTTGTGCGCTATCGGTCTC-3'), NL-3m (5'-GAGACCGATAGCGCACAAG-3') and NL4m (5'-GGTCCGTGTTTCAAGACG-3') (O’DONNELL, 1993). As sequiências foram comparadas com seqüências da região D1/D2 do DNAr de linhagens disponíveis na base de dados do GenBank (http://www.ncbi.nem.nih.gov) utilizando a rotina BLAST N (Tabela 3). 
Tabela 3. Espécies mais próximas aos fungos derivados de ambiente marinho baseado nas análises do BLAST e dados de identificação morfológica.

\begin{tabular}{|c|c|c|c|c|c|}
\hline $\begin{array}{l}\text { Códig } \\
\mathrm{O}^{*}\end{array}$ & $\begin{array}{l}\text { Número } \\
\text { de acesso } \\
\text { CBMAI }\end{array}$ & Fonte & Espécies relativas & $\begin{array}{c}\% \\
\text { similarida } \\
\text { de }\end{array}$ & $\begin{array}{l}\text { Identificação } \\
\text { macro e } \\
\text { microscópica }\end{array}$ \\
\hline Gc5 & 930 & $\begin{array}{l}\text { Geodia } \\
\text { corticostylifera }\end{array}$ & $\begin{array}{l}\text { Penicillium miczynskii } \\
\text { Penicillium rivolii } \\
\text { Penicillium waksmanii }\end{array}$ & $\begin{array}{l}99 \\
99 \\
99\end{array}$ & $\begin{array}{l}\text { Penicillium } \\
\text { miczynskii }\end{array}$ \\
\hline Ce16 & 931 & $\begin{array}{l}\text { Chelonaplysylla } \\
\text { erecta }\end{array}$ & $\begin{array}{l}\text { Penicillium raistrickii } \\
\text { Penicillium sclerotigenum } \\
\text { Penicillium freii }\end{array}$ & $\begin{array}{l}100 \\
99 \\
99\end{array}$ & $\begin{array}{l}\text { Penicillium } \\
\text { raistrickii }\end{array}$ \\
\hline Gc1 & 932 & G. corticostylifera & $\begin{array}{l}\text { Trichoderma sp. } \\
\text { Trichoderma inhamatum } \\
\text { Trichoderma viride }\end{array}$ & $\begin{array}{c}100 \\
99 \\
98\end{array}$ & $\begin{array}{l}\text { Trichoderma } \\
\text { sp. }\end{array}$ \\
\hline Gc12 & 933 & G. corticostylifera & $\begin{array}{l}\text { Aspergillus sydowii } \\
\text { Aspergillus caesiellus } \\
\text { Aspergillus versicolor }\end{array}$ & $\begin{array}{l}100 \\
100 \\
99\end{array}$ & $\begin{array}{l}\text { Aspergillus } \\
\text { sydowii }\end{array}$ \\
\hline Ce19 & 934 & C. erecta & $\begin{array}{l}\text { Aspergillus sydowii } \\
\text { Aspergillus caesiellus } \\
\text { Aspergillus versicolor }\end{array}$ & $\begin{array}{c}100 \\
100 \\
99\end{array}$ & $\begin{array}{l}\text { Aspergillus } \\
\text { sydowii }\end{array}$ \\
\hline Ce15 & 935 & C. erecta & $\begin{array}{l}\text { Aspergillus sydowii } \\
\text { Aspergillus caesiellus } \\
\text { Aspergillus versicolor }\end{array}$ & $\begin{array}{l}100 \\
99 \\
99\end{array}$ & $\begin{array}{l}\text { Aspergillus } \\
\text { sydowii }\end{array}$ \\
\hline $\mathrm{Ce} 5$ & 936 & C. erecta & $\begin{array}{l}\text { Bionectria sp. } \\
\text { Nectria ochroleuca } \\
\text { (=Bionectria ochroleuca) } \\
\text { Bionectria ochroleuca }\end{array}$ & $\begin{array}{l}100 \\
99\end{array}$ & Bionectria sp. \\
\hline
\end{tabular}

*Fungos derivados de ambiente marinho 


\subsection{Materiais}

\subsubsection{Reagentes e solventes}

Os reagentes substratos (cetonas) e solventes (acetato de etila, metanol, clorofórmio, éter de petróleo, hexano, dicloroetano, etc) utilizados foram obtidos de fontes comerciais (Aldrich e Fluka) e utilizados sem prévia purificação. Os sais utilizados também foram obtidos de fontes comerciais (Synth, Merck e Vertec)

\subsubsection{Cromatografia em coluna}

As cromatografias em coluna (CC) foram realizadas utilizando-se sílica gel 60 230400 flesh da Across e cromatofolhas de sílica gel $60 \mathrm{~F}_{254}$ da Sorbent Technologies para cromatografia em camada delgada (CCD). As cromatofolhas foram observadas em uma câmara com luz UV (254 nm) e reveladas: com solução de anisaldeído (100 mL de ácido acético, $1 \mathrm{~mL}$ de $p$-anisaldeído e $1 \mathrm{~mL}$ de ácido sulfúrico) ou solução alcoólica de vanilina (135 mL $\mathrm{H}_{2} \mathrm{O}$ destilada, $30 \mathrm{~mL}$ de $\mathrm{H}_{2} \mathrm{SO}_{4}, 35 \mathrm{~mL} \mathrm{MeOH}$ e 3,0 g vanilina). Como fase móvel, utilizou-se misturas de solventes, sendo o mais adequado para cada situação.

\subsubsection{Espectroscopia de infravermelho (IV)}

Os espectros de absorção na região do infravermelho (IV) foram obtidos em um espectrofotômetro de infravermelho com transformada de Fourier Bomem/MB-102 e calibração interna. As amostras foram preparadas na forma de filme em pastilha de silício da 
Nicodom Ltda (optical grade silicon, window undrilled $13 \times 2 \mathrm{~mm}$ ) e as freqüências de absorção foram expressas em $\mathrm{cm}^{-1}$.

\subsubsection{Espectroscopia de ressonância magnética nuclear (RMN)}

Os espectros de RMN de ${ }^{1} \mathrm{H}$ foram obtidos no aparelho Bruker /AC200 operando com freqüências $200 \mathrm{MHz}$ e $400 \mathrm{MHz}$. O solvente utilizado foi clorofórmio deuterado, $\left(\mathrm{CDCl}_{3}\right)$ e os deslocamentos químicos $(\delta)$ estão expressos em parte por milhão (ppm) em relação ao padrão interno tetrametilsilano (TMS). A multiplicidade dos sinais observados está indicada pelas seguintes abreviaturas: $\mathrm{s}=$ singleto, $\mathrm{d}=$ dupleto, $\mathrm{t}=$ tipleto, $\mathrm{m}=$ multipleto, $\mathrm{dd}=$ duplo, dt $=$ duplo tripleto número de hidrogênios deduzidos na integral relativa e a constante de acoplamento (J) expressa em Hertz (Hz).

\subsubsection{Espectrometria de massas (EM)}

Os espectros de massa foram obtidos em um aparelho Shimadzu modelo 2010, equipado com auto injetor modelo AOC-29i e detector de massas. Esse equipamento se encontra instalado no laboratório da Profa. Dra. Maria Olímpia de Oliveira Rezende (IQSCUSP).

As análises de IV, RMN de ${ }^{1} \mathrm{H}$ foram realizadas junto a Central Analítica do Instituto de Química de São Carlos (CAQUI) e no Departamento de Química da Universidade Federal de São Carlos (DQ-UFSCar). 


\subsubsection{Polarímetro}

As medidas de rotação ótica foram realizadas DQ-UFSCar em um Polarímetro Perkin-Elmer modelo 241 (Waltham MA, USA) equipado com lâmpada de $\mathrm{Na}(\lambda 589 \mathrm{~nm})$. As amostras foram diluídas em $1 \mathrm{~mL} \mathrm{CHCl}_{3}$ grau espectroscópico e os experimentos realizados a $25^{\circ} \mathrm{C}$. As análises foram realizadas no laboratório do Prof. Dr. Alcindo A. dos Santos.

\subsubsection{Cromatografia a gás}

Os cromatogramas foram obtidos em um cromatógrafo a gás (CG) Heweltt Packard/5890. A coluna quiral utilizada de fase estacionária foi CP-Chirasil-Dex-CB - Varian Capillary Column with EZ-GRIP ${ }^{\mathrm{TM}},(25 \mathrm{~m} \times 0,25 \mathrm{~mm} \times 0,39 \mathrm{~mm})$. O gás de arraste foi hidrogênio. As condições de análise para cada composto encontram-se na (Tabela 4).

\subsubsection{Evaporadores rotativos}

Para remoção dos solventes das soluções orgânicas, foram utilizados: Rota evaporador Fisaton e Tecnal T - 210 ambos equipados com bomba de vácuo TE - 058 e refrigeração Tecnal Modelo TE - 2005. 


\subsubsection{Centrífuga}

As alíquotas retiradas da reações de biorredução foram centrifugadas com 6000 rpm e duração de 6 min em uma centrífuga modelo Hermle.

\subsubsection{Agitador orbital rotativo termostatizado}

O crescimento dos fungos e as reações de biorredução de cetonas foram realizadas em agitador rotativo modelo Tecnal TE-421 ou Superohn.

\subsubsection{Outros equipamentos utilizados}

Balança analítica modelo AY 220 - Suimadzu, capela de fluxo laminar marca Veco, autoclaves vertical modelo Phoenix, medidor de pH modelo 8010 da marca Qualxtron. 
Tabela 4. Programas utilizados no cromatógrafo a gás utilizando-se coluna quiral de ciclodextrinas. ${ }^{\mathrm{a}}$

\begin{tabular}{|c|c|c|c|c|c|c|}
\hline Composto & $\mathbf{T}_{\mathbf{i}}\left({ }^{\circ} \mathbf{C}\right)$ & $\mathbf{t}_{\mathbf{i}}(\mathbf{m i n})$ & $\mathbf{T}_{\mathbf{f}}\left({ }^{\circ} \mathbf{C}\right)$ & $\mathbf{t}_{\mathrm{f}}(\mathbf{m i n})$ & $\mathbf{r}\left({ }^{\circ} \mathrm{C} / \mathrm{min}\right)$ & $\mathbf{t}_{\mathrm{r}}(\min )$ \\
\hline 1 & 120 & 2 & 165 & 8 & 2 & 7,9 \\
\hline $1 \mathrm{a}$ & 120 & 2 & 165 & 8 & 2 & $\begin{array}{l}(S)-12,7 \mathrm{e} \\
(R)-13,3\end{array}$ \\
\hline 1 & 150 & 2 & 165 & 8 & 2 & 5,0 \\
\hline 2 & 120 & 2 & 165 & 8 & 2 & 10,4 \\
\hline $2 a$ & 120 & 2 & 165 & 8 & 2 & $\begin{array}{c}(R)-15,0 \mathrm{e} \\
(S)-15,6\end{array}$ \\
\hline 2 & 150 & 2 & 165 & 8 & 2 & 6,0 \\
\hline $2 a$ & 150 & 2 & 165 & 8 & 2 & $\begin{array}{c}(R)-8,8 \mathrm{e} \\
(S)-9,1\end{array}$ \\
\hline 3 & 120 & 2 & 165 & 8 & 2 & 25,38 \\
\hline $3 a$ & 120 & 2 & 165 & 8 & 2 & 9,9 e 10,2 \\
\hline 4 & 130 & 2 & 200 & 2 & 2 & 29,9 \\
\hline $4 a$ & 130 & 2 & 200 & 2 & 2 & 15,3 e 15,7 \\
\hline 5 & 120 & 2 & 165 & 2 & 2 & 12,1 \\
\hline $5 \mathbf{a}$ & 120 & 2 & 165 & 2 & 2 & $\begin{array}{c}(R)-20,4 \mathrm{e} \\
(S)-23,3\end{array}$ \\
\hline 6 & 120 & 2 & 165 & 2 & 2 & 12,51 \\
\hline $6 a$ & 120 & 2 & 165 & 2 & 2 & 20,4 e 21,2 \\
\hline 7 & 120 & 2 & 165 & 2 & 2 & 15,5 \\
\hline $7 \mathbf{a}$ & 120 & 2 & 165 & 2 & 2 & $\begin{array}{l}(R)-21,5 \mathrm{e} \\
(S)-22,4\end{array}$ \\
\hline
\end{tabular}




\section{Resultados e Discussão}

Objetivos

O principal objetivo deste trabalho foi realizar uma triagem com fungos de origem marinha para investigar a redução de cetonas para a obtenção de álcoois quirais. Outra parte do trabalho envolveu um ensaio colorimétrico para a determinação de peroxidases em vegetais e em microrganismos (Apêndice).

\subsection{Fungos de origem marinha}

Os fungos de origem marinha utilizados para triagem das reações de biocatálise foram isolados das esponjas Geodia corticostylifera $(\mathrm{Gc})$ e Chelonaplysilla erecta $(\mathrm{Ce})$. As esponjas $G$. corticostylifera e C. erecta foram coletadas no Litoral Norte do Estado de São Paulo, na cidade de São Sebastião pelo grupo do Prof. Dr. Roberto G. de S. Berlinck (IQSCUSP). O isolamento dos fungos foi realizado pelo grupo da Profa. Dra. Mirna H. R. Seleghim do Departamento de Ecologia e Biologia Evolutiva (UFSCar).

A identificação taxonômica dos fungos derivados de ambiente marinho foi realizada pelo grupo da Dra. Lara Durães Sette do Centro de Pesquisas Químicas, Biológicas e Agrárias (CPQBA/UNICAMP). A identificação baseou-se na utilização de métodos de taxonomia convencional e taxonomia molecular (Seção 2.4.1.). Os fungos foram depositados na Coleção Brasileira de Cultura de Microrganismos de Ambiente e Indústria (CBMAI, Brasil) do Centro de Pesquisas Químicas, Biológicas e Agrícolas.

Nas (Figura 6) A-F estão fotos de alguns fungos derivados de ambientes marinhos e dos fungos $C$. fumago e $P$. sclerotiorum que foram utilizados como fontes de biocatalisadores neste trabalho. Deve-se destacar que esses estudos realizados são inéditos com os fungos de 
origem marinha, pois foram utilizados pela primeira vez para promover reações em compostos orgânicos.

Antes de iniciar as reações de biocatálise no laboratório de química orgânica foi realizado um estágio no laboratório de microbiologia por um período de 2 meses totalizando de 100 horas, sob a supervisão da Profa. Dra. M.H.R. Seleghim. O treinamento foi orientado pela técnica Darci da Consolação Diniz Javaroti. Este estágio teve como objetivo treinar o manuseio básico das técnicas de microbiologia, como cultivos, repiques, preparos de meios de cultura e soluções, descartes, assepsias, esterilizações de materiais, etc. O treinamento foi essencial para o aprendizado de técnicas para se utilizar com os fungos no laboratório, de forma que estes pudessem ser considerados como quaisquer outros reagentes ordinariamente empregados em química orgânica, mas com os devidos cuidados requeridos aos organismos vivos.

A manipulação de microrganismos em um laboratório não é uma tarefa fácil, por isso é necessário um treinamento do aluno em um laboratório de microbiologia. Conhecendo as técnicas fundamentais, principalmente quanto aos cuidados que envolvem a manutenção das culturas vivas (repiques), bem como a pureza das cepas, é essencial para obter-se um bom desempenho nas reações biocatálise. Dentre os diversos fungos isolados do invertebrado Chelonaplysylla erecta $(\mathrm{Ce})$, três microrganismos foram escolhidos para a realização das reações de biocatálise. Esses fungos foram isolados por Hercules Vicente Ferreira e Lenilson Coutinho da Rocha. 


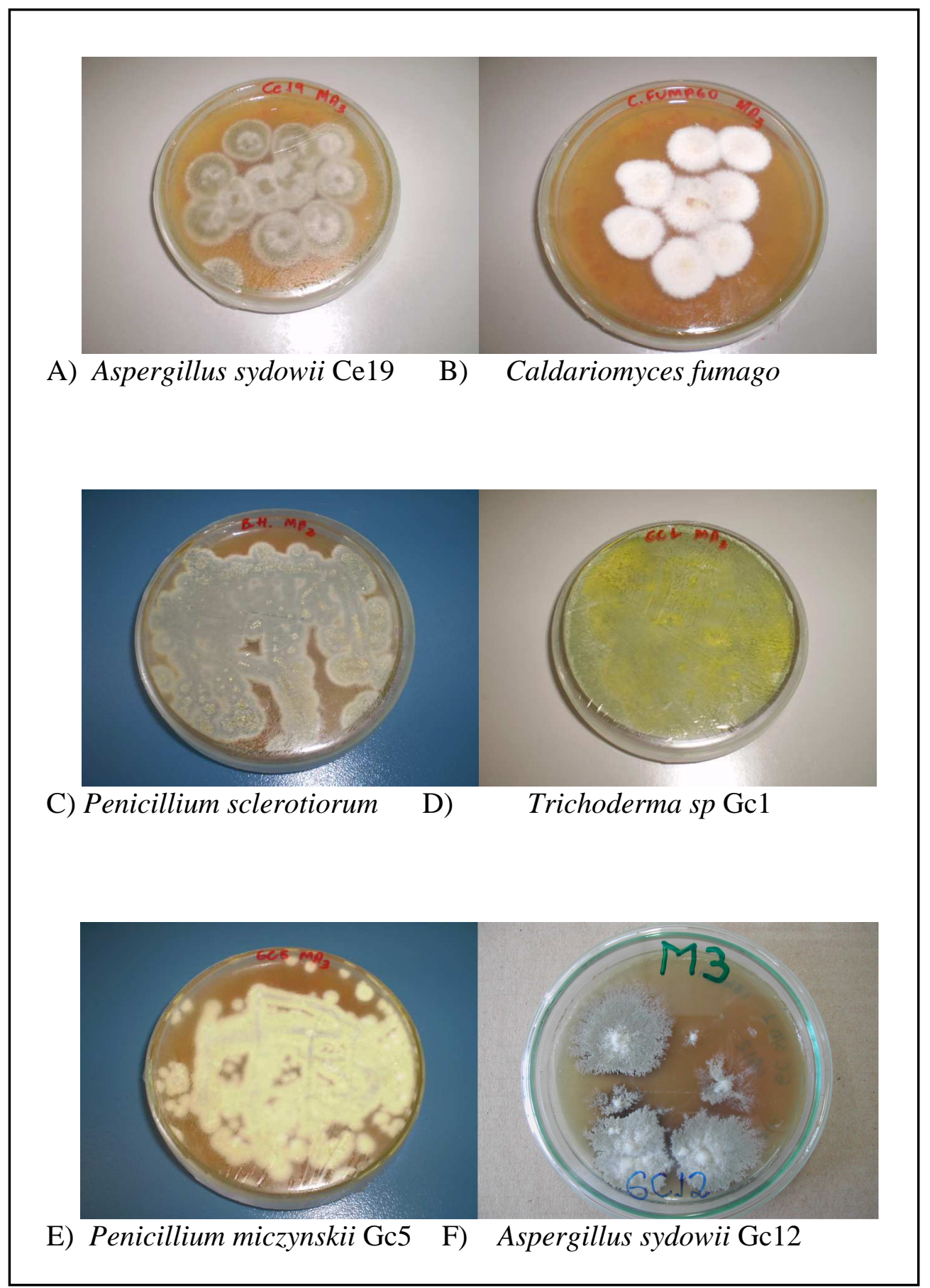

Figura 6: Fotos de alguns fungos utilizados nas biorreduções das cetonas. Os fungos (B) Penicillium sclerotiorum e (C) Caldariomyces fumago não fazem parte dos fungos marinhos, são fungos terrestres. $\mathrm{O}$ fungo $P$. sclerotiorum foi utilizado na triagem da redução da $\alpha$-cloroacetofenona (1) e o fungo $C$. fumago foi utilizado em ensaios de peroxidasae (Apêndice). 


\subsection{Biorredução de cetonas com fungos de origem marinha}

\subsubsection{Cetonas comerciais utilizadas na triagem}

Para avaliar a redução com fungos de origem marinha selecionou-se a $\alpha$ cloroacetofenona (1), $\alpha$-bromoacetofenona (2), $p$-bromo- $\alpha$-bromoacetofenona $(3)$ e a $p$-nitro$\alpha$-bromoacetofenona (4). Também se utilizaram a orto-iodo-acetofenona (5), meta-iodoacetofenona (6) e para-iodo-acetofenona (7) nas reações de redução. As reduções de grupos halocetônicos de 1-4 formam as respectivas haloidrinas, enquanto as cetonas 5-7 formam os correspondentes álcoois secundários.

As reações de redução enzimática forneceram resultados bastante distintos de acordo com as cetonas e o biocatalisador utilizados.

\subsubsection{Síntese das haloidrinas 1a-3a racêmicas utilizadas como padrões}

Inicialmente, prepararam-se os padrões racêmicos das haloidrinas 1a-3a por redução das $\alpha$-halocetonas 1-3 utilizando-se boroidreto de sódio em metanol (Esquema 13). O rendimento da redução para a cloroidrina 1a foi de $90 \%$. Enquanto que as bromoidrinas 2a-3a foram obtidas em baixo rendimento devido à formação de uma mistura 1:1 dos álcoois $\mathbf{2 a - 3 a}$ com os epóxidos $\mathbf{2 b - 3 b}$. Esta proporção foi determinada por cromatografia gasosa. A formação dos epóxidos $\mathbf{2 b - 3 b}$ ocorreu espontaneamente durante as sínteses das bromoidrinas quando se utilizou as $\alpha$-bromocetonas 2-3. Nos espectros de $\mathrm{RMN}{ }^{1} \mathrm{H}$ (Anexos) pôde-se observar as misturas das bromoidrinas $\mathbf{2 a - 3 a}$ com os epóxidos $\mathbf{2 b - 3 b}$, cujos sinais foram comparados com os dados da literatura (CARVALHO et al., 1991; WEI et al., 1998). Quando se realizou a purificação das bromoidrinas 2a-3a por cromatografia em coluna com sílica gel, 
obteve-se um rendimento muito baixo para as bromoidrinas 2a (20\%) e 3a (30\%). Mas, posteriormente análises por CG levaram a uma mistura de produtos entre as cloroidrinas e os epóxidos. Na literatura há métodos químicos que descrevem as sínteses de bromoidrinas sem a formação de epóxidos (RODRIGUES et al, 2004). Entretanto, várias tentativas foram realizadas em relação à redução química, mas sem nenhum sucesso, pois não foi possível obter as bromoidrinas 2a-3a puras. Sempre foi observada a presença dos correspondentes epóxidos $\mathbf{2 b - 3 b}$ em misturas com as bromoidrinas após várias tentativas de purificação.

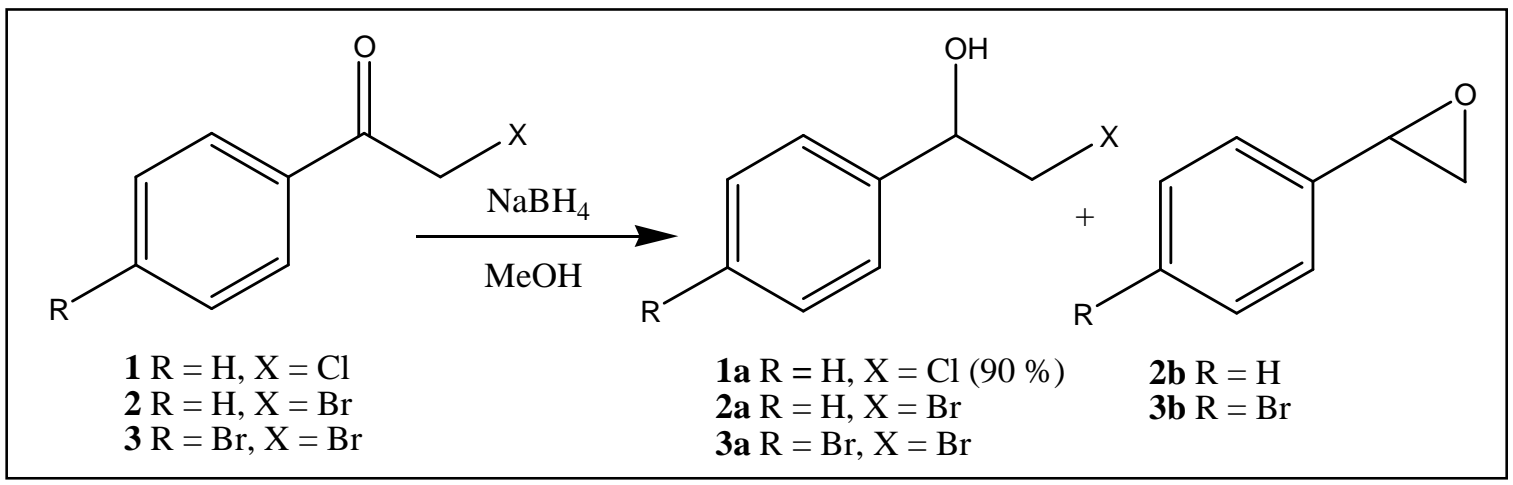

Esquema 13. Redução de $\alpha$-halocetonas $\mathbf{1 - 3}$ com $\mathrm{NaBH}_{4}$

\subsubsection{Redução da $\alpha$-cloroacetofenona (1) com fungos de origem marinha}

Devido a instabilidade das bromoidrinas 2a-3a, quando foram sintetizadas quimicamente para fornecer os padrões racêmicos, achou-se conveniente iniciar a triagem biocatalítica com os fungos derivados marinhos utilizando-se a $\alpha$-cloroacetofenona (1). Os fungos utilizados na triagem foram isolados das esponjas marinhas Geodia corticostylifera e Chelonaplysylla erecta e identificados como: Trichoderma sp Gc1, Penicillium miczynskii Gc5, Aspergillus sydowii Gc12, Bionectria sp Ce5, Aspergillus sydowii Ce15, Penicillium raistrickii Ce16 e Aspergillus sydowii Ce19. Na (Tabela 5) encontram-se descritos os resultados obtidos na biorredução da $\alpha$-cloroacetofenona (1). 
Primeiramente, os fungos foram cultivados em água do mar artificial (Artificial Sea Water - ASW) cuja solução aquosa contém uma elevada concentração de íons cloretos $(0,63$ mols $\left.\mathrm{L}^{-1}\right)$.

Tabela 5. Triagem da $\alpha$-cloroacetofenona 1 com fungos de origem marinha. ${ }^{\mathrm{a}}$<smiles>O=C(CCl)c1cccc(I)c1</smiles>

\begin{tabular}{|c|c|c|c|c|c|c|c|c|c|}
\hline \multicolumn{2}{|l|}{ \# } & \multicolumn{4}{|c|}{$\begin{array}{l}\text { Reação com células totais dos } \\
\text { fungos }\end{array}$} & \multicolumn{4}{|c|}{$\begin{array}{l}\begin{array}{l}\text { Reação com } \\
\text { enzimático }\end{array} \\
\text { en caldo }\end{array}$} \\
\hline Fungos & $\mathrm{t}$ & $\begin{array}{l}\mathrm{c} \\
\mathbf{1}\end{array}$ & $\begin{array}{c}\mathrm{c} \\
\mathbf{1 a}\end{array}$ & $\begin{array}{c}\text { e.e. } \\
\mathbf{1}\end{array}$ & $\begin{array}{c}\mathrm{ca} \\
\mathbf{1}\end{array}$ & $\begin{array}{l}\mathrm{c} \\
\mathbf{1}\end{array}$ & $\begin{array}{c}\mathrm{c} \\
\mathbf{1 a}\end{array}$ & $\begin{array}{c}\text { e.e } \\
1\end{array}$ & $\begin{array}{c}\mathrm{ca} \\
\mathbf{1}\end{array}$ \\
\hline P. miczynskii Gc5 & 48 & 5 & $95^{b}$ & 50 & $S$ & 100 & - & - & - \\
\hline Trichoderma sp Gc1 & 48 & 70 & 30 & 66 & $S$ & 100 & - & - & - \\
\hline A. sydowii Gc12 & 48 & 77 & 23 & 20 & $S$ & 100 & - & - & - \\
\hline A. sydowii Ce19 & 72 & 22 & 78 & 20 & $S$ & 100 & - & - & - \\
\hline Bionectria sp Ce5 & 72 & 12 & 88 & 35 & $S$ & 100 & - & - & - \\
\hline A. sydowii Ce15 & 72 & 1 & 99 & 22 & $S$ & 100 & - & - & - \\
\hline P. raistrickii $\mathrm{Ce} 16$ & 72 & 1 & 99 & 17 & $S$ & 100 & - & - & - \\
\hline P. sclerotiorum* & 72 & 54 & 46 & 90 & $S$ & - & - & - & - \\
\hline
\end{tabular}

${ }^{\mathrm{a} C}$ Condições de reação: $5 \mathrm{~g}$ de células totais de fungos; $50 \mathrm{mg}$ de $\alpha$-cloroacetofenona (1); $200 \mu \mathrm{L}$ de DMSO; 150 $\mathrm{rpm} ; 32^{\circ} \mathrm{C} ; 100 \mathrm{~mL}$ de tampão fosfato em $\mathrm{pH}=7$; ${ }^{\mathrm{b}}$ rendimento isolado $60 \%$; $(\%)=$ concentração determinada por CG; e.e. $(\%)=$ excesso enantiomérico; ca $=$ configuração absoluta $\mathrm{t}=$ tempo $(\mathrm{h})$. Penicilium sclerotiorum $*$ é um fungo terrestre (cultivado no meio sem ASW). Condições de análises no CG: $\mathrm{t}_{\mathrm{i}}=120^{\circ} \mathrm{C} ; \mathrm{r}=2^{\circ} \mathrm{C} / \mathrm{min} ; \mathrm{t}_{\mathrm{f}}=$ $165^{\circ} \mathrm{C} ; 8 \mathrm{~min} ; \mathrm{r}=2{ }^{\circ} \mathrm{C} / \mathrm{min}$

A composição de íons cloretos presentes no meio de cultivo foram semelhantes à água do mar no meio natural $\left(0,50 \mathrm{mols}^{-1}\right)$. Em outros experimentos cultivaram-se os fungos derivados marinhos na ausência da água do mar artificial, utilizando-se apenas água destilada.

Foi observado que os cultivos de fungos derivados marinhos em água do mar artificial apresentaram crescimentos de micélios semelhantes àqueles que foram cultivados apenas em água destilada. Contudo, as reações biocatalíticas apresentaram resultados bastante distintos em função do cultivo dos fungos serem realizados na presença de altas concentrações de íons cloreto ou em sua ausência. 
Assim, a redução da $\alpha$-cloroacetofenona (1) ocorreu tão somente quando se utilizou os micélios dos fungos derivados marinhos quando cultivadas em $A S W$. Esses estudos foram realizados para todos os microrganismos descritos na tabela 5. Interessantemente, foi que em todas as reações realizadas observou-se uma dependência das enzimas redutases no meio de crescimento semelhante àquele em que foram isolados os microrganismos de origem marinha, ou seja, a concentração de íons cloretos foi determinante nas reações de redução da $\alpha$ cloroacetofenona (1).

Certamente, existem muitas variáveis que influenciam o curso de uma reação enzimática e neste caso ficou evidente que a alta concentração de íons cloreto no meio de crescimento dos fungos foi fundamental para a que reação de redução ocorresse sob essas condições investigadas.

Não foi observada a redução da $\alpha$-cloroacetofenona (1) quando se utilizou o filtrado do meio de cultura, os quais contêm elevadas concentrações de íons cloreto.

Assim, foi observado que a redução da $\alpha$-cloroacetofenona (1) em solução tampão fosfato com as células totais dos fungos P. miczynskii Gc5, Trichoderma sp Gc1, A. sydowii Gc12, A. sydowii Ce19, Bionectria sp Ce5, A. sydowii Ce15, P. raistrickii Ce16 cultivados em $A S W$ apresentaram resultados distintos. Mas, todos os fungos foram capazes de reduzir a clorocetona 1 na cloroidrina 1a (Tabela 5). Na (Figura 7) têm-se os cromatogramas das reações analisadas por cromatografia a gás em coluna quiral com cada um dos fungos utilizados na triagem. 


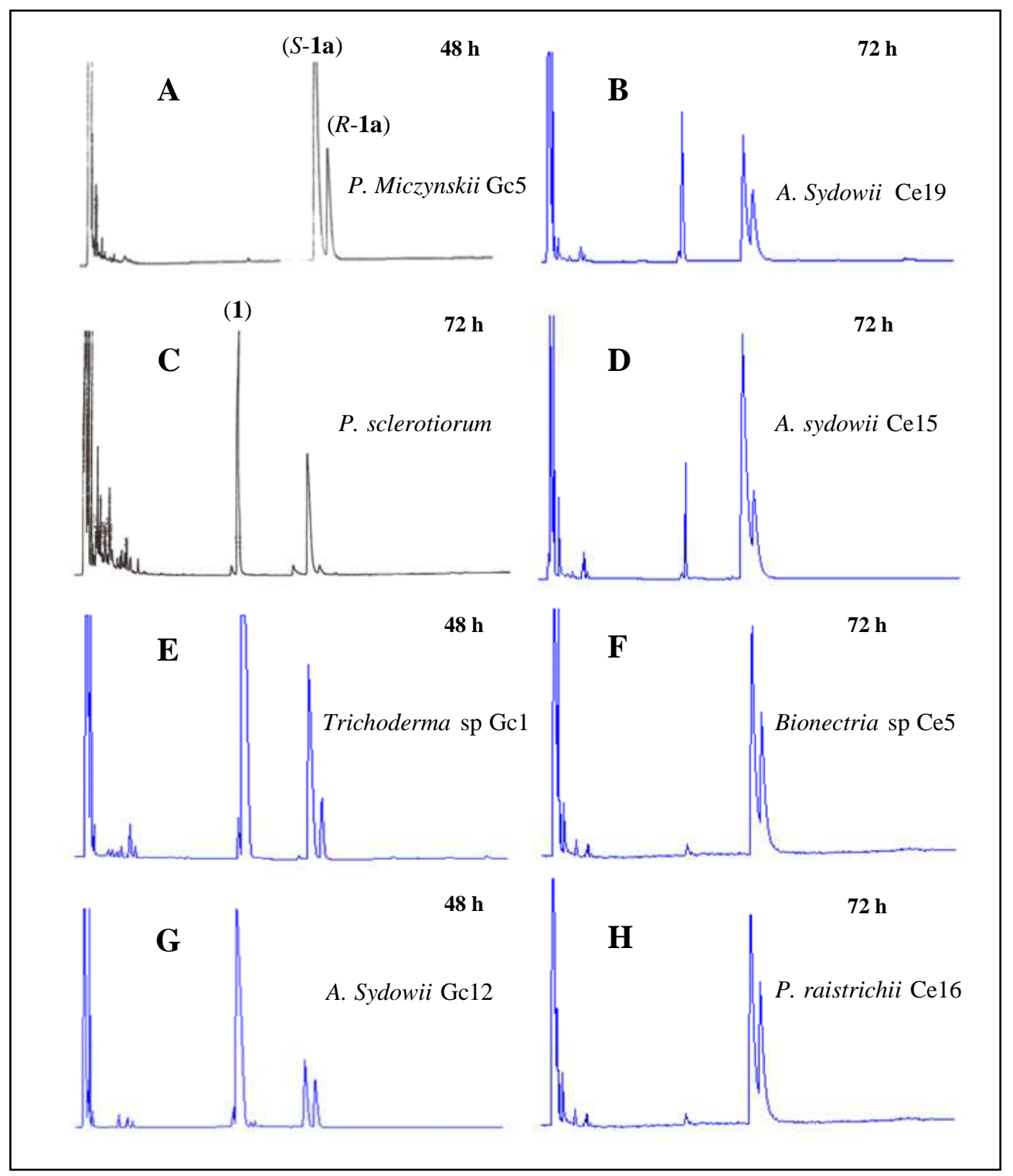

Figura 7. Cromatogramas obtidos por CG em coluna quiral de $\beta$-ciclodextrina para as reações com $100 \mathrm{~mL}$ de tampão fosfato em $\mathrm{pH}=7,0 ; 50 \mathrm{mg}$ de $\alpha$-cloroacetofenona (2); $200 \mu \mathrm{L} \mathrm{DMSO} ; 150 \mathrm{rpm} ; 32^{\circ} \mathrm{C} ; 5 \mathrm{~g}$ de células totais dos fungos. (A) P. miczynskii Gc5; (B) A. sydowii Ce19; (C) P. sclerotiorum* - fungo terrestre; (D) A. sydowii Ce15; (E) Trichoderma sp Gc1; (F) Bionectria sp Ce5; (G) A. sydowii Gc12; (H) P. raistrichii Ce16.

Condições de análises no CG: $\mathrm{t}_{\mathrm{i}}=120^{\circ} \mathrm{C} ; \mathrm{r}=2{ }^{\circ} \mathrm{C} / \mathrm{min} ; \mathrm{t}_{\mathrm{f}}=165^{\circ} \mathrm{C} ; 8 \mathrm{~min} ; \mathrm{r}=2{ }^{\circ} \mathrm{C} / \mathrm{min}$

Como pode ser observado na tabela 5 o melhor resultado foi alcançado quando se realizou a reação com as células úmidas do fungo Penicillium miczynskii Gc5, pois a reação ocorreu rapidamente $(48 \mathrm{~h})$ levando à redução da $\alpha$-cloroacetofenona $(\mathbf{1})$ na cloroidrina $\mathbf{1 a}$. $\mathrm{O}$ fungo reduziu a $\alpha$-cloroacetofenona (1) ao $(S)$-2-cloro-1-feniletanol (1a) com alta taxa de conversão (c $95 \%$ ), porém com modesta pureza enantiomérica, e.e. 50 \% (Tabela 5, Figuras 7 e 8). O rendimento isolado da cloridrina (S)-2-cloro-1-feniletanol (1a) após purificação por 
cromatografia em coluna foi de $60 \%$. Para obter o rendimento isolado da reação utilizaramse quatro frascos erlenmeyers de $250 \mathrm{~mL}$ onde se adicionou em cada frasco reacional $50 \mathrm{mg}$ da $\alpha$-cloroacetofenona (1) sob as mesmas condições reacionais utilizadas durante a triagem (Seção 3.2.3.).

Um levantamento na literatura constatou-se que os resultados obtidos para a redução da $\alpha$-cloroacetofenona (1) não é fácil obter purezas óticas elevadas, e.e. 44\% (CARVALHO et al., 1991), e.e. 85\% (BARBIERI et al., 2001), e.e. 56\% (NASCIMENTO et al., 2002;). Exceto, para o M. subtilissimus que forneceu $99 \%$ de conversão e $96 \%$ de excesso enantiomérico para a $(R)$-cloroidrina 1a (BARBIERI et al., 2001). Recentemente, o grupo da Profa. Dra. Maria da Graça Nascimento, da Universidade Federal de Santa Catarina (UFSC) utilizou a montmorilonita K 10 como suporte na imobilização do fermento de pão (Saccharomyces cerevisiae) em reações de redução enantiosseletiva da $\alpha$-cloroacetofenona (1). Neste trabalho a redução da $\alpha$-cloroacetofenona (1) forneceu o $(R)$-2-cloro-1-feniletanol (1a) com 79 \% de pureza ótica após 72 h de reação (ALBUQUERQUE, 2007).

A biorredução da $\alpha$-cloroacetofenona (1) também foi investigada com o Trichoderma sp Gc1 e Aspergillus sydowii Gc12. Esses fungos reduziram a $\alpha$ cloroacetofenona (1) na (S)-2-cloro-1-feniletanol (1a) com baixa conversão, onde o fungo Trichoderma sp Gc1 apresentou o melhor valor de excesso enantiomérico nesta triagem (Tabela 5). Enquanto os fungos Bionectria sp Ce5, Aspergillus sydowii Ce15, Penicillium raistrickii Ce16 e Aspergillus sydowii Ce19 catalisaram a redução da $\alpha$-cloroacetofenona (1) sob as mesmas condições, contudo forneceram melhores resultados quanto às conversões (78$99 \%$ ), mas também nestes casos observou-se uma modesta pureza enantiomérica do $(S)$-2cloro-1-feniletanol (1a), e.e. 17-35\% (Tabela 5).

Pôde-se constatar que através destes resultados que as enzimas redutases presentes em todos os fungos derivados marinhos avaliados apresentaram preferência anti-Prelog na 
redução da $\alpha$-cloroacetofenona (1) de acordo com o postulado proposto por Prelog (REZENDE, 2007). Na (Figura 8) encontra-se o cromatograma da reação com o fungo $P$. miczynskii Gc5.

As reações com o caldo enzimático dos fungos derivados marinhos não levaram a nenhum produto de biotransformação da $\alpha$-cloroacetofenona (1), onde foi obtido somente o material de partida (Tabela 5). Possivelmente no caldo enzimático (filtrado) não continha as enzimas e seus cofatores responsáveis pela redução da cetona $\mathbf{1}$.

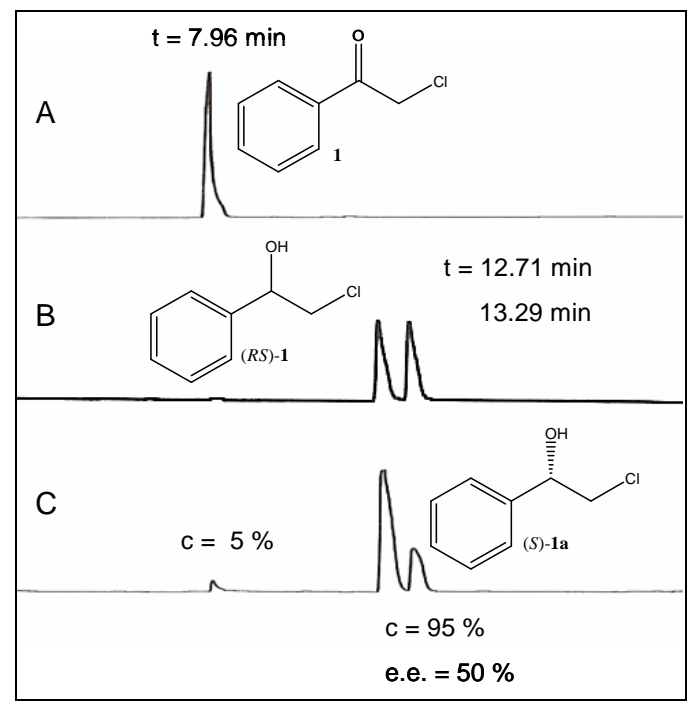

Figura 8. Cromatogramas obtidos por CG: (A) Padrão da $\alpha$-cloroacetofenona (1); (B) Padrão do (RS)-2-cloro-1feniletanol (1a); (C) Reação com o P. miczynskii Gc5 (5 g células, 48 h). Condições de análises no CG: $\mathrm{t}_{\mathrm{i}}=120$ ${ }^{\circ} \mathrm{C} ; \mathrm{r}=2{ }^{\circ} \mathrm{C} / \mathrm{min} ; \mathrm{t}_{\mathrm{f}}=165^{\circ} \mathrm{C} ; 8 \mathrm{~min} ; \mathrm{r}=2{ }^{\circ} \mathrm{C} / \mathrm{min}$

Nesta triagem com fungos de origem marinha, em todos os experimentos realizados, a pureza enantiomérica do $(S)$-2-cloro-1-feniletanol (1a) foi determinada por análises em CG utilizando-se coluna quiral de ciclodextrina (Figura 8). Após a purificação e caracterização da $\alpha$-cloroacetofenona (1) por RMN ${ }^{1} \mathrm{H}$, IV e CG-EM foi determinada a pureza ótica do produto formado como sendo o $(S)$-2-cloro-1-feniletanol (1a). A configuração absoluta de $(S)$-1a foi atribuída por comparação do sinal da rotação ótica específica descrita na literatura. Rotação ótica experimental: $[\alpha]_{\mathrm{D}}^{25}=+17,08^{\circ}\left(c 3,2 \mathrm{CHCl}_{3}\right)$ e rotação ótica da literatura: $[\alpha]_{\mathrm{D}}^{25}=-$ 
39,3 (c 1,7 Ciclohexano) (CARVALHO et al., 1991). Todos os fungos testados na triagem mostraram-se potenciais para reduzir seletivamente a clorocetona $\mathbf{1}$ à cloroidrina $\mathbf{1 a}$.

De posse dos melhores resultados obtidos na triagem para a redução da cetona $\mathbf{1}$ selecionou-se o fungo Penicillium miczynskii Gc5 para realizar novos estudos em busca de se obter melhores resultados em relação à pureza ótica da cloridrina 1a, pois em uma reação biocatalisada é sempre desejável que um enantiômero seja obtido com excesso enantiomérico superior a $99 \%$.

\subsubsection{Estudo do efeito do $\mathrm{pH}$ na redução da $\alpha$-cloroacetofenona (1) com células totais do fungo Penicillium miczynskii Gc5 na ausência de glicose}

O objetivo deste estudo foi realizar novas condições reacionais na redução da cetona $\mathbf{1}$ com o intuito de melhorar a pureza enantiomérica da haloidrina 1a. Assim, realizaram-se os experimentos avaliando-se a influência da variação do pH na redução da $\alpha$-cloroacetofenona (1). E na ausência de glicose, é conhecido que a glicose favorece a reciclagem de cofatores podendo melhorar o desempenho das reações enzimáticas catalisadas por microrganismos. O uso de glicose é comumente empregado nas reduções com células totais e em geral as reações são favorecidas quando são adicionadas glicose ao meio reacional (GROGER et al., 2006).

Nestes estudos utilizaram-se as células totais do fungo P. miczynskii Gc5 cultivado sob as mesmas condições em que foram realizadas as reações descritas anteriormente. Contudo, a suspensão das células totais foram realizadas em soluções tamponadas com diferentes valores de $\mathrm{pH}(4,5,6,7$ e 8). Os resultados obtidos com a variação de $\mathrm{pH}$ na ausência de glicose na redução da $\alpha$-cloroacetofenona (1) encontram-se sumarizadas na (Tabela 6 e Figura 9).

Em todos os casos o uso das células do fungo P. miczynskii Gc5 na ausência de glicose levou à redução da $\alpha$-cloroacetofenona (1) à cloridrina 1a. Pode-se observar também que a 
variação de $\mathrm{pH}$ influenciou na conversão da $\alpha$-cloroacetofenona (1), bem como na pureza ótica da cloroidrina 1a. Em valores de $\mathrm{pH}$ ácidos $(\mathrm{pH} 4,5$ e 6) as biorreduções não foram favorecidas, pois as conversões e purezas óticas foram muito modestas. Em pH básico $(\mathrm{pH}=$ 8,0) a conversão foi também relativamente baixa, bem como a pureza ótica da cloridrina $\mathbf{1 a}$. O melhor resultado alcançado foi obtido em condições neutras $(\mathrm{pH}=7,0)$ como já havia sido obtido nos estudos da triagem, pois se obteve a cloroidrina 1a com uma alta conversão (c 95 $\%$ ) e pureza ótica (e.e. $50 \%$, Tabela 5 e 6). Assim, verificou-se que nas condições utilizadas de pH ácidos ou básico e na ausência de glicose não promoveu nenhum acréscimo desejável na pureza ótica do produto, que seria acima de $98 \%$. Portanto, a partir destes estudos o melhor resultado alcançado foi quando se realizou as reação em $\mathrm{pH}=7$.

$\mathrm{Na}$ (Figura 9) tem-se graficamente os dados obtidos da redução da cetona $\mathbf{1}$ com o fungo P. miczynskii Gc5 sob diferentes valores de pH e na ausência de glicose. 
Tabela 6. Redução da $\alpha$-cloroacetofenona (1) com o fungo Penicillium miczynskii Gc5 na ausência de glicose e em diferentes valores de $\mathrm{pH}^{\mathrm{a}}{ }^{\mathrm{a}}$

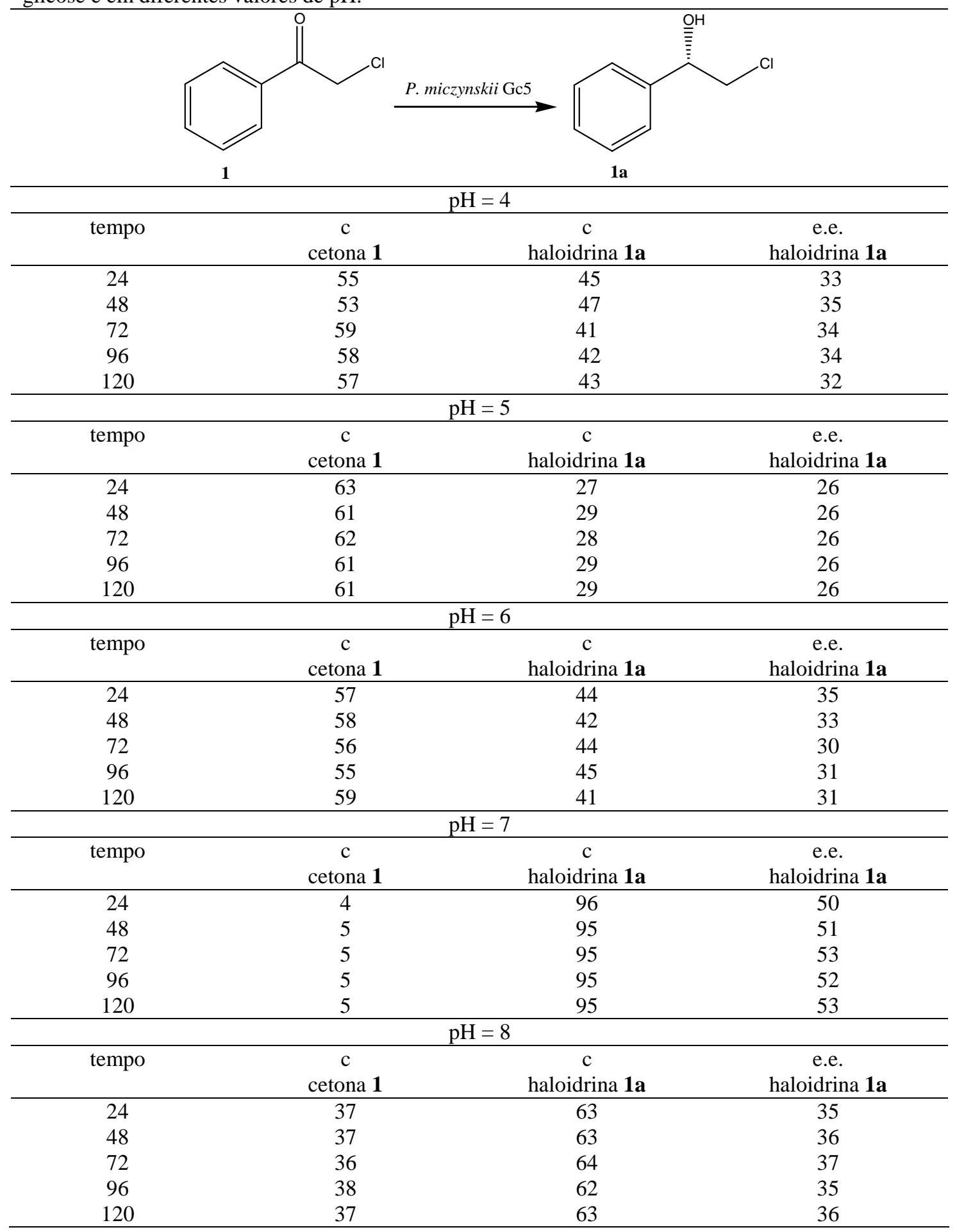

${ }^{\mathrm{a} C}$ Condições de reação: $5 \mathrm{~g}$ de massa celular úmida de fungo; $50 \mathrm{mg}$ de $\alpha$-cloroacetofenona (1); $200 \mu \mathrm{L}$ de DMSO; $150 \mathrm{rpm} ; 32{ }^{\circ} \mathrm{C} ; 50 \mathrm{~mL}$ de tampão (pH 4, 5, 6, 7 e 8); c $(\%)=$ concentração determinada por CG; e.e. $(\%)=$ excesso enantiomérico; tempo $(\mathrm{h})$ 


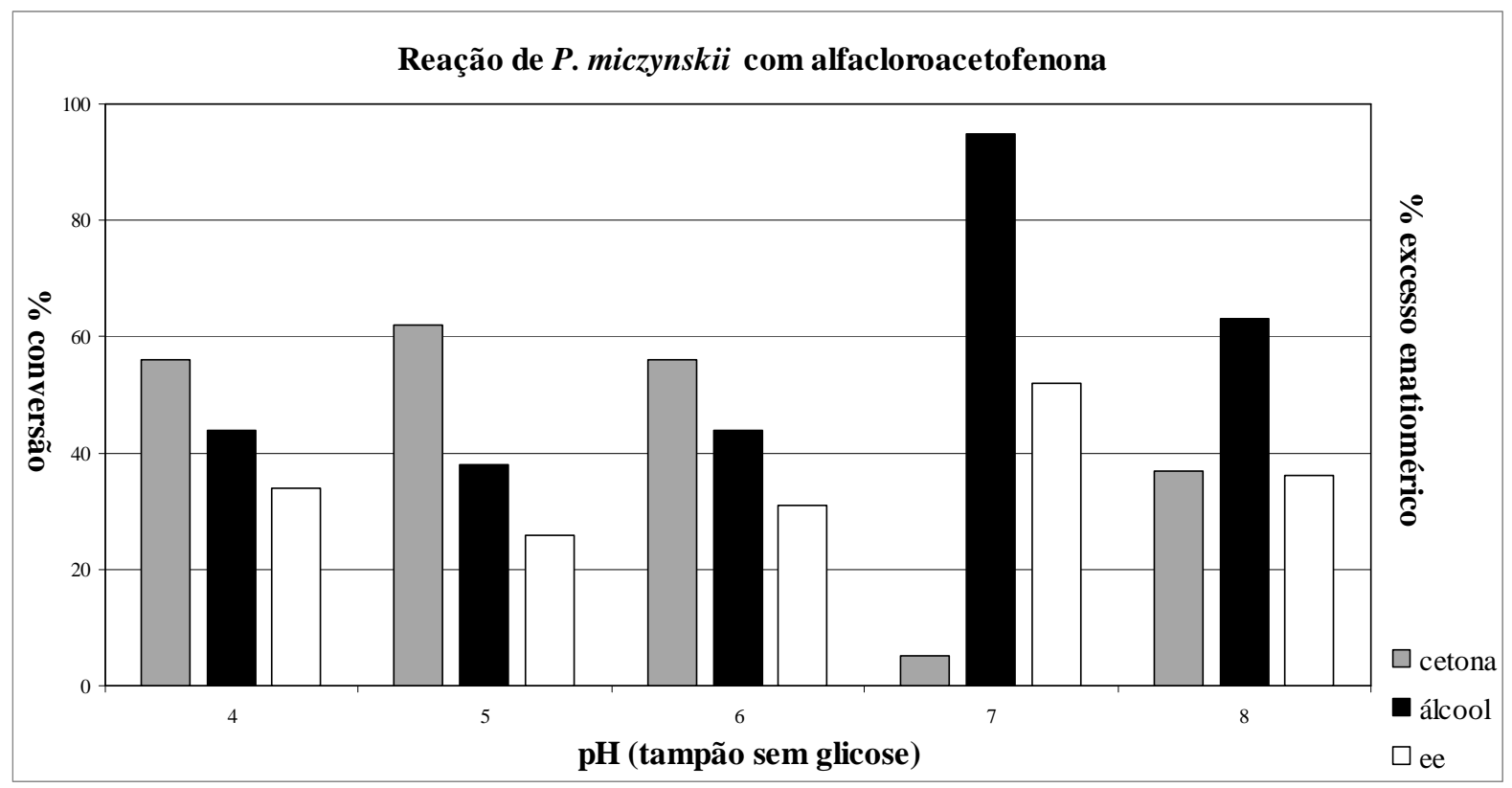

Figura 9. Gráfico das reações da $\alpha$-cloroacetofenona (1) com o fungo Penicillium miczynskii Gc5 com diferentes valores de $\mathrm{pH}$ e na ausência de glicose

\subsubsection{Estudo do efeito do pH na redução da $\alpha$-cloroacetofenona (1) com células totais do fungo Penicillium miczynskii Gc5 na presença de glicose}

Nestes estudos utilizou-se as células totais do fungo P. miczynskii Gc5 cultivado nas mesmas condições em que foram realizadas as reações descritas anteriormente. Realizou-se a suspensão das células totais em soluções tamponadas com diferentes faixas de $\mathrm{pH}(4,5,6,7$ e 8) e adicionou-se em cada frasco $250 \mathrm{mg}$ de glicose. Os resultados obtidos com a variação de pH e adição de glicose na redução da $\alpha$-cloroacetofenona (1) encontram-se sumarizadas na (Tabela 7 e na Figura 10).

Em todos os casos o uso das células do fungo P. miczynskii Gc5 na presença de glicose levou a um decréscimo na redução da $\alpha$-cloroacetofenona (1) à cloridrina 1a em comparação com a reação de redução na ausência de glicose. Pôde-se observar claramente que além do pH, a adição de glicose influenciou desfavoravelmente tanto a conversão quanto a pureza ótica da cloroidrina 1a. Nos valores de $\mathrm{pH}$ extremos investigados ( $\mathrm{pH} 4$ e 8) as 
reduções praticamente foram desprezíveis. Modestas purezas óticas ocorreram nas demais condições estudadas e praticamente sem sucesso, ou seja, longe do valor desejável, pois não ocorreu um aumento na pureza ótica. Ainda destaca-se que a reação em $\mathrm{pH}=7$ foi desfavorecida pela adição glicose ao meio reacional, pois houve um decréscimo acentuado tanto da conversão (c $25 \%$ ) quanto do excesso enantiomérico (e.e. $25 \%$ ) em comparação aos estudos realizados com a ausência de glicose (Tabelas 6 e 7). Portanto, concluiu-se que a presença de glicose causou uma inibição das enzimas responsáveis pela redução da clorocetona 1 à cloroidrina 1a. Estes resultados podem ser melhores visualizados na (Figura 9). 
Tabela 7. Redução da $\alpha$-cloroacetofenona (1) com o fungo Penicillium miczynskii Gc5 na presença de glicose e em diferentes valores de $\mathrm{pH}^{\mathrm{a}}$

\begin{tabular}{|c|c|c|c|}
\hline & & $1 \mathbf{a}$ & \\
\hline \multicolumn{4}{|c|}{$\mathrm{pH}=4$} \\
\hline tempo & $\begin{array}{c}\mathrm{c} \\
\text { cetona } \mathbf{1}\end{array}$ & $\begin{array}{c}\mathrm{c} \\
\text { haloidrina 1a }\end{array}$ & $\begin{array}{c}\text { e.e. } \\
\text { haloidrina 1a }\end{array}$ \\
\hline 24 & 100 & 0 & - \\
\hline 48 & 99 & 1 & - \\
\hline 72 & 99 & 1 & - \\
\hline 96 & 99 & 1 & - \\
\hline 120 & 99 & 1 & - \\
\hline \multicolumn{4}{|c|}{$\mathrm{pH}=5$} \\
\hline tempo & $\begin{array}{c}\mathrm{c} \\
\text { cetona } \mathbf{1}\end{array}$ & $\begin{array}{c}\mathrm{c} \\
\text { haloidrina 1a }\end{array}$ & $\begin{array}{c}\text { e.e. } \\
\text { haloidrina 1a }\end{array}$ \\
\hline 24 & 89 & 11 & 39 \\
\hline 48 & 84 & 16 & 39 \\
\hline 72 & 83 & 17 & 38 \\
\hline 96 & 82 & 18 & 38 \\
\hline 120 & 82 & 18 & 38 \\
\hline \multicolumn{4}{|c|}{$\mathrm{pH}=6$} \\
\hline tempo & $\begin{array}{c}\mathrm{c} \\
\text { cetona } \mathbf{1}\end{array}$ & $\begin{array}{c}c \\
\text { haloidrina 1a }\end{array}$ & $\begin{array}{c}\text { e.e. } \\
\text { haloidrina 1a }\end{array}$ \\
\hline 24 & 85 & 15 & 57 \\
\hline 48 & 85 & 15 & 56 \\
\hline 72 & 84 & 16 & 55 \\
\hline 96 & 84 & 16 & 55 \\
\hline 120 & 84 & 16 & 55 \\
\hline \multicolumn{4}{|c|}{$\mathrm{pH}=7$} \\
\hline tempo & $\begin{array}{c}\mathrm{c} \\
\text { cetona } \mathbf{1}\end{array}$ & $\begin{array}{c}c \mathrm{c} \\
\text { haloidrina 1a }\end{array}$ & $\begin{array}{c}\text { e.e. } \\
\text { haloidrina 1a }\end{array}$ \\
\hline 24 & 78 & 22 & 42 \\
\hline 48 & 75 & 25 & 39 \\
\hline 72 & 75 & 25 & 40 \\
\hline 96 & 73 & 27 & 35 \\
\hline 120 & 73 & 27 & 38 \\
\hline \multicolumn{4}{|c|}{$\mathrm{pH}=8$} \\
\hline tempo & $\begin{array}{c}\mathrm{c} \\
\text { cetona } \mathbf{1}\end{array}$ & $\begin{array}{c}c \mathrm{c} \\
\text { haloidrina 1a }\end{array}$ & $\begin{array}{c}\text { e.e. } \\
\text { haloidrina 1a }\end{array}$ \\
\hline 24 & 95 & 5 & 47 \\
\hline 48 & 95 & 5 & 49 \\
\hline 72 & 95 & 5 & 49 \\
\hline 96 & 95 & 5 & 48 \\
\hline 120 & 93 & 7 & 48 \\
\hline
\end{tabular}

a condições de reação: $5 \mathrm{~g}$ de massa celular úmida de fungo; $50 \mathrm{mg}$ de $\alpha$-cloroacetofenona (1); $200 \mu \mathrm{L}$ de DMSO; $250 \mathrm{mg}$ de glicose; $150 \mathrm{rpm} ; 32^{\circ} \mathrm{C} ; 50 \mathrm{~mL}$ de tampão $(\mathrm{pH} 4,5,6,7$ e 8); c $(\%)=$ concentração determinada por $\mathrm{CG}$; e.e. $(\%)=$ excesso enantiomérico; tempo $(\mathrm{h})$ 


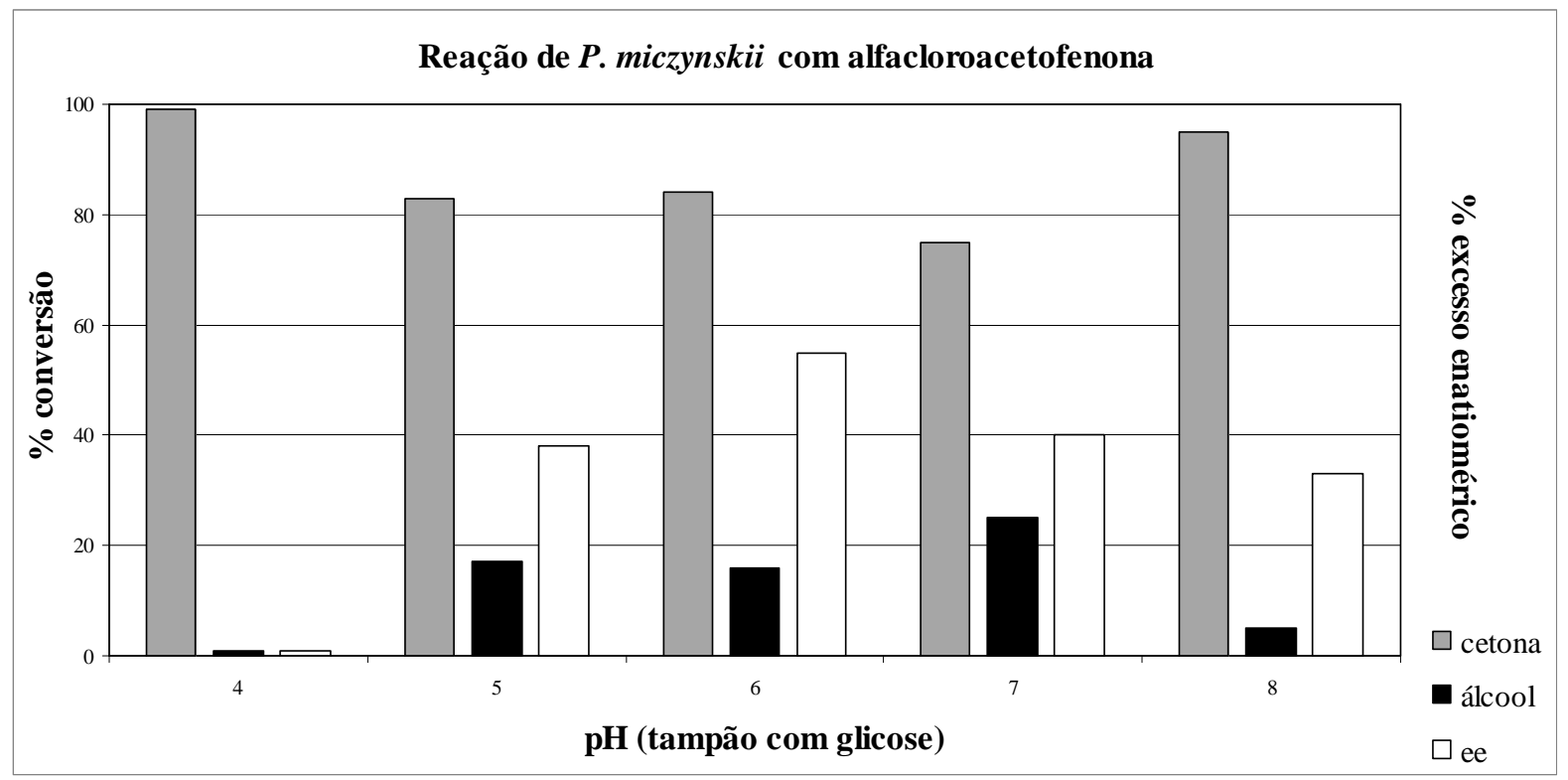

Figura 9. Gráfico das reações da $\alpha$-cloroacetofenona (1) com o fungo Penicillium miczynskii Gc5 com diferentes valores de $\mathrm{pH}$ e na presença de glicose

\subsubsection{Redução da $\alpha$-bromocetofenona (2) com fungo de origem marinha Aspergillus sydowii Ce19}

De acordo com a triagem realizada com a $\alpha$-cloroacetofenona (1) procedeu-se os experimentos com a $\alpha$-bromoacetofenona (2) utilizando-se os micélios e o caldo do fungo de origem marinha Aspergillus sydowii Ce19. Os resultados obtidos estão sumarizados na (Tabela 8).

As reações com as células totais úmidas dos fungos mostraram uma boa redução da $\alpha$ bromoacetofenona (2) no correspondente 2-bromo-1-feniletanol (2a), pois ocorreu em um tempo curto, ou seja, a partir de $2 \mathrm{~h}$ foi observada a formação da bromoidrina 2a. Entretanto, quando a reação foi prolongada para maiores tempos reacionais, verificou-se um decréscimo na pureza ótica da bromoidrina $\mathbf{2 a}$ (Tabela $\mathbf{8}$ e Figura 10). 
Tabela 8. Redução de $\alpha$-bromo-cetofenona (3) com o fungo de origem marinha Aspergillus sydowii Ce19. ${ }^{\mathrm{a}}$<smiles>O=C(CCl)c1ccccc1</smiles>

\begin{tabular}{|c|c|c|c|c|c|c|c|c|c|}
\hline \# & \multicolumn{4}{|c|}{ Reação com as células ${ }^{b}$} & \multicolumn{5}{|c|}{ Reação com o caldo $^{c}$} \\
\hline $\mathrm{t}$ & $\begin{array}{l}\mathrm{c} \\
2\end{array}$ & $\begin{array}{c}c \\
\mathbf{2 a}\end{array}$ & $\begin{array}{c}\text { e.e. } \\
\mathbf{2 a}\end{array}$ & ca & $\begin{array}{l}\mathrm{c} \\
2\end{array}$ & $\begin{array}{c}c \\
2 \mathbf{a}\end{array}$ & $\begin{array}{c}\text { e.e. } \\
\mathbf{2 a}\end{array}$ & $\mathrm{ca}$ & $\begin{array}{l}\mathrm{c} \\
1\end{array}$ \\
\hline 2 & - & 100 & 55 & $S$ & - & - & - & - & 100 \\
\hline 4 & - & 100 & 53 & $S$ & - & - & - & - & 100 \\
\hline 6 & - & 100 & 55 & $S$ & - & - & - & - & 100 \\
\hline 10 & - & 100 & 54 & $S$ & - & - & - & - & 100 \\
\hline 24 & - & 100 & 32 & $S$ & - & - & - & - & 100 \\
\hline 72 & - & 100 & 27 & $S$ & - & - & - & - & 100 \\
\hline 120 & - & 100 & 16 & $S$ & - & - & - & - & 100 \\
\hline
\end{tabular}

${ }^{\mathrm{a} C}$ Condições de reação: $5 \mathrm{~g}$ de massa celular úmida do fungo; $100 \mathrm{mg}$ de $\alpha$-bromo-acetofenona (2); $200 \mu \mathrm{L}$ de DMSO; $150 \mathrm{rpm} ; 32{ }^{\circ} \mathrm{C}$; meio de cultura malte $3 \%$; ${ }^{\mathrm{b}} 50 \mathrm{~mL}$ de tampão fosfato $(\mathrm{pH}=7) ;{ }^{\mathrm{c}} 50 \mathrm{~mL}$ de água do mar artificial (ASW); c $(\%)=$ concentração determinada por $\mathrm{CG}$; e.e. $(\%)$ = excesso enantiomérico; ca $=$ configuração absoluta; $\mathrm{t}$ = tempo (h); Detectado por CG-EM = 2-hidróxi-1-feniletanona (2c)

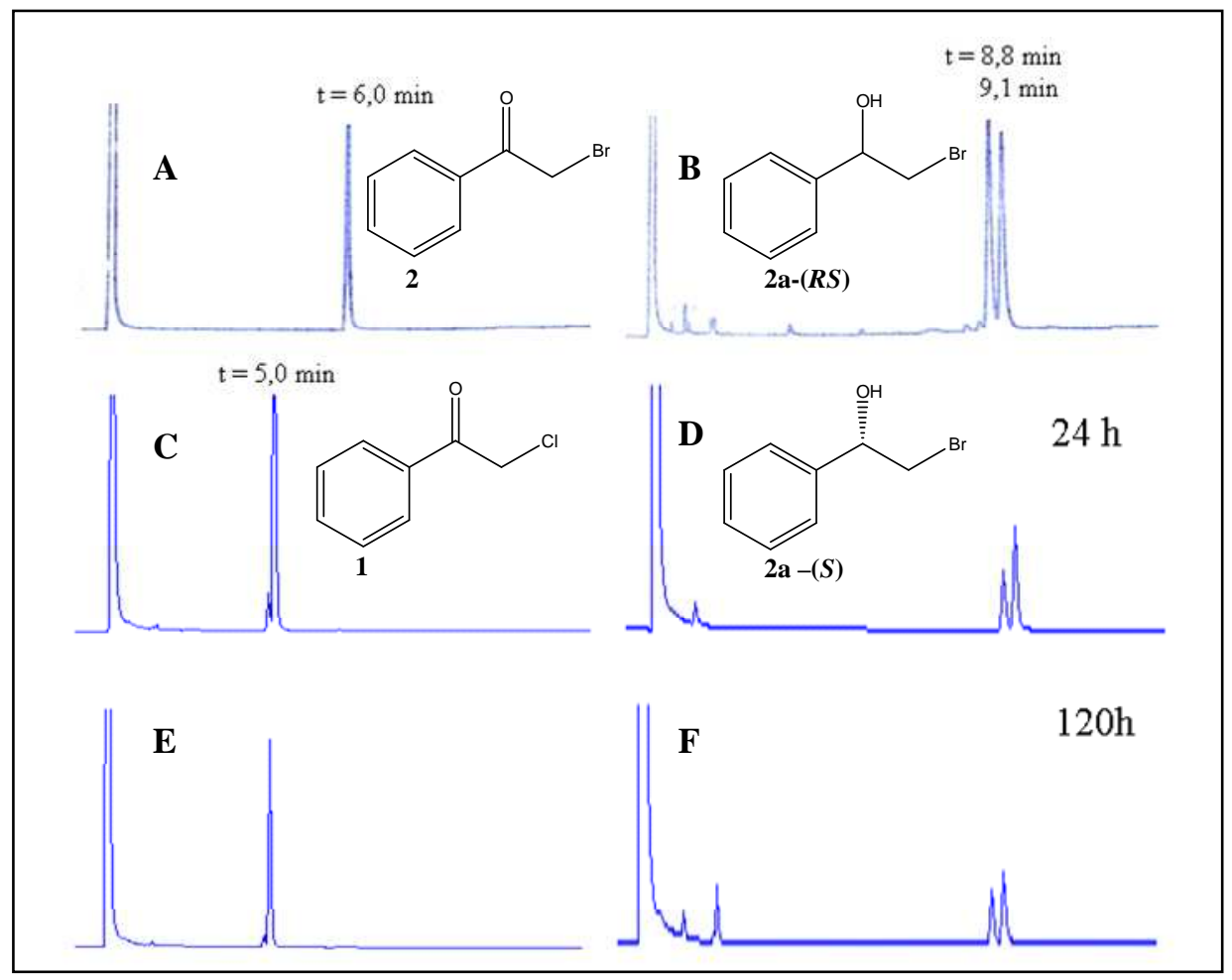

Figura 10. Cromatogramas obtidos em coluna quiral de $\beta$-ciclodextrina: (A) padrão $\alpha$-bromoacetofenona (2); (B) Padrão da (RS)-2-bromo-1-feniletanol (2a); (C) Reação com o caldo enzimático A. sydowii Ce19 com 24 h; (D) Reação com células totais do fungo A. sydowii Ce19 com 24 h; (E) Reação com o caldo enzimático do fungo A. sydowii Ce19 com 120 h; (F) Reação com células totais do fungo A. sydowii Ce19 com 120 h. As reações foram realizadas com $100 \mathrm{~mL}$ de caldo enzimático ou com $5 \mathrm{~g}$ células de totais; $100 \mathrm{mg}$ de $\alpha$-bromoacetofenona (2); $200 \mu \mathrm{L}$ DMSO; $150 \mathrm{rpm} ; 32^{\circ} \mathrm{C} ; 100 \mathrm{~mL}$ tampão fosfato $\mathrm{pH}=7,0$. Condições de análises no CG: $\mathrm{t}_{\mathrm{i}}=150$ ${ }^{\circ} \mathrm{C} ; 2 \mathrm{~min} ; \mathrm{t}_{\mathrm{f}}=165^{\circ} \mathrm{C} ; 8 \mathrm{~min} ; \mathrm{r}=2{ }^{\circ} \mathrm{C} / \mathrm{min}$ 
Quando se realizou a extração e posteriormente a purificação, observou-se a perda da bromoidrina 2a. Como comentado anteriormente durante a síntese do padrão racêmico, a bromoidrina 2a foi transformada espontaneamente no epóxido $\mathbf{2 b}$. Possivelmente durante as etapas de extração e purificação a bromoidrina 2a poderia estar sendo convertida no epóxido 2b. Portanto, não foi possível determinar o rendimento da reação de redução da bromocetona 2. Estes experimentos foram realizados por mais de três vezes e infelizmente não conseguiu obter a bromoidrina pura e a cada purificação ocorria uma perda significativa do composto. Assim, tornou-se inviável insistir nestes experimentos, até porque a pureza enantiomérica do bromoidrina $\mathbf{2 a}$ foi muito baixa.

Mas, para determinar a configuração absoluta da bromoidrina 2a realizou-se uma resolução enzimática do álcool racêmico $(R S)$-2-bromo-1-feniletanol (2a) com a enzima lipase de Candida antarctica. Embora a enzima tenha esterificodo preferencialmente um álcool da mistura racêmica, o rendimento da reação foi muito baixo (20\%), mas o produto formado foi o suficiente para a análise da rotação ótica. Assim, a configuração absoluta da bromoidrina 2a foi estabelecida por comparação da rotação ótica e seu valor foi comparado com a literatura (CARVALHO, 1991).

Quando as reações de redução da $\alpha$-bromoacetofenona (2) foram realizadas com o caldo enzimático (filtrado) sob as mesmas condições utilizadas com os micélios/células totais levaram a formação exclusiva da $\alpha$-cloroacetofenona (1) discussão (seção 3.2.7.). A formação da $\alpha$-cloroacetofenona (1) foi comprovada realizando-se um branco com a água de mar artificial, onde se detectou a formação da $\alpha$-cloroacetofenona (1). Assim, obteve-se a partir da $\alpha$-bromoacetofenona (2) a $\alpha$-cloroacetofenona (1) com rendimento isolado de $95 \%$ e conversão de $100 \%$. Portanto, concluiu-se que a troca de bromo por cloro ocorreu espontaneamente no meio reacional em função do caldo enzimático apresentar uma alta concentração de íons cloreto. 
Quando se realizou a reação com a $\alpha$-bromoacetofenona (2), após extração final da reação com acetato de etila e análises por cromatografia gasosa e espectrometria de massas detectou-se a formação de vários produtos no meio reacional (Figura 11 e 12). A maioria dos compostos foi obtida por reações enzimáticas; exceto $\alpha$-cloroacetofenona (1) que foi obtida espontaneamente pela substituição do bromo por cloro no próprio meio reacional, como mencionado anteriormente. Todos os sinais identificados nos cromatogramas provenientes da reação da $\alpha$-bromoacetofenona (2) foram confirmados por injeção dos respectivos padrões, exceto para a $\alpha$-hidróxi-acetofenona (2c) que foi identificada somente pelos dados dos espectros de massa. Na (Figura 11) tem as análises por CG-EM que confirmaram os resultados obtidos.

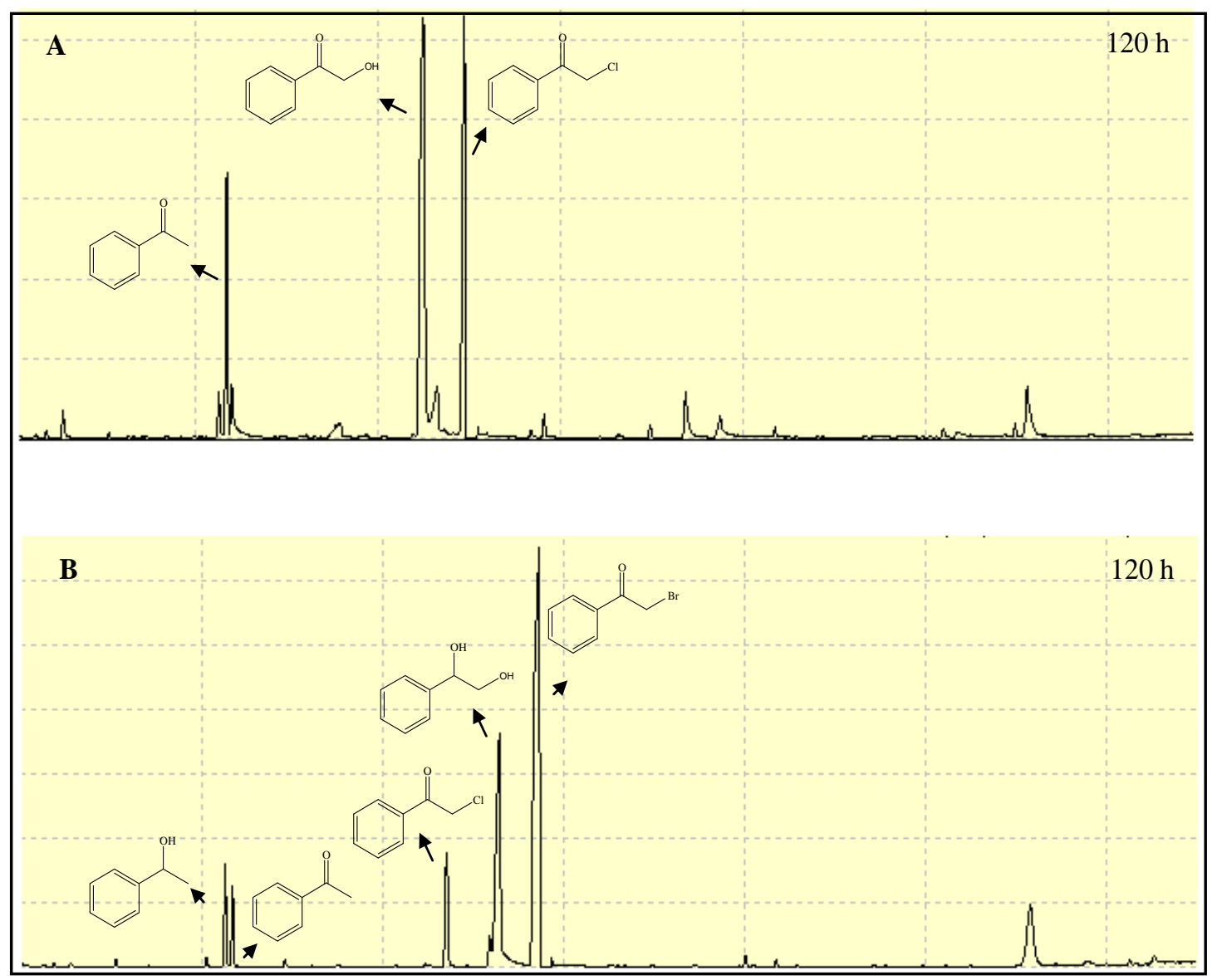

Figura 11. Cromatogramas obtidos em CG-EM. (A) Reação com caldo enzimático do fungo A. sydowii Ce19 com $\alpha$-bromoacetofenona (2); (B) Reação das células totais do fungo A. sydowii Ce19 com $\alpha$-bromoacetofenona (2). Condições de reação: $5 \mathrm{~g}$ de células totais do fungo; $50 \mathrm{mg}$ de $\alpha$-bromoacetofenona (2); $100 \mu \mathrm{L}$ de DMSO; $150 \mathrm{rpm} ; 32^{\circ} \mathrm{C}$; extrato de malte $3 \%, 50 \mathrm{~mL}$ de tampão fosfato $\mathrm{pH}=7$ 
Desta forma pode-se observar que um dos motivos pelos os quais a purificação da haloidrina 2a não foi possível, devido a obtenção de vários compostos oriundos do material de partida. Assim, concluiu-se que a $\alpha$-bromoacetofenona (2) não foi um bom substrato para realizar triagem com células totais de microrganismos, devido a labilidade do composto em sofrer várias reações enzimáticas e não enzimáticas.

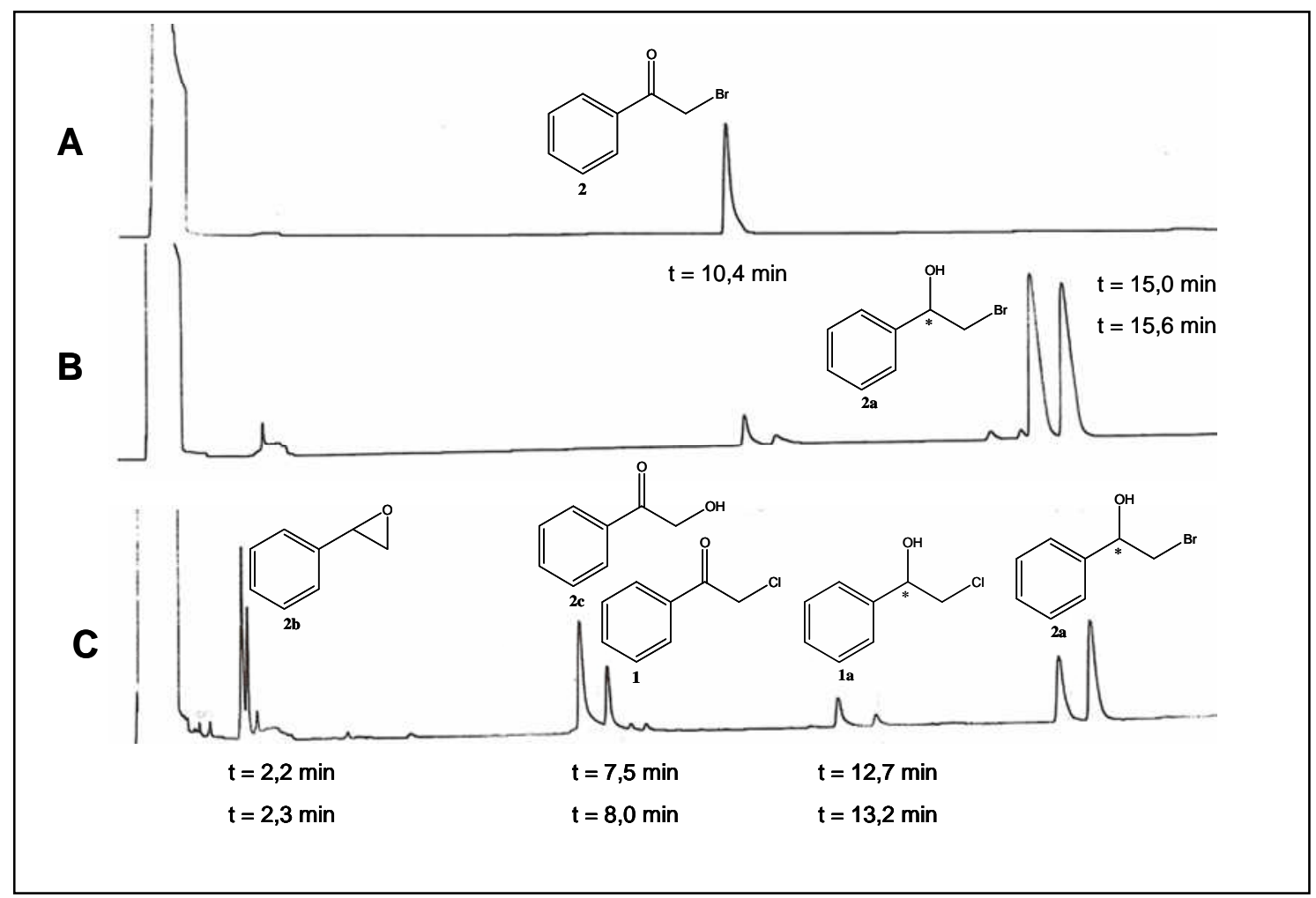

Figura 12. Cromatogramas obtidos em coluna quiral de $\beta$-ciclodextrina. (A) Cromatograma da $\alpha$ bromoacetofenona (2); (B) Cromatograma da bromoidrina racêmica, $(R S)$-2a; (C) Reação da $\alpha$ bromoacetofenona (2) com o fungo A. sydowii Ce19. Condições de reação: $5 \mathrm{~g}$ de massa celular úmida de fungo; $50 \mathrm{mg}$ de $\alpha$-bromoacetofenona (2); $100 \mu \mathrm{L}$ de DMSO; $150 \mathrm{rpm} ; 32^{\circ} \mathrm{C}$; extrato de malte $3 \%, 50 \mathrm{~mL}$ de tampão

fosfato $\mathrm{pH}=7$. Condições de análises no $\mathrm{CG}: \mathrm{t}_{\mathrm{i}}=120^{\circ} \mathrm{C} ; 2 \mathrm{~min} ; \mathrm{t}_{\mathrm{f}}=165^{\circ} \mathrm{C} ; 8 \mathrm{~min} ; \mathrm{r}=2{ }^{\circ} \mathrm{C} / \mathrm{min}$

Todos os compostos detectados por CG e CG-EM foram identificados por padrões autênticos com exceção do $\alpha$-hidroxiacetofenona (2c). No CG foram identificados epóxido estireno (2b), $\alpha$-hidroxiacetofenona (2c), $\alpha$-cloroacetofenona (1), cloroidrina 1a, bromoidrina 2a. As analises por CG- EM (caldo enzimático) foram identificados acetofenona, $\alpha$ hidroxiacetofenona (2c), $\alpha$-cloroacetofenona (1). Analises por CG-EM (células totais) 
detectou-se $\alpha$-bromoacetofenona (2), 1-feniletano-1,2-diol, $\quad \alpha$-cloroacetofenona acetofenona e fenil etanol.

\subsubsection{Reação da $\alpha$-bromoacetofenona (2) com caldo enzimático do fungo Aspergillus sydowii Ce19 e reação da $\alpha$-bromoacetofenona (2) somente com água do mar artificial (branco)}

A reação com o caldo enzimático do fungo A. sydowii Ce19 forneceu um sinal no cromatograma com o tempo de retenção em 5,0 minutos (Figura 13). Este sinal foi reprodutivo mesmo quando a reação foi realizada em triplicata. Este sinal foi distinto do tempo de retenção do padrão da bromoidrina 2a que foi de 8,8 e 9,1 min em coluna quiral de $\beta$-ciclodextrina (Figura 10). Em paralelo, realizou-se outro experimento utilizando somente água do mar artificial e a bromocetona 2 na ausência do caldo enzimático do fungo A. sydowii Ce19. A análise por cromatografia em camada delgada e cromatografia gasosa destes experimentos (branco) levou ao mesmo produto obtido com a reação com o caldo enzimático. Em seguida realizou-se uma análise por cromatografia gasosa acoplada por espectrometria de massas e constatou-se que o produto obtido das reações tanto com o caldo enzimático do fungo A. sydowii Ce19 quanto com a água do mar artificial forneceram os mesmos compostos (Esquema 13, Figuras 11 e 13).

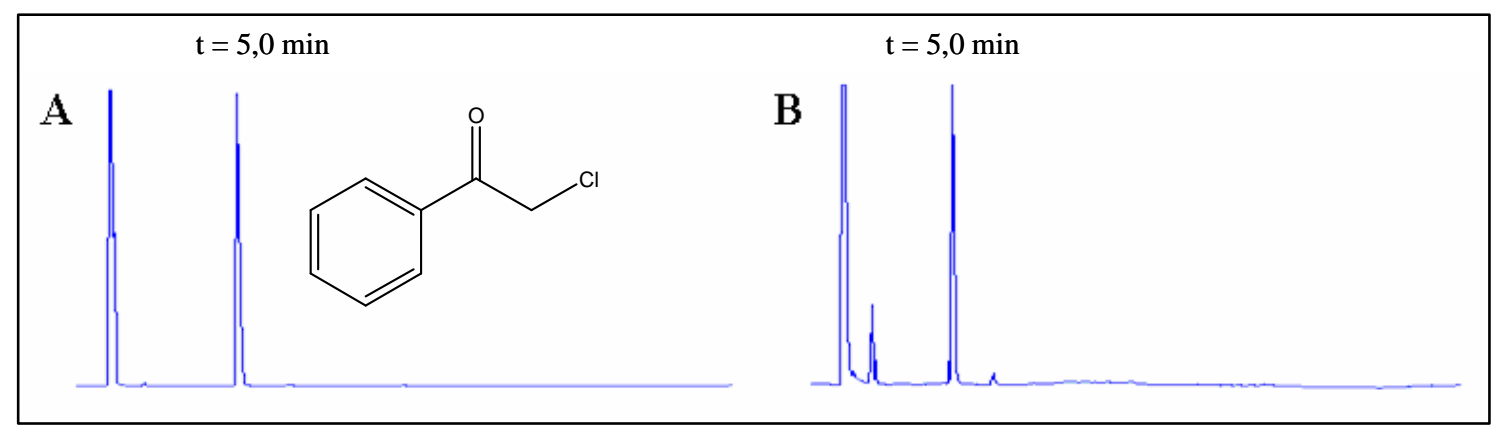

Figura 13. Cromatogramas obtido por CG: (A) padrão $\alpha$-cloroacetofenona (1); (B) reação da $\alpha$ bromoacetofenona (2) com caldo do fungo A. sydovii Ce19; Condições de análises no CG: $\mathrm{t}_{\mathrm{i}}=150{ }^{\circ} \mathrm{C} ; 2$ min; $\mathrm{t}_{\mathrm{f}}=$ $165^{\circ} \mathrm{C} ; 8 \mathrm{~min} ; \mathrm{r}=2{ }^{\circ} \mathrm{C} / \mathrm{min}$ 
Em ambos os casos, o caldo e a água do mar artificial, contêm uma elevada concentração de íons cloreto. Assim, quando se utilizou a $\alpha$-bromoacetofenona (2) ocorreu uma substituição do bromo por cloro, formando espontaneamente a $\alpha$-cloroacetofenona (1). Neste caso a reação com o caldo enzimático não promoveu a redução da $\alpha$-cloroacetofenona (1). Foi observado também nestas reações, embora em menor proporção, a formação do 2hidróxi-1-feniletanona (2c) como mostrado no (Esquema 13).

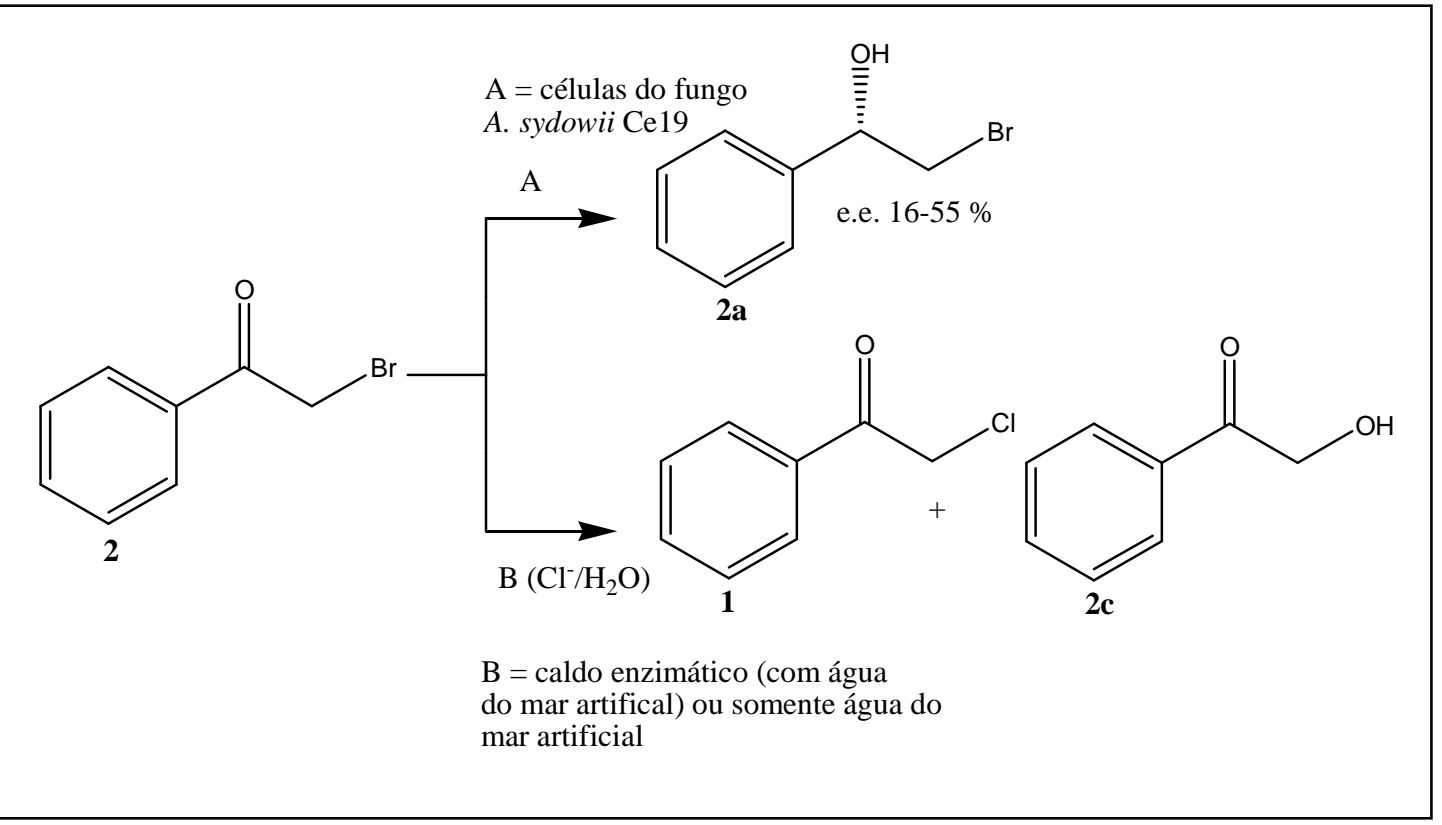

Esquema 13. (A) Redução da $\alpha$-bromoacetofenona (2) com o fungo A. sydowii Ce19; (B) Reação da $\alpha$ bromoacetofenona (2) com o caldo enzimático do fungo A. sydowii Ce19 e com a água do mar artificial $(A S W)$

A biotransformação da $\alpha$-bromo-acetofenona (2) com as células do fungo A. sydowii Ce19 apresentou um comportamento distinto em relação a $\alpha$-cloroacetofenona (1) sob as mesmas condições reacionais. Portanto, o tipo de halogênio ligado na posição $\alpha$-carbonila influenciou diretamente o caminho reacional enzimático ou não enzimático. Os possíveis compostos formados podem ser observados no (Esquema 13 e nas Figuras 11 e 12). 


\subsubsection{Influência da produção enzimática do fungo Aspergillus sydowii Ce19 no meio de cultura com extrato de malte $3 \%$ com ou sem a água do mar artificial na reação de redução}

O fungo Aspergillus sydowii Ce19, por ser isolado de um organismo marinho, a esponja Chelonaplysylla erecta, utilizou-se as condições de cultivo com extrato de malte $3 \%$ na presença de uma mistura de sais de tal forma que se assemelhasse à água do mar, sendo majoritariamente constituído por íons cloreto.

Entretanto, pelos motivos discutidos na seção (3.2.7.) quando se utilizou a água do mar artificial ao realizar a reação com a $\alpha$-bromoacetofenona (2) observou-se a substituição espontânea do bromo pelo íon cloreto. Assim, foi preciso substituir a composição da água do mar artificial pela água destilada, ou seja, sem adição de íons cloreto durante o crescimento do fungo A. sydowii Ce19.

Então se realizou o cultivo do fungo em extrato de malte $3 \%$ na ausência de íons cloreto e em seguida realizaram-se as reações com as células e o caldo enzimático. As reações com o caldo enzimático não levou a redução da $\alpha$-bromoacetofenona (2) como já era esperado e neste caso, também não promoveu a formação da $\alpha$-cloroacetofenona (1). Concluiu-se que na ausência de íons cloreto não ocorreu a substituição espontânea do bromo pelo íon cloreto.

Posteriormente realizaram-se as reações com as células totais do fungo A. sydowii Ce19 cultivadas na ausência da água do mar artificial, surpreendentemente a reação de redução tanto da $\alpha$-cloroacetofenona (1) quanto da $\alpha$-bromoacetofenona (2) deixaram de ocorrer. O cultivo do fungo A. sydowii Ce19 na ausência de íons cloreto as respectivas reações foram realizadas por três vezes e em todos os casos não levou a redução das cetonas $\mathbf{1}$ e $\mathbf{2}$. Portanto, constatou-se que a composição da água do mar artificial, rica em íons cloreto, foi 
fundamental para a produção das enzimas responsáveis pela redução das cetonas $\alpha$ halocarbonilados.

\subsubsection{Biotransformação da $p$-bromo- $\alpha$-bromoacetofenona (3) e da $p$-nitro- $\alpha$ - bromoacetofenona (3) com fungo de origem marinha Aspergillus sydowii Ce19}

As reações da $p$-bromo- $\alpha$-bromoacetofenona (3) foram realizadas com as células totais Aspergillus sydowii Ce19 cultivadas em $A S W$ nas mesmas condições realizadas com as cetonas 1 e 2. As reações com a $p$-bromo- $\alpha$-bromoacetofenona (3), também levaram a formação de vários picos, como podem ser observados nas análises por CG (Figura 14). Entretanto, quando analisou as reações por CG-EM não foi identificado compostos provenientes da $p$-bromo- $\alpha$-bromoacetofenona (3), exceto um sinal correspondente à $p$ bromocetofenona. A presença deste composto foi confirmada através da injeção com padrão. Entretanto, a maioria dos picos analisados era proveniente de metabólitos do fungo, principalmente a presença de ácidos graxos. Assim, concluiu-se que ocorreu uma biodegradação total da $p$-bromo- $\alpha$-bromoacetofenona (2) em poucas horas de reação. A formação da $p$-bromocetofenona possivelmente ocorreu via reação enzimática.

A reação com a $p$-nitro- $\alpha$-bromoacetofenona (4) ocorreu de forma similar à $p$-bromo$\alpha$-bromoacetofenona (3), ou seja, houve uma degradação total da cetona 4 como pode ser observado nos cromatogramas da (Figura 15). Análises por CG-EM permitiram identificar a p-nitroacetofenona obtida possivelmente via biotransformação enzimática. As reações com a $p$-bromo- $\alpha$-bromoacetofenona (3) e $p$-nitro- $\alpha$-bromoacetofenona (4) foram realizadas três vezes e em todos os casos obteve-se uma mistura de produtos que não eram provenientes do material de partida. 


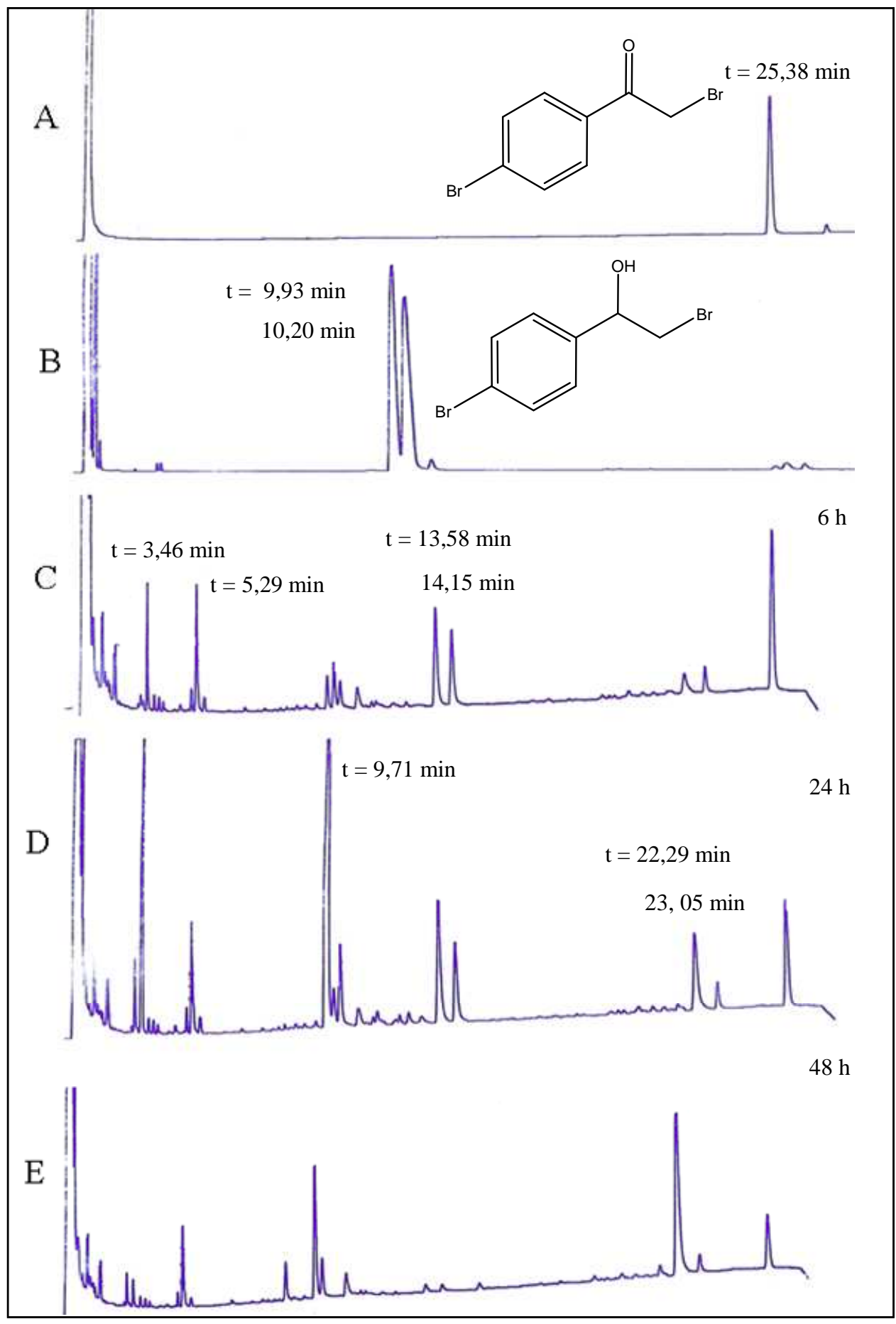

Figura 14. Cromatogramas obtidos em coluna quiral de $\beta$-ciclodextrina. (A) Cromatograma da $p$-bromo- $\alpha$ bromoacetofenona (3); (B) Cromatograma do álcool $(R S)$-3a; (C, D, E) Reações da $p$-bromo- $\alpha$ -

bromoacetofenona (3) com o fungo A. sydowii Ce19; Condições da reação: $5 \mathrm{~g}$ de massa celular úmida de fungo; $50 \mathrm{mg}$ de $p$-bromo- $\alpha$-bromo-acetofenona (3); $100 \mu \mathrm{L}$ de DMSO; $150 \mathrm{rpm} ; 32^{\circ} \mathrm{C}$; extrato de malte $3 \%, 50 \mathrm{~mL}$ de tampão fosfato em $\mathrm{pH}=7$; Condições de análises no CG: $\mathrm{t}_{\mathrm{i}}=120^{\circ} \mathrm{C} ; 2 \mathrm{~min} ; \mathrm{t}_{\mathrm{f}}=165^{\circ} \mathrm{C} ; 8 \mathrm{~min} ; \mathrm{r}=2{ }^{\circ} \mathrm{C} / \mathrm{min}$ 


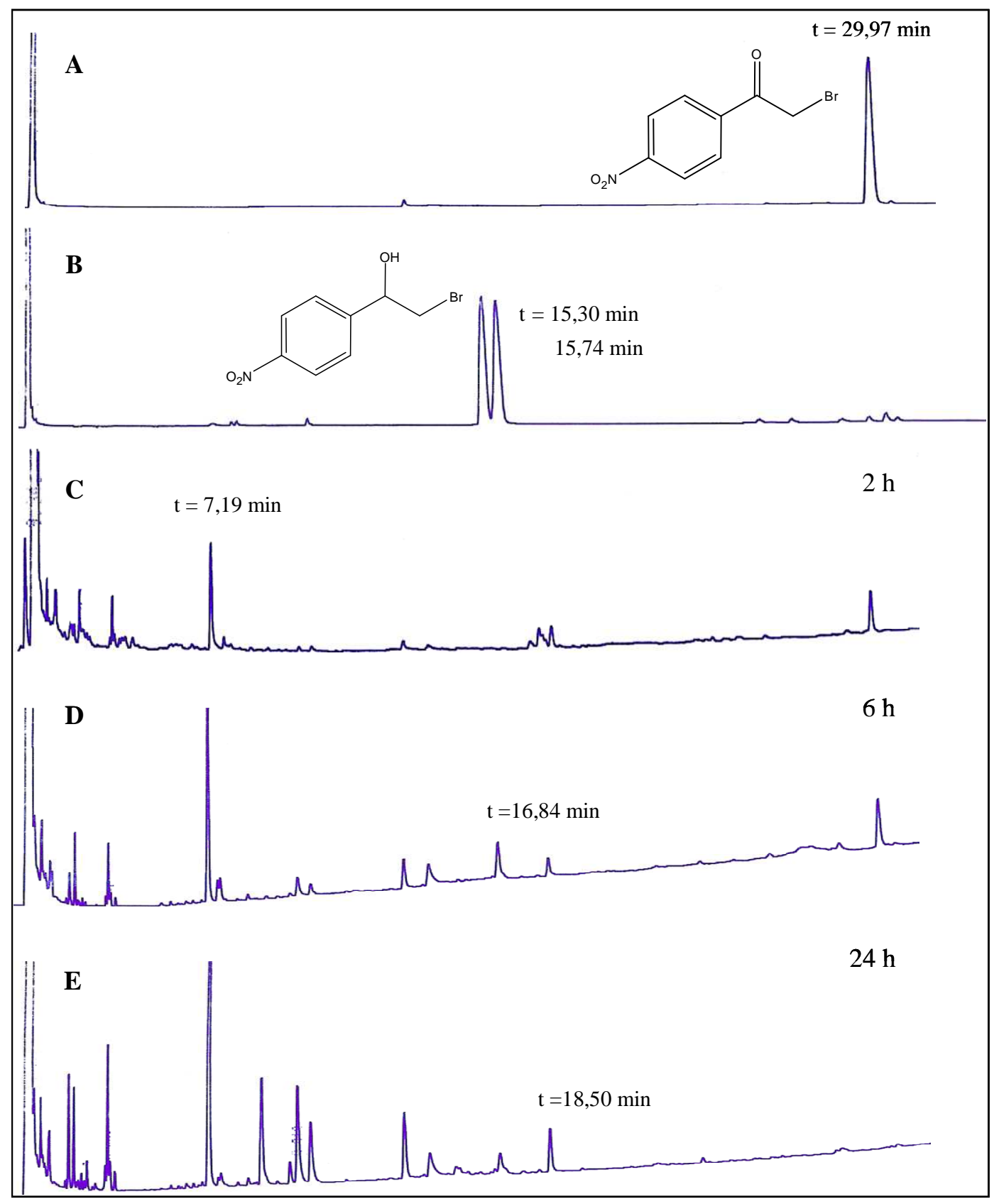

Figura 15 Cromatogramas obtidos em coluna quiral de $\beta$-ciclodextrina. (A) Cromatograma da $p$-nitro- $\alpha$ bromoacetofenona (4); (B) Cromatograma do álcool $(R S)-4 \mathbf{a} ;(\mathrm{C}, \mathrm{D}, \mathrm{E})$ Reações da $p$-nitro- $\alpha$-bromoacetofenona (4) com o fungo A. sydowii Ce19; Condições da reação: $5 \mathrm{~g}$ de massa celular úmida de fungo; $50 \mathrm{mg}$ de $p$-nitro$\alpha$-bromoacetofenona (2); $100 \mu \mathrm{L}$ de DMSO; $150 \mathrm{rpm} ; 32^{\circ} \mathrm{C}$; extrato de malte $3 \%, 50 \mathrm{~mL}$ de tampão fosfato em $\mathrm{pH}=7$. Condições de análises no $\mathrm{CG}: \mathrm{t}_{\mathrm{i}}=130{ }^{\circ} \mathrm{C} ; 2 \mathrm{~min} ; \mathrm{t}_{\mathrm{f}}=200^{\circ} \mathrm{C} ; 8 \mathrm{~min} ; \mathrm{r}=2{ }^{\circ} \mathrm{C} / \mathrm{min}$ 


\subsubsection{Redução de orto-, meta- e para-iodoacetofenonas 5-7 com os fungos de origem marinha Trichoderma sp Gc1 e P. miczynskii Gc5}

Uma vez realizada a triagem biocatalítica com os fungos de origem marinha com a $\alpha$ cloroacetofenona (1) selecionou-se os fungos Trichoderma sp Gc1 e P. miczynskii Gc5 para realizar as reações de redução com as iodoacetofenonas 5-7. As reações foram realizadas com as células do fungo Trichoderma sp Gc1 e levaram à redução das cetonas aos respectivos álcoois secundários com diferentes seletividades e conversões. Os resultados estão sumarizados na (Tabela 9).

As reações de redução das cetonas 5-6 ocorreram em 48 h e até em 168 h não sofreram variações significativas nas conversões e nos excessos enantioméricos. O fungo Trichoderma sp Gc1 reduziu as iodoacetofenonas 5-6 seletivamente, produzindo os álcoois 5a-6a com altos excessos enantioméricos, e.e. > $99 \%$ (Tabela 9). Entretanto, as conversões não atingiram um valor desejável, a cetona 5 foi convertida em $62 \%$ e a cetona 6 em apenas $24 \%$ de conversão. Enquanto que a cetona 7 apresentou modesta conversão e baixa pureza ótica. Inclusive houve um decréscimo considerável no valor do excesso enantiomérico do álcool 7a na medida em que o tempo reacional passou de 24 a 168 h (Tabela 9). Esse decréscimo no excesso enantiomérico pode ser devido à reação de desracemização ou estereoinversão. Trabalhos na literatura mostram reações de estereoinversão em derivados do feniletanol, por exemplo, a desracemização do $p$-nitro-feniletanol (COMASSETO et al 2006).

Os rendimentos isolados dos álcoois $5 \mathbf{a}$ e $6 \mathbf{a}$ foram de $55 \%$ e $25 \%$, respectivamente. Esses rendimentos foram determinados utilizando-se $50 \mathrm{mg}$ das cetonas 5 e $\mathbf{6}$ em um frasco erlenmeyer de $250 \mathrm{~mL}$ cada (Seção 2.1.). Enquanto que o rendimento isolado do álcool 7a foi de $70 \%$ utilizando-se dois frascos erlenmeyers de $250 \mathrm{~mL}$, onde se adicionou $50 \mathrm{mg}$ de cetona 7 em cada frasco (Seção 2.1.). 
Em razão do tempo de trabalho, não foi possível otimizar estes experimentos para melhorar os resultados com as cetonas $\mathbf{5 - 7}$, principalmente em relação ao aumento do rendimento dos álcoois 5a-6a, pois foram obtidos com excelentes excessos enantioméricos. A baixa solubilidade das iodoacetofenonas 5-7 podem ter também dificultado um melhor desempenho destas reações.

As iodoacetofenonas 5-7 também foram submetidas frente às reações de redução com as células totais do fungo Penicillium miczynskii Gc5. Entretanto, os resultados não foram satisfatórios, pois ocorreu uma baixa conversão das cetonas 5-7 nos respectivos álcoois, 5a-7a (Tabela 9). Portanto concluiu-se que as reações de redução dependem exclusivamente das espécies de microrganismos utilizadas.

As configurações absolutas dos álcoois $5 \mathbf{a}$ e 7a foram determinadas comparando-se as rotações óticas experimentais com os valores da literatura (XU et al., 2006; SALVI E CHATTOPADHYAY, 2006). 
Tabela 9. Redução de iodoacetofenonas 5-7 com o fungo de origem marinha Trichoderma sp Gc1. ${ }^{a}$

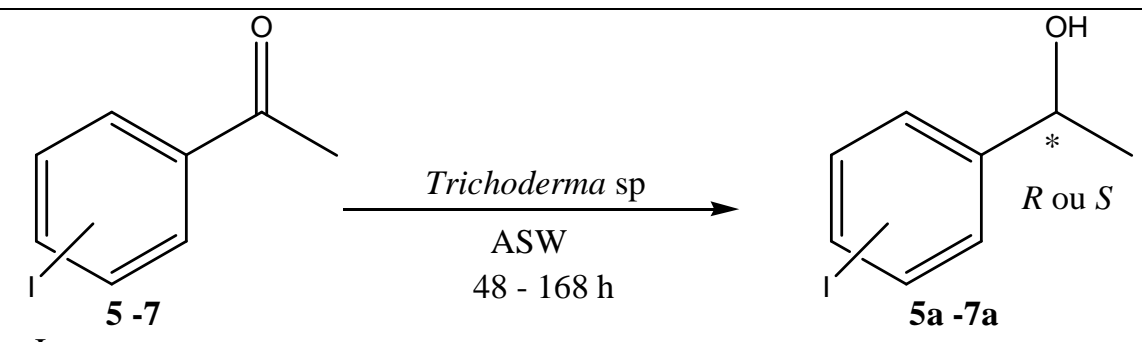

$\mathrm{I}=$ orto, meta, para

orto-iodoacetofenona 5

\begin{tabular}{ccccc}
\hline $\mathrm{t}$ & c 5 & c 5a & e.e. 5a & c.a \\
\hline 48 & 38 & 62 & $>99$ & $S$ \\
96 & 38 & 62 & $>99$ & $S$ \\
168 & 38 & 62 & $>99$ & $S$
\end{tabular}

meta-iodoacetofenona 6

\begin{tabular}{ccccc}
\hline $\mathrm{t}$ & c 6 & c 6a & e.e. 6a & nd \\
\hline 48 & 75 & 25 & $>99$ & nd \\
96 & 76 & 24 & $>99$ & nd \\
168 & 76 & 24 & $>99$ & nd \\
\hline
\end{tabular}

para-iodoacetofenona 7

\begin{tabular}{ccccc}
\hline $\mathrm{t}$ & $\mathrm{c} \mathrm{7}$ & $\mathrm{c} \mathrm{7a}$ & e.e. 7a & \\
\hline 48 & 27 & 73 & 55 & $R$ \\
96 & 29 & 71 & 38 & $R$ \\
168 & 33 & 67 & 32 & $R$
\end{tabular}

${ }^{\mathrm{a}}$ Condições de reação: $5 \mathrm{~g}$ células totais do fungo Trichoderma sp Gc1; $50 \mathrm{mg}$ de iodoacetofenonas 5-7; $600 \mu \mathrm{L}$ de DMSO; $150 \mathrm{rpm} ; 32^{\circ} \mathrm{C}$; água do mar artificial (ASW); c $(\%)=$ concentração determinada por CG; e.e. $(\%)=$ excesso enantiomérico; $\mathrm{t}=$ tempo $(\mathrm{h})$ 


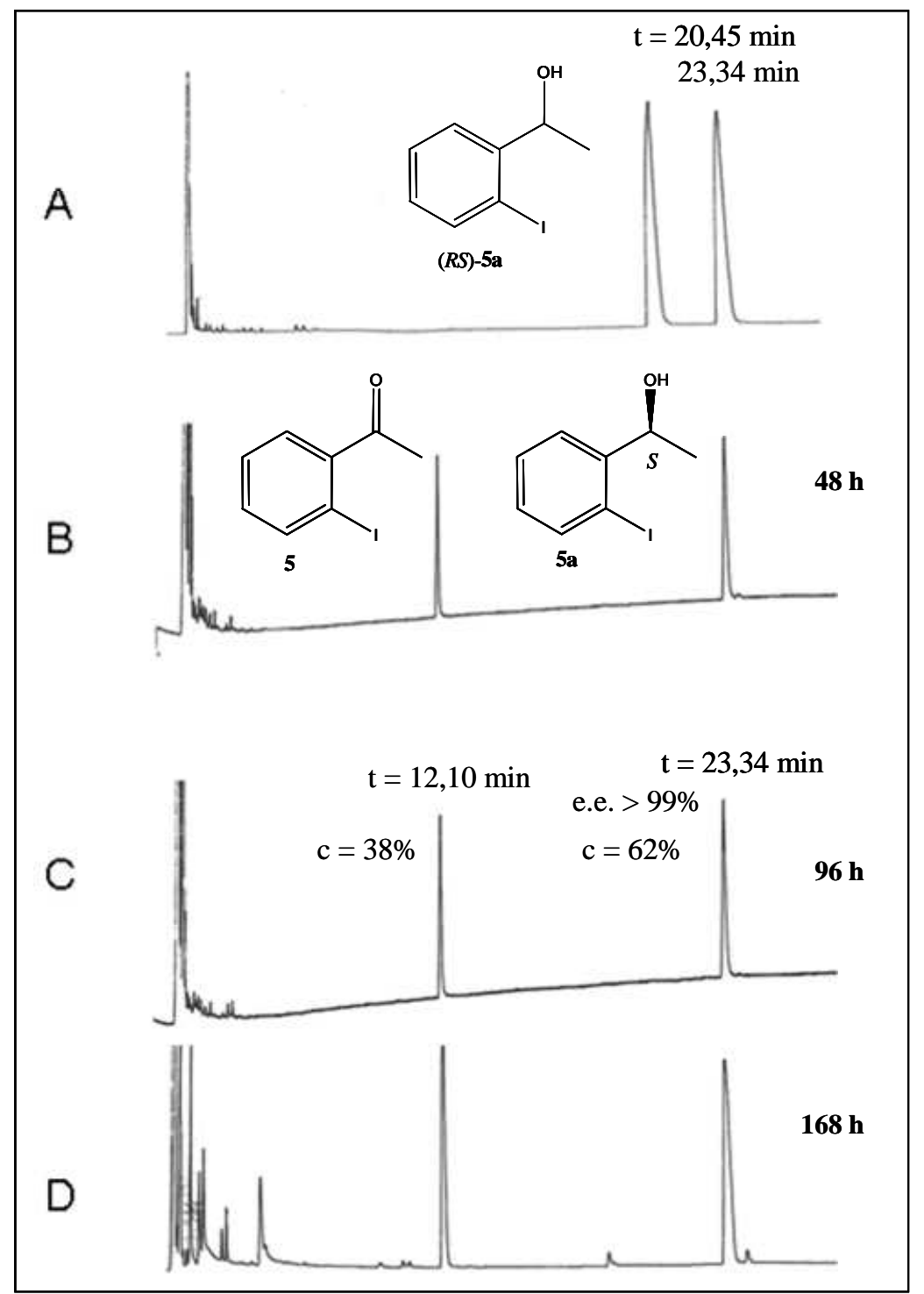

Figura 16. Cromatogramas: (A) Padrão da (RS)-o-iodo-1-fenil-etanol (5a); (B) Reação com $48 \mathrm{~h}$ com o fungo Trichoderma sp Gc1; (C) Reação com reação 96 h com o fungo Trichoderma sp Gc1 (D) Reação com 168 h com o fungo Trichoderma sp Gc1; Condições de análises no CG: $\mathrm{t}_{\mathrm{i}}=120^{\circ} \mathrm{C} ; 2 \mathrm{~min} ; \mathrm{t}_{\mathrm{f}}=165^{\circ} \mathrm{C} ; 8 \mathrm{~min} ; \mathrm{r}=2{ }^{\circ} \mathrm{C} / \mathrm{min}$ 


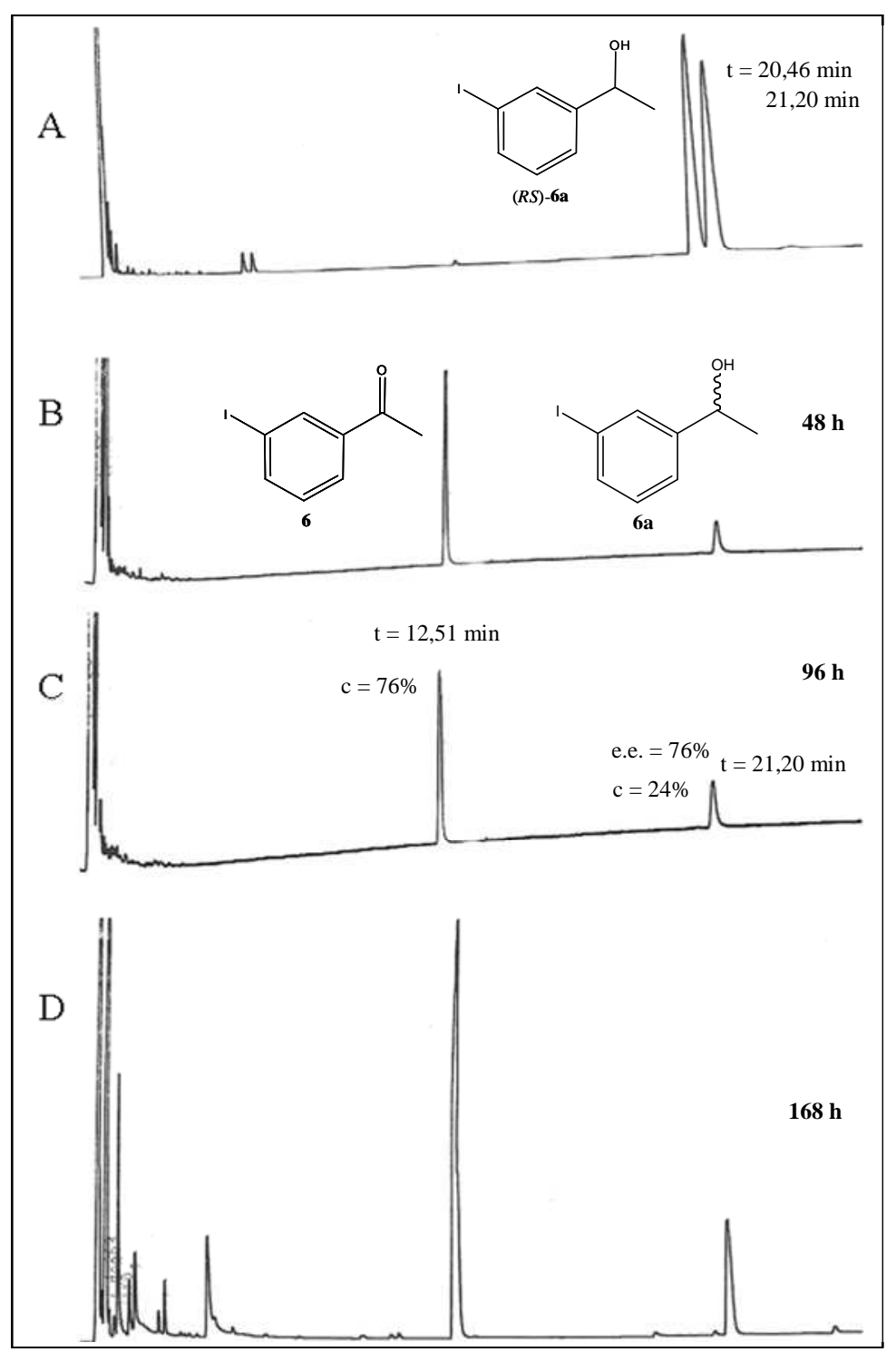

Figura 17. Cromatogramas: (A) Padrão da $(R S)$ - $m$-iodo-1-fenil-etanol (6a); (B) Reação com $48 \mathrm{~h}$ com o fungo Trichoderma sp Gc1; (C) Reação com 96 h com o fungo Trichoderma sp Gc1; (D) Reação com 168 h com o fungo Trichoderma sp Gc1.Condições de análises no CG: $\mathrm{t}_{\mathrm{i}}=120^{\circ} \mathrm{C} ; 2 \mathrm{~min} ; \mathrm{t}_{\mathrm{f}}=165^{\circ} \mathrm{C} ; 8 \mathrm{~min} ; \mathrm{r}=2{ }^{\circ} \mathrm{C} / \mathrm{min}$ 


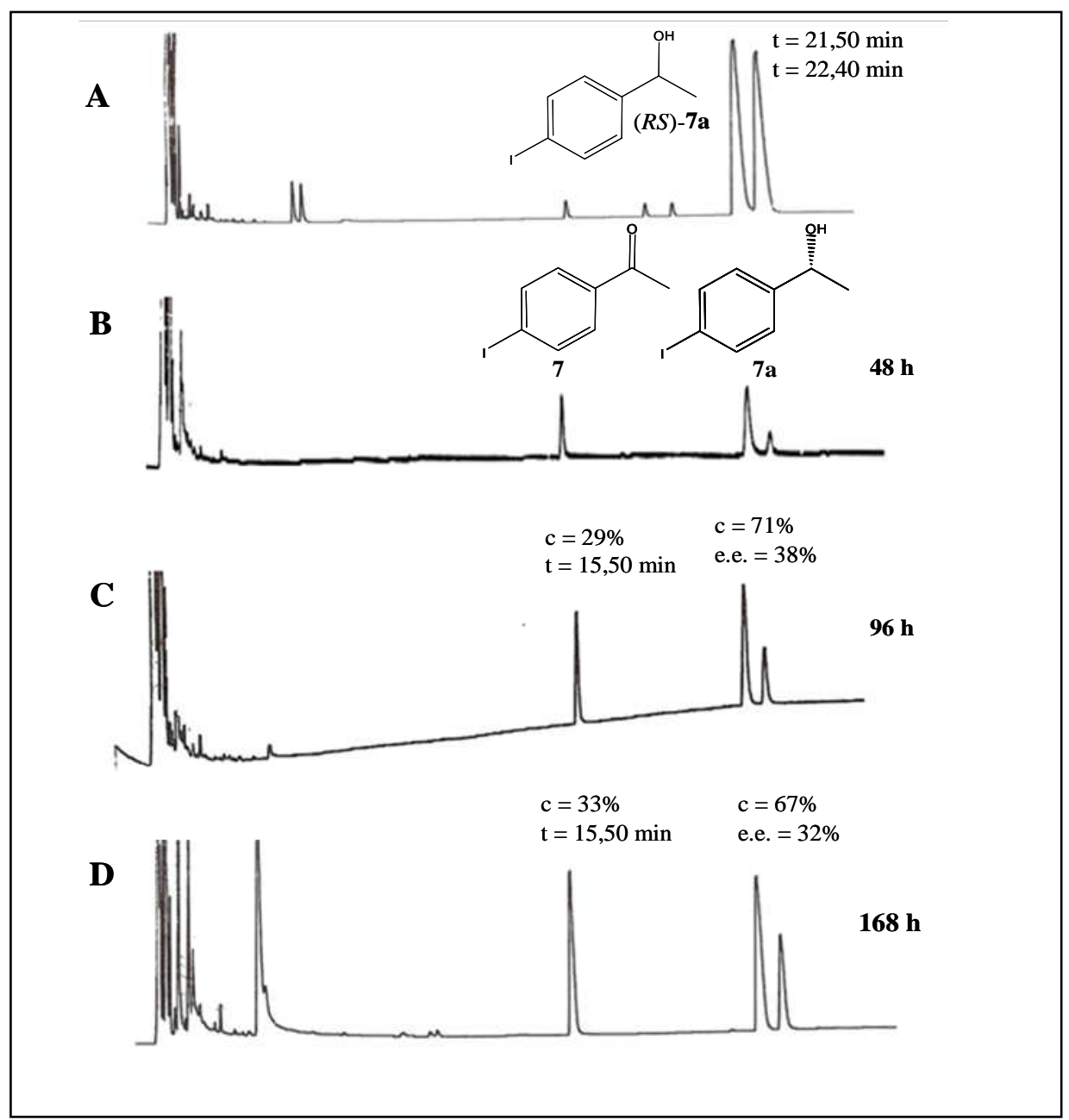

Figura 18. Cromatogramas: (A) Padrão da $(R S) p$-iodo-1-fenil-etanol 7a; (B) $p$-iodo-acetofenona e $p$-iodo-1fenil-etanol, com 48 h de reação; (C) ) $p$-iodo-acetofenona e $p$-iodo-1-fenil-etanol, com 96 h de reação; (D) ) $p$ iodo-acetofenona e $p$-iodo-1-fenil-etanol, com $168 \mathrm{~h}$ de reação. Condições de análises no CG: $\mathrm{t}_{\mathrm{i}}=120^{\circ} \mathrm{C} ; 2$ min; $\mathrm{t}_{\mathrm{f}}=165^{\circ} \mathrm{C} ; 8 \mathrm{~min} ; \mathrm{r}=2{ }^{\circ} \mathrm{C} / \mathrm{min}$ 
Tabela 10. Redução de iodoacetofenonas 5-7 com o fungo de origem marinha Penicillium miczynskii Gc5. ${ }^{a}$

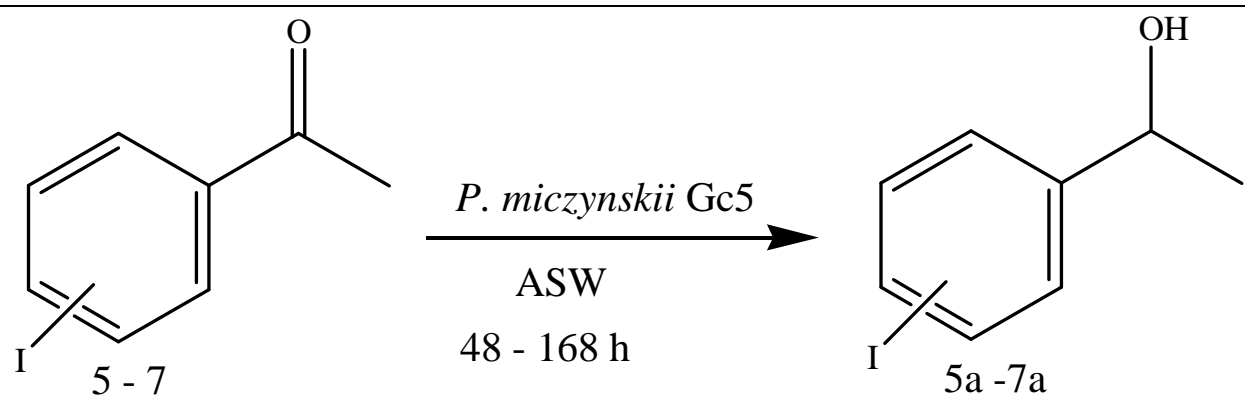

$\mathrm{I}=$ orto, meta e para

\begin{tabular}{|c|c|c|c|c|}
\hline \multicolumn{5}{|c|}{ orto-iodoacetofenona 5} \\
\hline $\mathrm{t}$ & c 5 & c 5a & e.e. 5a & c.a. \\
\hline 48 & 91 & 9 & $>99$ & $S$ \\
\hline 96 & 73 & 27 & $>99$ & $S$ \\
\hline 168 & 73 & 27 & $>99$ & $S$ \\
\hline \multicolumn{5}{|c|}{ meta-iodoacetofenona 6} \\
\hline $\mathrm{t}$ & c 6 & c 6a & e.e. $\mathbf{6 a}$ & $\mathrm{Nd}$ \\
\hline 48 & 80 & 20 & - & $\mathrm{Nd}$ \\
\hline 96 & 77 & 23 & 75 & $\mathrm{Nd}$ \\
\hline 168 & 74 & 26 & 62 & $\mathrm{Nd}$ \\
\hline \multicolumn{5}{|c|}{ para-iodoacetofenona 7} \\
\hline $\mathrm{t}$ & c 7 & c 7a & e.e. $7 \mathbf{a}$ & c.a \\
\hline 48 & 100 & - & - & $R$ \\
\hline 96 & 100 & - & - & $R$ \\
\hline 168 & 75 & 25 & 18 & $R$ \\
\hline
\end{tabular}

${ }^{\mathrm{a} C}$ Condições de reação: $100 \mathrm{~mL}$ de tampão fosfato $\mathrm{pH}=7 ; 5 \mathrm{~g}$ de células de Penicillium miczynskii Gc5; extrato de malte 3\%; água do mar artificial; $50 \mathrm{mg}$ de iodoacetofenonas 5-7; $600 \mu \mathrm{L}$ de DMSO; $150 \mathrm{rpm} ; 32^{\circ} \mathrm{C}$; tampão

fosfato $\mathrm{pH}=7$; água do mar artificial; c $(\%)=$ concentração determinada por $\mathrm{CG}$; e.e. $(\%)=$ excesso enantiomérico; $\mathrm{t}$ = tempo $(\mathrm{h}) ; \mathrm{Nd}=$ não determinado 


\subsubsection{Caracterização dos compostos}

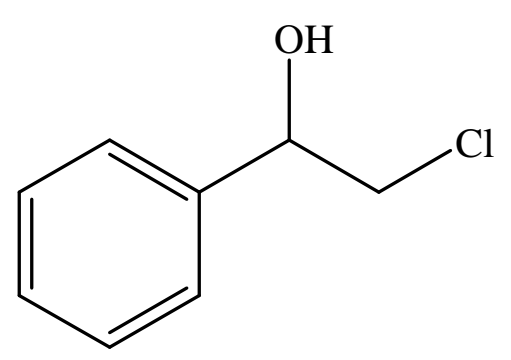

2-cloro-1-feniletanol - 1a $[\alpha]_{D}{ }^{25}=+17,08$ (c 3,2

$\mathrm{CHCl}_{3}$ ); $\mathbf{R M N}{ }^{1} \mathbf{H}:(400 \mathrm{MHz}), \delta(\mathrm{ppm})$ 7,34 (5H, m); $4,89(1 \mathrm{H}, \mathrm{dd}, J=8,8$ e $3,6 \mathrm{~Hz}) ; 3,73(1 \mathrm{H}, \mathrm{dd}, J=11,2 \mathrm{e}$ 3,6 Hz); 3,64 (1H, dd, $J=11,2$ e 8,4 Hz); 2,7 (1H, sl); IV filme em pastilha de silício $\left(\mathrm{cm}^{-1}\right): 3409(\mathrm{OH}) 1065$ (-C-O).

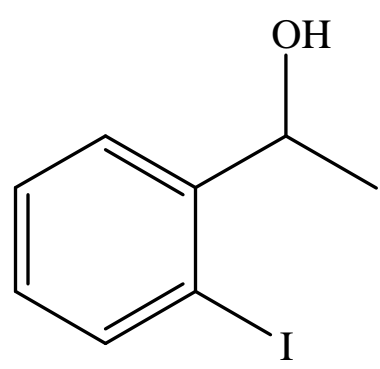

1(2-iodofenil)etanol - 5a $[\alpha]_{\mathrm{D}}^{25}=-1,20\left(c 4,4 \mathrm{CHCl}_{3}\right)$; RMN ${ }^{1} \mathbf{H}:(400 \mathrm{MHz}), \delta$ (ppm) 7,80 (1H, dd, $J=8,0 \mathrm{e}$ 0,8 Hz); 7,56 (1H, dd, $J=7,6$ e 1,6 Hz); 7,37 (1H, m); $6,95(1 \mathrm{H}, \mathrm{m}) ; 5,06(1 \mathrm{H}, \mathrm{q}, J=6,4 \mathrm{~Hz}) ; 2,0(1 \mathrm{H}, \mathrm{sl}) ; 1,45$ $(3 \mathrm{H}, \mathrm{d}, J=6,4 \mathrm{~Hz})$ IV filme em pastilha de silício $\left(\mathrm{cm}^{-}\right.$ $\left.{ }^{1}\right): 3341(\mathrm{OH}) 1087(-\mathrm{C}-\mathrm{O})$.<smiles>CC(O)c1ccc(I)cc1</smiles>

1(3-iodofenil)etanol - $\mathbf{6 a}[\alpha]_{\mathrm{D}}^{25}=+1,05\left(c\right.$ 1,5 $\left.\mathrm{CHCl}_{3}\right)$; RMN ${ }^{1} \mathbf{H}:(400 \mathrm{MHz}), \delta$ (ppm) 7,67 (2H, d, $\left.J=8,4 \mathrm{~Hz}\right)$; $7,11(2 \mathrm{H}, \mathrm{d}, J=8,4 \mathrm{~Hz}) ; 4,84(1 \mathrm{H}, \mathrm{q}, J=6,4 \mathrm{~Hz}) ; 1,70$ $(1 \mathrm{H}, \mathrm{sl}) ; 1,45(3 \mathrm{H}, \mathrm{d}, J=6,4 \mathrm{~Hz})$ IV filme em pastilha de silício $\left(\mathrm{cm}^{-1}\right)$ : $3348(\mathrm{OH}) 1086(-\mathrm{C}-\mathrm{O})$. 


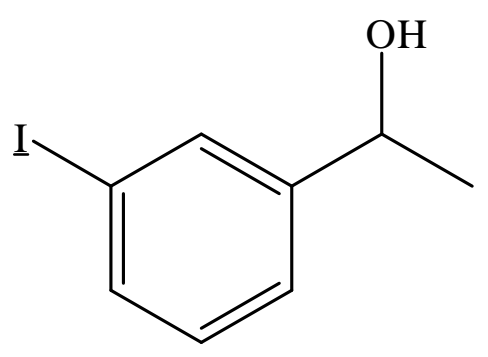

1(4-iodofenil)etanol - 7a $[\alpha]_{\mathrm{D}}^{25}=-0,31\left(c 2,4 \mathrm{CHCl}_{3}\right)$;

RMN ${ }^{1} \mathbf{H}:(400 \mathrm{MHz}), \delta(\mathrm{ppm})$ 7,74 (1H, s); 7,60 (1H, $\mathrm{d}, J=7,6 \mathrm{~Hz}) ; 7,33(1 \mathrm{H}, \mathrm{d}, J=7,6 \mathrm{~Hz}) ; 7,08(1 \mathrm{H}, \mathrm{t}, \mathrm{J}=$ 7,6 Hz); 4,84 (1H, q, $J=6,4 \mathrm{~Hz}) ; 1,48(3 \mathrm{H}, \mathrm{d}, J=6,4$ Hz) IV filme em pastilha de silício $\left(\mathrm{cm}^{-1}\right): 3348(\mathrm{OH})$ 1065 (-C-O).

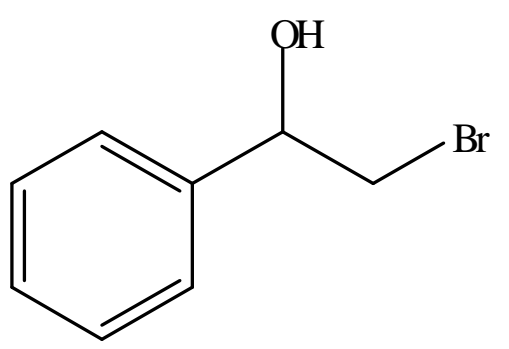

bromo-1-feniletanol - 2a feniloxirano - 2b RMN ${ }^{\mathbf{1}} \mathbf{H}$ : (200 MHz), Mistura Óleo amarelo; $\delta$ (ppm): $2.64(1 \mathrm{H}$, $\mathrm{d}, \mathrm{J}=3.2 \mathrm{~Hz}, \mathrm{OH}), 2.80(1 \mathrm{H}, \mathrm{dd}, \mathrm{J}=2.5$ e $5.4 \mathrm{~Hz}), 3.14$ $(1 \mathrm{H}, \mathrm{dd}, \mathrm{J}=4.1$ e $5.4 \mathrm{~Hz}), 3.54(1 \mathrm{H}, \mathrm{dd}, \mathrm{J}=8.6$ e 10.5<smiles>C1=CCC(C2CO2)C=C1</smiles>
$\mathrm{Hz}), 3.65(1 \mathrm{H}, \mathrm{dd}, \mathrm{J}=3.5$ e $10.5 \mathrm{~Hz}), 3.86(1 \mathrm{H}, \mathrm{dd}, \mathrm{J}=$ 2.54 e $4.12 \mathrm{~Hz}), 4.92(1 \mathrm{H}, \mathrm{m}), 7.33$ (10H. m) 


\subsection{Analises de espectros de massas (EM)}

Os compostos foram identificados em CG e confirmados por CG-EM e estão dispostos abaixo.
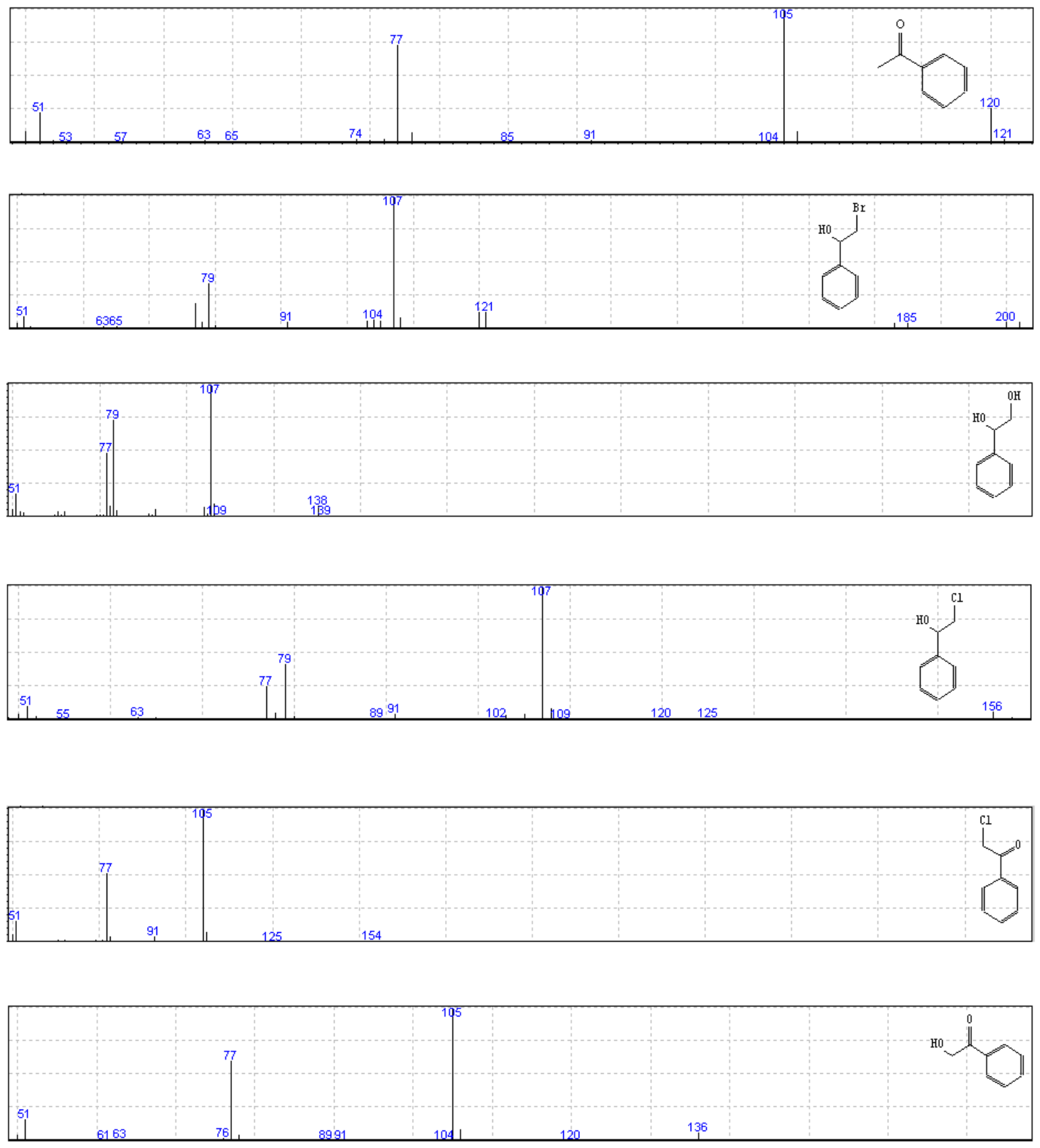


\section{Conclusão}

Os objetivos deste trabalho foram alcançados, pois foi possível utilizar microrganismos de origem marinha em reações de redução de cetonas. Neste trabalho realizou-se a redução de derivados de acetofenonas com fungos de origem marinha. A redução da $\alpha$-cloroacetofenona (1) foi realizada com os fungos Trichoderma sp Gc1, Penicillium miczynskii Gc5, Aspergillus sydowii Gc12, Bionectria sp Ce5, Aspergillus sydowii Ce15, Penicillium raistrickii Ce16 e Aspergillus sydowii Ce19. O (S)-(+)-2-cloro-1feniletanol (1a) foi obtido com excesso enantiomérico 17- $66 \%$. Embora as purezas enantioméricas fossem modestas, todos os fungos apresentaram seletividade anti-Prelog na redução da cetona $\mathbf{1}$, o que é bastante vantajoso, pois a maioria das reduções com microrganismos apresentam seletividade Prelog.

A redução da orto-iodoacetofenona (5) e da meta-iodoacetofenona (6) levaram à produção dos correspondetes álcoois com excessos enantioméricos superiores a $98 \%$.

O uso das $\alpha$-bromoacetofenonas (2-4) não foi bons substratos para as reações biocatalíticas, pois nas condições utilizadas, observou-se uma eliminação espontânea do bromo, bem como uma biodegradação das cetonas.

Neste trabalho conclui-se que os microrganismos de origem marinha, podem ser utilizados como fontes de novos biocatalisadores para promoverem reações de redução em cetonas proquirais. Ainda, foi observado que existe uma dependência na produção das enzimas redutases com o cultivo dos microrganismos em condições contendo altas concentrações de íons cloreto, pois na ausência de $\mathrm{Cl}^{-}$não foram obtidas as reações de redução das cetonas $\mathbf{1}$ e $\mathbf{2}$ utilizando-se as células totais dos fungos de origem marinha.

Conclui-se que através destes estudos que os resultados preliminares são promissores para promover reações de redução pela metodologia biocatalítica utilizada. 


\section{Referências Bibliográficas}

ALCÂNTRA, A. F. C.; BARROSO. H. S. Redução de amidas por boranos. Química Nova, v. 25, n. 2, p. 300-311, 2002.

ALBUQUERQUE, P. M. Utilização de saccharomyces cerevisiae na redução de substratos carbonílicos. 2007. 160f. Tese (Doutorado) - Centro de Ciências Físicas e Matemáticas, Universidade Federal de Santa Catarina, Santa Catarina, 2007.

BARBIERI, C.; BOSSI, L.; D’ARRIGO, P.; FANTONI, G. P.; SERVI, S. Bioreduction of aromatic ketones: preparation of chiral benzyl alcohols in both enantiomeric forms. Journal Molecular Catalysis B: Enzymatic, v. 11, p. 415-421, 2001.

BEATRIZ, A., LIMA, D. P.; MARQUES, M. R.; MARTINS, L. R.; MACHADO, V. E.; MENA, A. E. M.; PETRONI, J. M.; ITO, F. M. Seeking for new bioactive compounds from cage-like Diels-Alder adducts. In: BRAZILIAN SYMPOSIUM ON MEDICINAL

CHEMISTRY, 2004, Rio de Janeiro. Livro de resumos... Rio de Janeiro: IME, 2004. p. 62.

BONATO, P. S. Cromatografia gasosa. In: COLLINS, C. H.; BRAGA, G. L.; BONATO, P. S. (Org). Fundamentos de cromatografia. Canpinas: UNICAMP, 2006. p. 203-272.

BRZEZINSKA-RODAK, M.; ZYMANCZYK-DUDA, E.; KLIMEK-OCHAB, M.; KAFARSKI, P.; LEJCZAK, B. A simple and green procedure for the microbial effective synthesis of 1-phenylethyl alcohol in both enantiomeric forms. Biotechnology Letters, v. 28, p. 511-513, 2006.

CAMPA, A. Biological roles of plant peroxidases: know and potential function. In: EVERSE , K.; GRISHAN, M. B. (Eds.). Peroxidasein chemistry and biology. New York: CRC, 1991. v. 2

CÁNOVAS, M.; IBORRA, J. L. Whole cell biocatalysts stabilization for L-carnitine production. Biocatalysis Biotransformation, v. 23, n. 3-4, p. 149-158, 2005.

CARVALHO, M. C.; OKAMOTO, M. T.; MORAN, P. J. S.; RODRIGUES, J. A. R. Barer's yeast reduction of $\alpha$-Haloacetophenones. Tetrahedron, v. 47, p. 2073-2080, 1991. 
CARVALHO, P. O.; SILVANA, A. C.; MARASSI, M.; SILVA, D. S.; CONTESINI, F.C.; BIZACO. R.; MACEDO, G.A. Potencial de biocatálise enantiosseletiva de lipases microbianas. Química Nova, v. 28, n. 4, p. 614-621, 2005.

CHUNG, S. Y.; VERCELLOTTI, J. R.; SANDERS, T. H. Rapid test for alcohol dehydrogenase during peanut maturation and curing. Chemistry Markers for Processed and Stored Foods, v. 631, p. 179-188, 1996.

COMASSETO, J. V.; ANDRADE, L. H.; OMORI, A. T.; ASSIS, L. F.; PORTO, A. L. M. Deracemization of aryl ethanols and reduction of acetophenones by whole fungal cells of Aspergillus terreus CCT 4083, Apergillus. terreus CCT 3320 and Rhizopus oryzae CCT 4964. Journal of Molecular Catalysis B: Enzymatic, v. 29, p. 55-61, 2004.

COMASSETO, J. V.; ASSIS, L. F.; ANDRADE, L. H.; SCHOENLEINCRUSIUS, I. H.; PORTO, A. L. M. Biotransforamtions of ortho-, meta-and para aromatic nitrocompounds by of Aspergillus terreus. Reduction of ketones and deracemization of alcohols. Journal of Molecular Catalysis B: Enzymatic, v. 39, p. 24-30, 2006.

COMASSETO, J. V.; OMORI, A. T.; ANDRADE, L. H.; PORTO, A. L. M. Bioreduction of fluoroacetophenones by the fungi Aspergillus terreus and Rhizopus oryzae.

Tetrahedron:Asymmetry, v. 14, p. 711-715, 2003.

DEMIRJIAN, D. C.; SHAH, P. C.; MORIS-VAS, F. From discovery to application. Biocatalysis, v. 200, p. 1-29, 1999.

DEMIRJIAN, D. S.; SHAH, P. C.; MORÍS-VARAS, F. Screening for novel enzymes In: FRESSNER, W. D. (Ed.). Biocatalysis from discovery to application. Berlin: Springer, 2000. p. 1-30.

ETHUR, E. M. Síntese e caracterização de $\beta$ - e $\gamma$-ciclodextrinas modificadas como fases estacionárias quirais em cromatografia gasosa capilar enantiosseletiva. 2004. 147f. Tese (Doutorado) - Programa de Pós-Graduação em Química, Universidade Federal de Santa Maria, Santa Maria, 2004.

FABER, K. Biotranformations in organic chemistry. 3.ed. Berlin: Springer- Verlag, 1997. p. 911

FABER, K. Biotransformations in organic chemistry. 5.ed. Berlin: Springer- Verlag, 2004. p. 5 
FABER, K.; PATEL, R. Chemical biotechnology a happy marriage between chemistry and biotechnology: asymmetric synthesis via green chemistry. Current Opinion Biotechnology, v. 11, p. 517-519, 2000.

FILHO, F.; O.; VIERA, I. C. Uso analítico de tecidos e extratos brutos vegetais como fonte de enzima. Química Nova, v. 25, p. 455-464, 2002.

GROGER, H.; CHAMOULEAU, F.; OROLOGAS, N.; ROLLMANN, C.; DRAUZ, K.; HUMMEL, W.; WECKBECKER, A.; MAY, O. Enantioselective reduction of ketones with "Designer cells" at high substrate concentrations: Highly efficient access to functionalized optically active alcohols. Angewcandte Chemie International Edition, v. 45, p. 56-77-5681, 2006.

HAGE, A.; SCHOEMAKER, H. E.; FIELD, J. A Optimization of stereoselective ketone reduction by the white-rot fungus Merulius tremellosus ono991. Applied Microbiology and Biotechnology, v. 57, p. 79-84, 2001.

HOLLAND, H. L. Organic synthesis with oxidative enzymes. Weinheim: VCH, 1992. p. 1

HOMANN, M. J.; VAIL, R. B.; PREVITE, E.; TAMAREZ, M.; MORGAN, B.; DODDS, D. R.; ZAKS, A. Rapid identification of enantioselective ketone reductions using targeted microbial libraries. Tetrahedron, v. 60, n. 3, p. 787-797, 2004

ISHIGE, T. H. K.; SHIMIZU, S. Whole organism biocatalysis. Current Opinion Chemical Biology, v. 9, p. 174-180, 2005.

KONOVALOV, A. A. Selection for allelic variants of alcohol-dehydrogenase in inbred lines and hybrids of sugar-beet. Genética, v. 30, p. 945, 1994.

LACERDA, P. S. B.; RIBEIRO, J. B.; SELMA G. F.; LEITE, S. G. F.; COELHO, R. B.; LIMA, E. L. S.; B, ANTUNES, O. A. C. Microbial enantioselective reduction of ethyl-2-oxo4-phenyl-butanoate. Biochemical Engineering Journal, v. 28, p. 299-302, 2006.

MACHIDA, Y.; NISHI, H.; NAKAMURA, K.; NAKAI, H.; SATO, T. Enantiomer separation of amino compounds by a novel chiral stationary phase derived from crown ether. Journal of Chromatography A, v. 805, p. 85-92, 1998.

MANDAL, D.; AHMAD, A.; KHAN, M.I.; KUMAR, R. J. Enantioselective bioreduction of acetophenone and its analogous by the fungus Trichothecium sp. Journal of Molecular Catalysis B: Enzymatic, v. 27 p. 61-63, 2004. 
MARPLES, B. A. Elementary organic stereochemistry and conformational analysis. London: The Royal Society of Chemistry, 1981. v. 34.

MARSAIOLI, A. J.; PORTO, A. L. M.; GONÇALVES, R. A. C. Apostila de Biocatálise em Química Orgânica. In: WORKSHOP EM BIOCATÁLISE, 1., 2002, São Paulo. Livro de resumos... São Paulo: [s.n.], 2002. p. 6

MATSUDA, T.; HARADA, T.; NAKAJIMA, N.; NAKAMURA, K. Mechanism for improving stereoselectivity for asymmetric reduction using acetone powder of microorganism. Tetrahedron Letters, v. 41, p. 4135-4138, 2000.

METELITZA, I. D.; LITVINCHUK, A. V.; SAVENKOKA, M. I. Peroxidase-catalized cooxidation of halogen-substituted phenols and 4-aminoantipyrine. Jounal of Molecular Catalysis, v. 67, p 401-411, 1991.

MILLAR, A. A.; OLIVER, M. R.; DENNIS, E. S. The expression and anaerobic induction of alcohol-dehydrogenase in cotton. Biochemical Genetics, v. 32, p. 279, 1994.

MITCHELL, W. C.; JELENKOVIC, G. Characterizing nad-dependent and nadp-dependent alcohol-dehydrogenase enzymes of strawberries Journal of the American Society for Horticultural Science, v. 120, p. 798, 1995.

MORITA, T.; ASSUMPÇÃO, R. M. V. Manual de soluções, reagentes \& solventes. 2. ed. São Paulo: Edgar Blücher, 1995. 629p.

MUSA, M. M.; ZIEGELMANN-FJELD, K. I.; VIEILLE, C.; ZEIKUS, G.; PHILLIPS, R. S. Asymmetric reduction and oxidation of aromatic ketones and alcohols using W110A secondary alcohol dehydrogenase from Thermoanaerobacter ethanolicus. Journal Organic Chemistry, v. 72, p. 30-34, 2007.

NASCIMENTO, M. G.; ZANOTO, S. P.; MELEGARI, S. P. Estudos de proteção da célula de Saccharomyces cerevisiae para utilização em reações de redução em meio orgânico.

Química Nova, v. 25, n. 4, p. 456-471, 2002.

NAKAMURA, K.; YAMANAKA, R.; MATSUDA, T.; HARADA, T. Recent developments in asymmetric reduction of ketones with biocatalysts. Tetrahedron: Asymmetry, v. 14, p. 2659-2681, 2003.

NELSON, D. L; COX, M. M. Lehninger: principles of biochemistry. 3.ed. New York: Worth Publishers, 2000. p.1152 
O'DONNELL K. Fusarium and its near relatives. In: REYNOLDS, D.R. AND TAYLOR, J.W. (Eds.). The fungal holomorph: mitotic, meiotic and pleomorphic speciation in fungal systematics. Wallingford: CAB International, 1993. p. 225-233.

PATEL, R. N. Biocatalytic synthesis of chiral intermediates. Food Technology Biotechnology, v. 42, p. 305-325, 2004

PATEL, R. N.; CHU, L.; MUELLER, R. Diastereoselective microbial reduction of (S)-[3chloro-2-oxo-1-(phenylmethyl)propyl]carbamic acid, 1,1-dimethylethyl ester. Tetrahedron: Asymmetry, v. 14, p. 3105-3109, 2003.

PEREIRA, R. S. Projeto e construção de um bioreator para síntese orgânica assimétrica catalisada por Saccharomyces cerevisiae (Fermento Biológico de Padaria). Química Nova, v. 20, n. 5, p. 551-554, 1997.

PILLI, R. A. Catálise assimétrica e o prêmio Nobel de química de 2001. Novos paradigmas e aplicações práticas. Química Nova na Escola, v. 14, p. 16-24, 2001.

PITT, J.I. The genus penicillium and its teleomorphic states eupenicillium and talaromyces. London: Academic Press, 1979. p. 8

RAEDER, U.; BRODA P. Rapid preparation of DNA from filamentous fungi. Letters Applied Microbiology, v. 1, p. 17-20, 1985.

REZENDE, C.M. Vladimir Prelog e a esterequímica das moléculas orgânicas - um centenário de nascimento. Química Nova, v. 30, n. 4, p. 1046-1053, 2007.

ROBERTS, S. M.; TURNER, N. J.; WILLETTS, J.; TURNER, M. K. Introduction to biocatalysis using enzymes and micro-organisms. New York: Cambridge University Press, 1995. p. 20

RODRIGUES, J. A.; MORAN, P. J. S.; CONCEIÇÃO, G. J. A.; FARDELONE, L. C. Recent advances in the biocatalytic asymmetric reduction of acetophenones na $\alpha, \beta$-unsatured carbonyl compounds. Food Technology Biotechnology, v. 42, p. 295-303, 2004.

SALAS, J. J.; SANCHEZ, J. Alcohol dehydrogenases from olive (olea europaea) fruit. Phytochemistry, v. 48, p. 35, 1998. 
SALVI, N. A.; CHATTOPADHYAY, S. Asymmetric reduction of 3-aryl-3-keto esters using Rhizopus species. Bioorganic Medicinal Chemistry Letters, v. 14, p. 4918-4922, 2006.

SAMSON R. A.; HOEKSTRA E. S.; FRISVAD J. C; FILTENBORG, O. Introduction to Food- and Airborne Fungi. 6th ed. Centraalbureau voor Schimmelcultures, Utrecht, 2002.

SETTE, L. D.; PASSARINI, M. R. Z.; DELARMELINA, C.; SALATI, F.; DUARTE, M. C. T. Molecular characterization and antimicrobial activity of endophytic fungi from coffee plants. World Journal Microbiology Biotechnology, v. 22, p. 1185-1195, 2006.

SCARPI, D.; OCCHIATO, E. G.; GUARNA, A. Selectivity of Daucus carota roots and baker_s yeast in the enantioselective reduction of $\gamma$-nitroketones Tetrahedron Asymmetry, v. 16, p. 1479-1483, 2005.

SILVERMAN, R. B. The organic chemistry of enzyme-catalyzed reactions. San Diego: Academic Press, 2000. p.717.

STAMPFER, W.; KOSJEK, B.; MOITZI, C.; KROUTIL, W.; FABER, K. Biocatalytic asymmetric hydrogen transfer. Angewandte Chemie-International Edition, v. 41, p. 10141017, 2002.

STRAATHOF, A. J. J.; PANKE, S.; SCHIMID, A. The Production of Fine Chemical by Biotransformation. Current Opinion in Biotechnology, v. 13, p. 548-556, 2002.

SMITH, P.T.; COBB, B.G. Physiological and enzymatic activity of pepper seeds (Capsicum annuum) during priming. Physiologia Plantarum, v. 82, p. 433, 1991.

TANG, S. L.; CHANG, H. H. Studies on the flooding tolerance during seed-germination of soybean (Glycine-max (L.) Merrill). II. Relationship between ADH activity, ethanol accumulation and flooding tolerance. Journal of the Agricultural Association of China, v. 22 p.150, 1990.

TORRES, A. M. Genetics of sunflower seed alcohol-dehydrogenase. Genetics, v. 77, p. 65, 1974.

VERLI, H.; BARREIRO, E. Um paradigma da química medicinal: a flexibolidade dos ligantes e recepetores. Química Nova, v. 28, n. 1, p. 95-102, 2005. 
WEI, Z.L.;LI, Z. Y.; LIN, G. Q. anti-Prelog Microbial reduction of aryl $\alpha$-halomethyl Or $\alpha$-hydroxymethyl ketones with Geotrichum sp. 38. Tetrahedron, v. 54, p. 13059-13072, 1998.

WILBERG, K. Q. Oxidação de compostos fenólicos em solução aquosa com enzima peroxidase de extratos vegetais. 2003. 156f. Tese (Doutorado - Engenharia de Minas, Metalurgicae de Materiais) - Universidade do Rio Grande do Sul, Rio Grande do Sul, 2003.

XIE, Q.; WU, J.; XU, G.; YANG, L. Asymmetric Reduction of $o$-chloroacetophenone with Candida pseudotropicalis . Biotechnology Progress, v. 22, n. 5, p. 1301-1304, 2006.

XU, Y. A.; A DOCHERTY, G. F.; WOODWARDC, G.; WILLSA, M. Ru(II) complexes of cyclohexane diamine and monodentate phosphorus ligands for asymmetric ketone hydrogenation. Tetrahedron: Asymmetry, v. 17, p. 2925-2929, 2006.

YADAV, J. S.; NANDA, S.; REDDY, P. T.; RAO, A. B. Efficient enantioselective reduction of ketones with Daucus carota root. Journal Organic Chemistry, v. 67, p. 3900-3903, 2002.

YANG, W.; XU, J.-H.; XIE, Y.; XU, Y.; ZHAO, G.; LIN, G.-Q. Asymmetric reduction of ketones by employing Rhodotorula sp. AS2.2241 and synthesis of the $\beta$-blocker $(R)$-nifenalol. Tetrahedron: Asymmetry, v. 17, p. 1769-1774, 2006.

ZARSKY, V.; CHOMATOVA, S.; TUPY, J. Alcohol-dehydrogenase isoenzymes from nicotiana-tabacum include adh of both nicotiana-sylvestris and n-tomentosiformis. Biologia Plantarum, v. 36, p. 53, 1994.

ZHANG, J., ROBERGE, C., REDDY, J. CONNORS, N., CHARTRAIN, M., BUCKLAND, B., GREASHAM, R. Bioconversion of the indene to trans- $2 S, 1 S$-bromoindanol and $1 S, R$ indene by a bromoperoxidase/dehydrogenase preparation from Curvularia protuberate MF5400. Enzyme Microbiol Technology, v. 24, p. 86-95, 1999. 


\section{Apêndice}

\section{Detecção de peroxidase em vegetais e fungos}

Outra área em biocatálise que ainda requer avanços é a aplicação de peroxidases em reações de biocatálise.

Existe uma grande variedade de plantas (frutas e vegetais), que são de baixo custo e facilmente encontrados em todo o território nacional. Essas frutas e vegetais são fontes inesgotáveis de enzimas que podem ser utilizadas in natura ou como extrato bruto, obtido por procedimentos simples de extração. Schönbein em 1855, usando extratos de plantas com peróxido de hidrogênio e guaiacol observou que um composto de coloração intensa era formado. Linossier em 1898 isolou esta enzima e chamou-a de peroxidase (CAMPA, 1991).

A peroxidase (POD; EC 1.11.1.7) constitui uma classe de enzimas que está extensamente distribuída nos reinos animal e vegetal e pode ser facilmente extraída das células de alguns vegetais. Diversas são as fontes vegetais de peroxidase, como pêssego (Prunus persica), inhame (Alocasia macrorhiza), mandioca (Manihot utilissima), alcachofra (Cynara scolymus L.), batata doce (Ipomoea batatas (L.) Lam.), nabo (Brassica campestre ssp. rapifera), rabanete (Armoracia rusticana), abobrinha (Cucurbita pepo). Existe um grande interesse por esta enzima, devido as suas múltiplas aplicações como, por exemplo, em reações de biocatálise, na indústria de papel e celulose, de alimentos, em análises bioquímicas, entre outras (FILHO E VIEIRA, 2002).

As peroxidases catalisam a oxidação de alguns substratos pela ação do peróxido de hidrogênio. É conhecida como uma enzima termoestável que pode ter sua atividade regenerada após tratamento térmico. Comercialmente, as peroxidases vêm sendo amplamente utilizadas como um importante componente em processos biotecnológicos. Na indústria de 
papel e celulose é empregada na etapa de branqueamento da polpa e de seus efluentes. $\mathrm{Na}$ indústria têxtil é utilizada para melhorar o branqueamento em detergentes de lavanderias e inibir a transferência de cor durante a lavagem. Na oxidação de compostos fenólicos sem efluente de refinaria de petróleo apresentou uma eficiência de oxidação de pelo menos 95\% dos compostos (WIBERG, 2003).

Assim, neste trabalho realizaram-se alguns ensaios colorimétricos com vegetais [Malus domestica (maçã), Pyrus communis (pêra), Solanum tuberosum (batata), Arracacia xanthorrhiza (mandioquinha) e Daucus carot (cenoura)], microrganismos (Penicillium miczynskii Gc5, Trichoderma sp Gc1 e Caldariomyces fumago) e com a peroxidase comercial (E.C. 1.11.1.7).

\section{Procedimentos experimentais}

\section{Vegetais}

Primeiramente a triagem foi realizada com os vegetais que são produtores típicos de peroxidases, de acordo com o procedimento abaixo (METELITZA et al., 1991).

- Pesou-se $5 \mathrm{~g}$ do vegetal a ser analisado (sem casca). Em seguida, transferiu-se este material para um almofariz e adicionou-se $10 \mathrm{~mL}$ de tampão fosfato $\left(\mathrm{Na}_{2} \mathrm{HPO}_{4}, \mathrm{~K}_{2} \mathrm{PO}_{4}\right.$, $\mathrm{pH}=7 ; 0,1 \mathrm{M})$ e macerou-se a mistura com um pistilo.

- Após maceração, transferiu-se essa mistura para um béquer e deixou-se em repouso e em contato com o ar por 10 minutos. Decorridos este tempo, transferiu-se esta mistura para um tubo de centrífuga e centrifugou-se a $6.000 \mathrm{rpm}$ por 6 minutos.

- Coletou-se o sobrenadante e transferiu-se $5 \mathrm{~mL}$ para um tubo de ensaio e adicionou-se $2 \mathrm{~mL}$ de 2,4-dicloro-fenol (25 mM), $2 \mathrm{~mL}$ de peróxido de hidrogênio $(100 \mathrm{mM})$ e $2 \mathrm{~mL}$ de 4-aminoantipirina $(0,5 \mathrm{mM})$. Os ensaios foram fotografados antes e após a adição 
dos reagentes, sendo no final uma alíquota retirada de cada tubo e analisada por espectroscopia no Uv-vis.

Um resultado positivo para este teste é a formação de uma cor vermelha intensa da solução, indicando que houve a reação entre o 2,4-diclorofenol e a 4-aminoantipirina (Esquema 1). Esta mudança de cor é também caracterizada pelo surgimento de uma banda em $505 \mathrm{~nm}$ no espectro de Uv-vis (METELITZA et al., 1991).

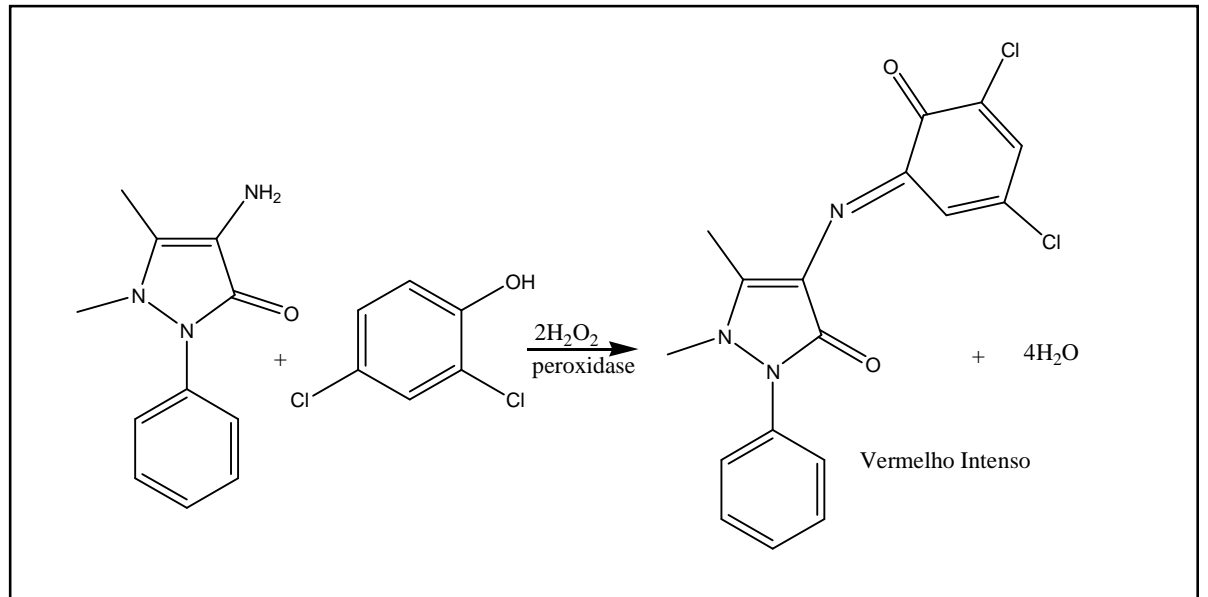

Esquema 1. Reação que ocorre quando o teste para peroxidase é positivo.

\section{Fungos}

Foram realizados dois procedimentos para a determinação de peroxidases em fungos. No primeiro ensaio utilizou-se o fungo direto da placa de Petri em que foi cultivado. $\mathrm{O}$ segundo ensaio utiizou o fungo cultivado em um meio de cultura líquido.

a) Procedimento para o ensaio com o fungo cultivado nas placas: Pesou-se $1 \mathrm{~g}$ de micélios dos fungos Trichoderma sp Gc1, Penicillium miczynskii Gc5 e Caldariomyces fumago cultivados em meio de cultura sólido e transferiu-se para um erlenmeyer contendo 10 $\mathrm{mL}$ de tampão fosfato, $2 \mathrm{~mL}$ de peróxido de hidrogênio (100 mM), $2 \mathrm{~mL}$ de 2,4-diclorofenol (25 mM) e $2 \mathrm{~mL}$ de 4-aminoantipirina $(0,5 \mathrm{mM})$.

Essa mistura foi mantida sob agitação durante $1 \mathrm{~h}$, decorrido este tempo, toda solução foi transferida para um tubo de centrífuga e posteriormente centrifugou-se a $6.000 \mathrm{rpm}$ por 6 
minutos. O sobrenadante foi transferido para um tubo de ensaio e deixou-se em repouso durante $24 \mathrm{~h}$.

b) Procedimento para o ensaio com o fungo cultivado em meio líquido: Pesou-se $1 \mathrm{~g}$ de micélios dos fungos Trichoderma sp Gc1, Penicillium miczynskii Gc5 e Caldariomyces fumago previamente cultivados em meio de cultura líquido (5 dias) e transferiu-se $1 \mathrm{~g}$ de micélios para um tudo de ensaio contendo $5 \mathrm{~mL}$ de tampão fosfato, $2 \mathrm{~mL}$ de peróxido de hidrogênio (100 mM), $2 \mathrm{~mL}$ de 2,4-diclorofenol $(25 \mathrm{mM})$ e $2 \mathrm{~mL}$ de 4-aminoantipirina $(0,5$ $\mathrm{mM})$.

Essa mistura foi macerada com um bastão de vidro e deixou-se em repouso durante 24 h.

\section{Enzima EC 1.11.1.7}

Um ensaio colorimétrico também foi realizado com a peroxidase comercial (EC 1.11.1.7) para verificar a viabilidade do ensaio colorimétrico. Em um tubo de ensaio adicionou-se $2 \mathrm{~mL}$ de peróxido de hidrogênio (100 mM), $2 \mathrm{~mL}$ de 2,4-diclorofenol (25 mM), $2 \mathrm{~mL}$ de 4-aminoantipirina $(0,5 \mathrm{mM})$ e $20 \mu \mathrm{L}$ de uma solução da enzima $(0,5 \mathrm{mM})$.

\section{Resultados e discussões}

O principal objetivo da triagem colorimétrica foi obter um procedimento que pudesse ser utilizado para qualquer microrganismo, de forma a determinar a pré-disposição deste em promover reações de biocatálise a partir de peroxidases, como por exemplo, as reações de halogenação a partir de haloperoxidases, uma vez que essas enzimas catalisam essas reações.

Primeiramente o teste foi realizado com vegetais, pois é conhecido que estes contêm peroxidases, como Malus domestica (maçã), Pyrus communis (pêra), Solanum tuberosum 
(batata), Arracacia xanthorrhiza (mandioquinha) e Daucus carota (cenoura). Se o ensaio for positivo observa-se uma banda característica em $505 \mathrm{~nm}$ (METELITZA et al., 1991) bem como presença de uma coloração vermelha intensa na solução após a adição dos reagentes.

Realizaram-se também ensaios do tipo "brancos" para verificar a presença ou ausência de interferentes. $\mathrm{O}$ primeiro branco foi feito com a adição de todos os reagentes, mas sem a presença do biocatalisador vegetal. A (Figura 1) ilustra que não houve mudança de cor na solução e a (Figura 2) mostra o espectro de UV-vis para este ensaio.

É possível observar nas (Figuras 1 e 2) que o branco não apresentou banda em 505 nm e nem alteração em sua coloração, portanto não houve interferentes no ensaio.

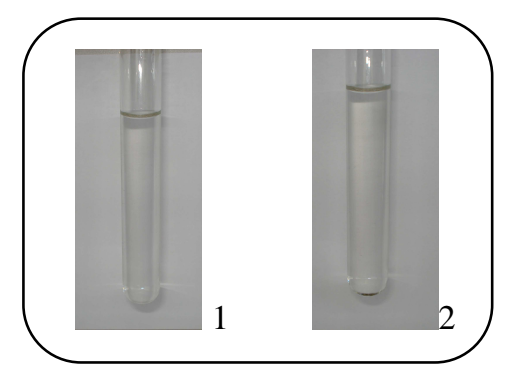

Figura 1. A coloração antes da adição dos reagentes. 2: A coloração após a adição dos reagentes.

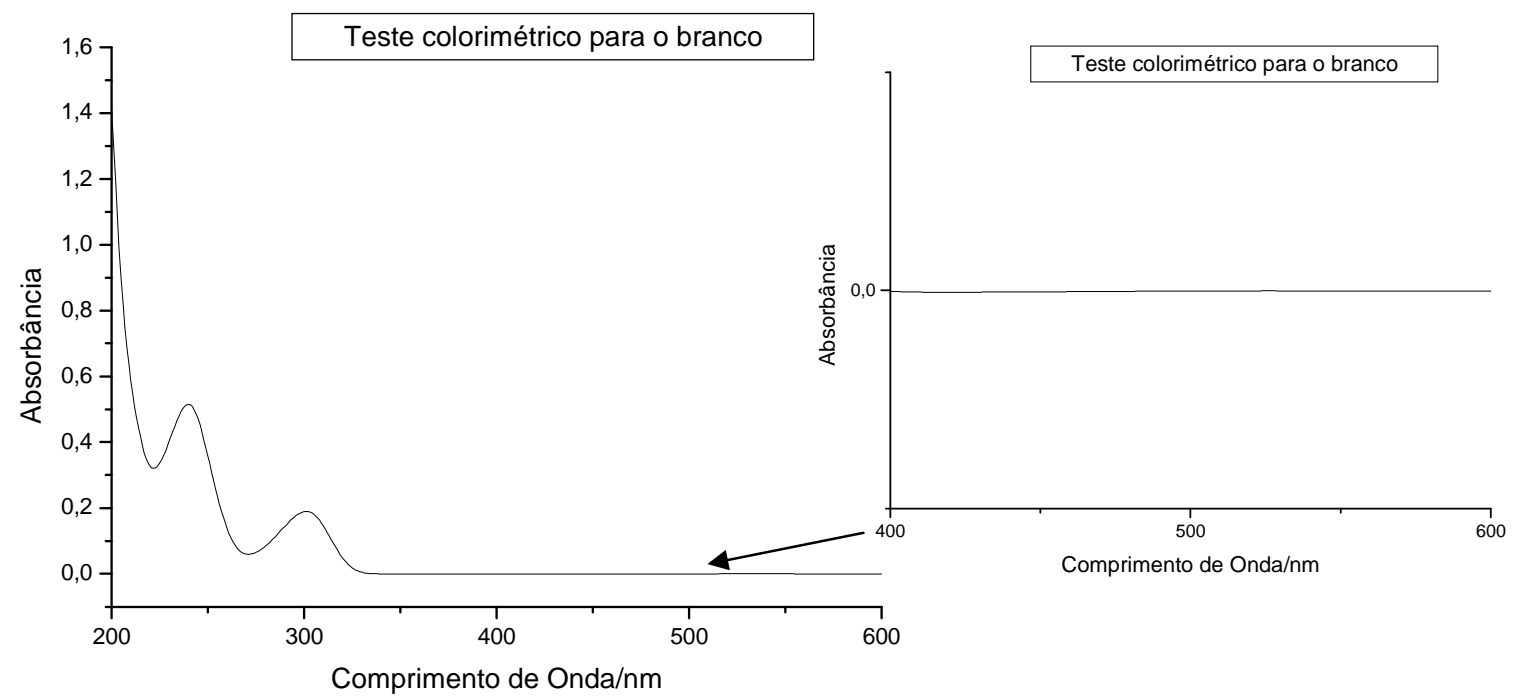

Figura 2. Espectro de Uv-vis para o teste do branco (ausência de absorção em $\lambda 505 \mathrm{~nm}$ ). 
Em sequiência foram realizados ensaios para determinar se o peróxido de hidrogênio utilizado no teste era produzido pelo próprio biocatalisador vegetal. Para isso, foram feitos testes colorimétricos com os biocatalisadores sem adição de peróxido de hidrogênio para se observar mudança ou não de coloração no ensaio. Em todos os casos os resultados foram negativos, evidenciando que não há interferentes.

Com a validação dos brancos, realizou-se os ensaios com biocatalisadores vegetais e com os microrganismos. Nas (Figura 3 e 4) encontram-se respectivamente as fotos do teste e o espectro de Uv-vis do ensaio.

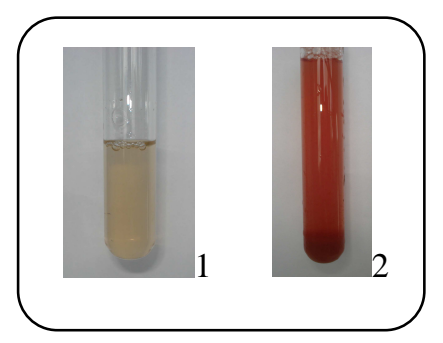

Figura 3. Teste colorimétrico para Solanum tuberosum (batata). 1: Caldo enzimático antes da adição dos reagentes e 2: Caldo após adição dos reagentes.

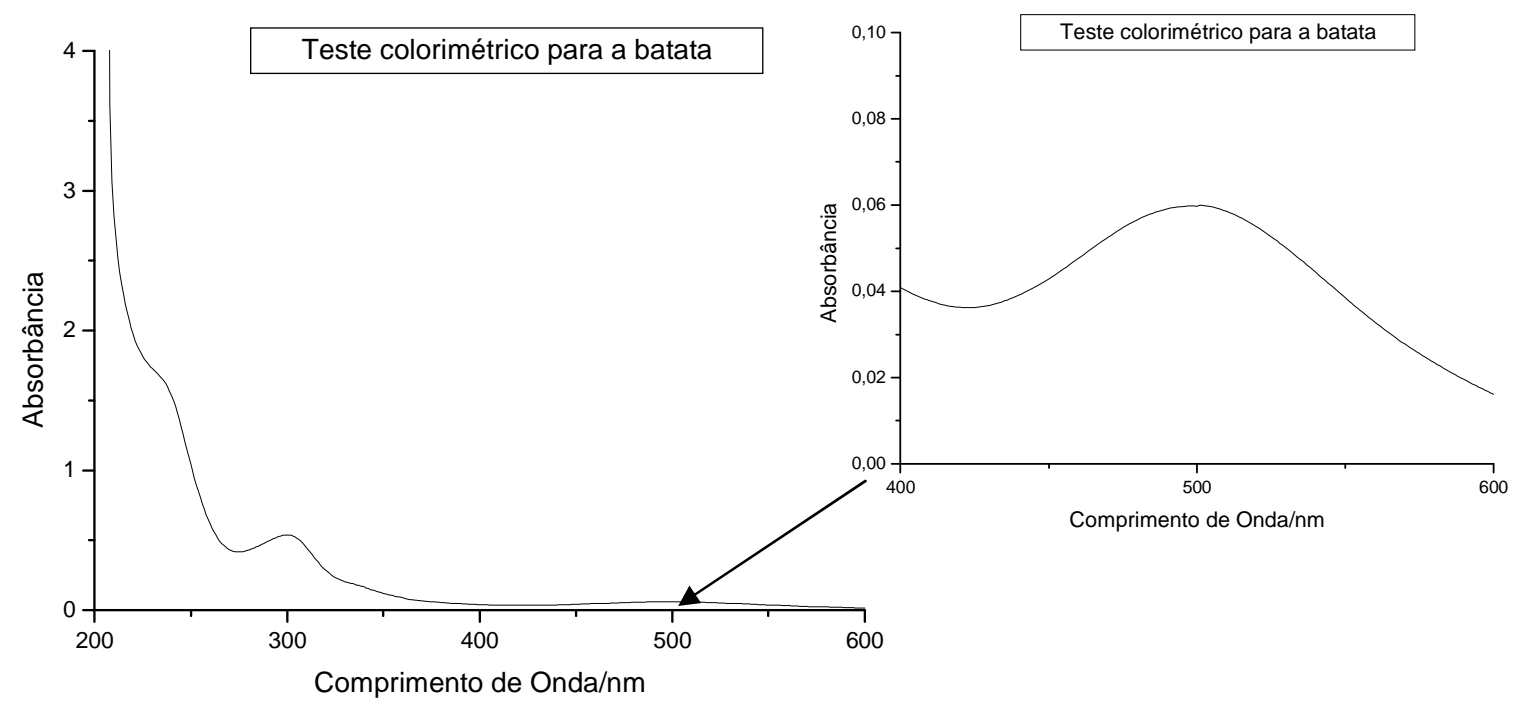

Figura 4. Espectro de Uv-vis para o resultado do teste colorimétrico da Solanum tuberosum (batata). 
$\mathrm{Na}$ (Figura 3) observa-se claramente a mudança de coloração da solução, de uma coloração creme opaca passou para um vermelho intenso. A confirmação vem da (Figura 4) que representa o aparecimento da banda em $505 \mathrm{~nm}$, caracterizando um resultado positivo para o teste. Resultados semelhantes foram obtidos para outros biocatalisadores vegetais.

Conclui-se que com estes resultados, o teste se mostrou eficiente para detecção de peroxidases em biocatalisadores vegetais. Em sequiência foram feitos os testes com os fungos.

O ensaio com o branco para os microrganismos foi negativo como esperado. Os ensaios com os fungos cultivados tanto em placas de Petri quanto em meio de cultura produziram uma coloração da solução. Entretanto a cor observada foi bastante discreta em relação aos ensaios com os vegetais, pois se obteve um tom vermelho claro. O motivo pelo qual o teste foi discreto não permite afirmar se o fungo produz peroxidases em quantidades apreciáveis. Os ensaios colorimétricos assim que otimizados, tornam-se muito úteis, pois sem dúvida, são valiosos para realizar reações biocatalíticas quando se tem um grande número de microrganismos para serem avaliados. 
Anexos 
Espectros de infravermelho

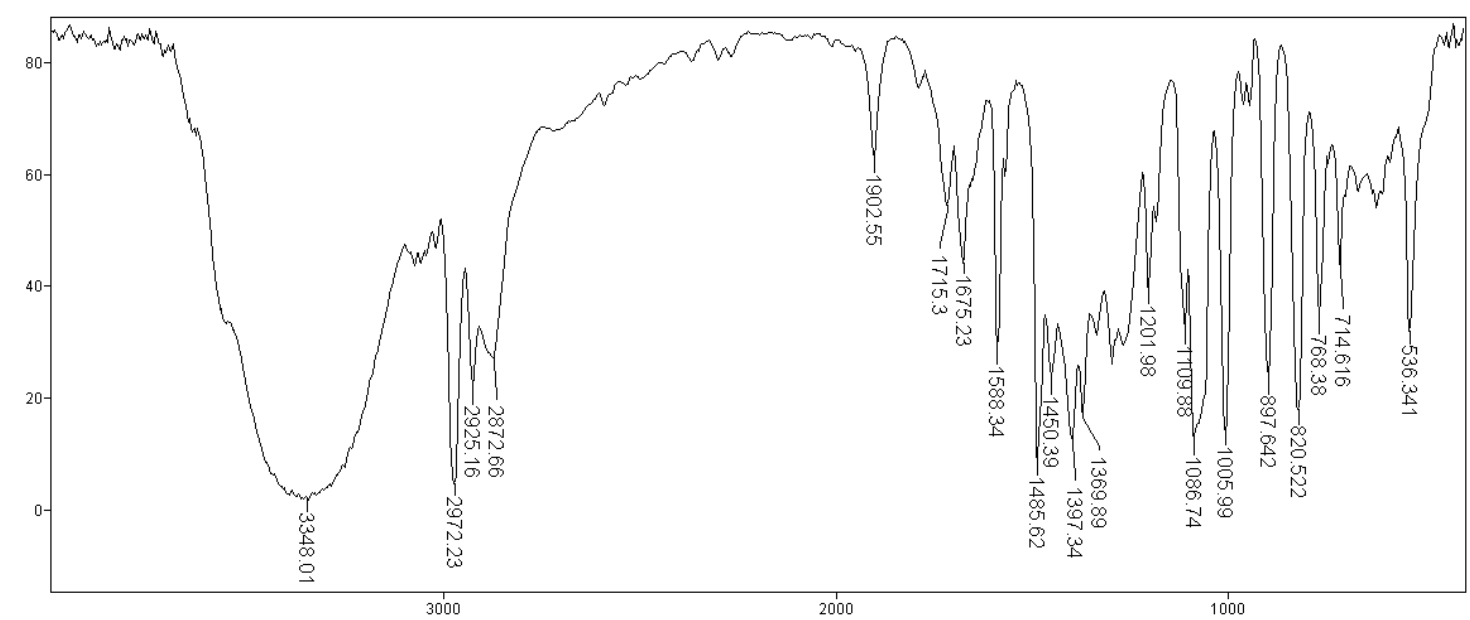

1-(4-iodofenil)etanol

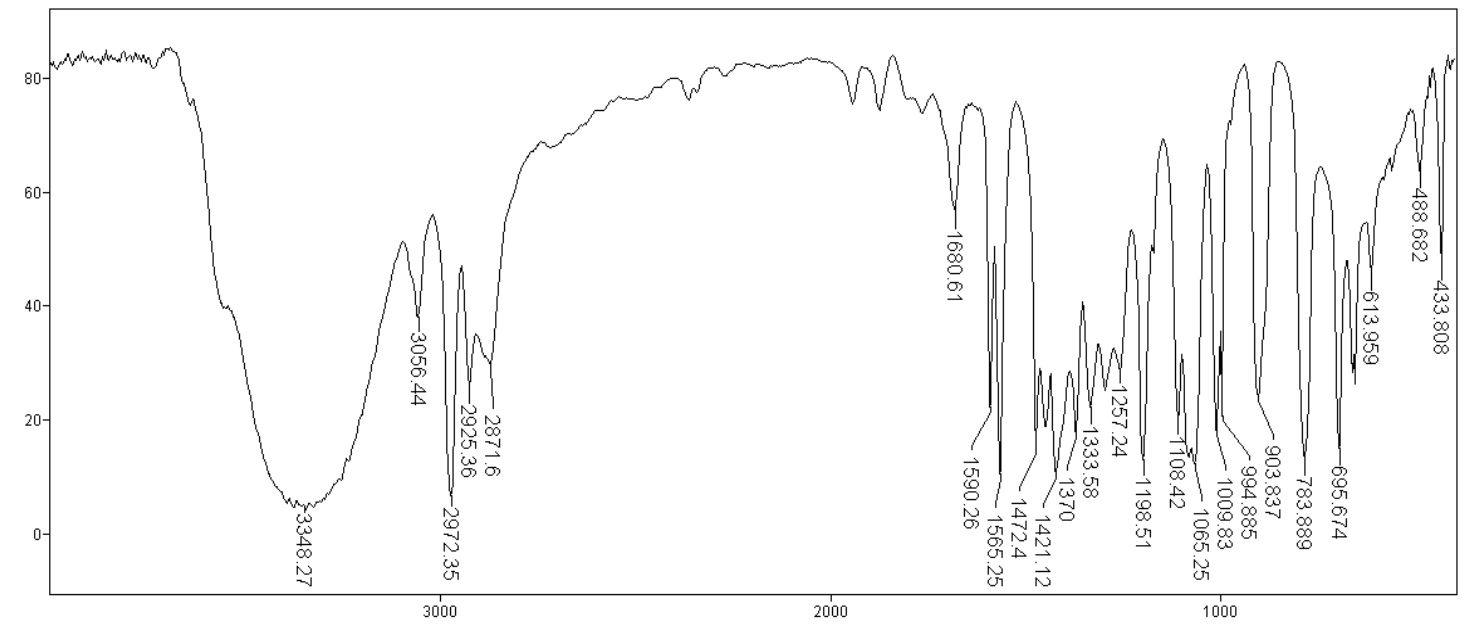

venumber (cm-1)

1-(3-iodofenil)etanol 


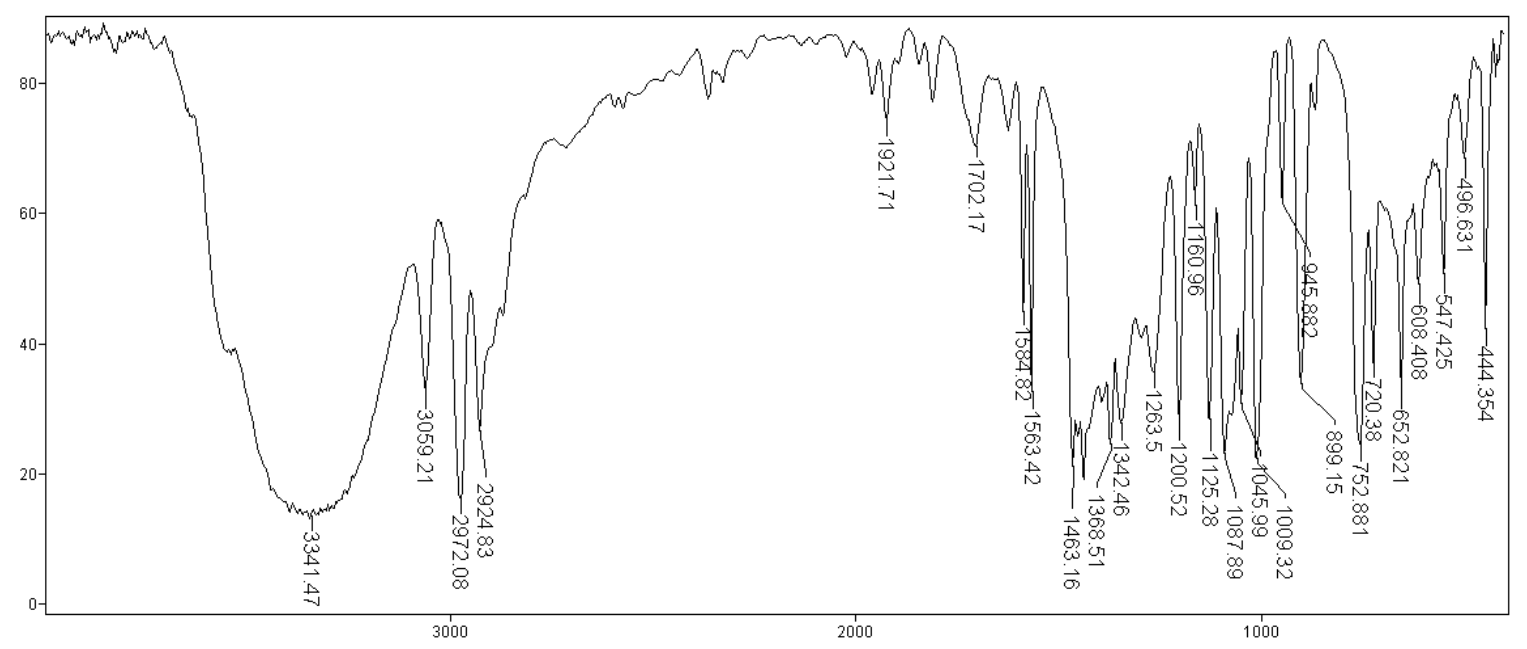

1-(2-iodofenil)etanol

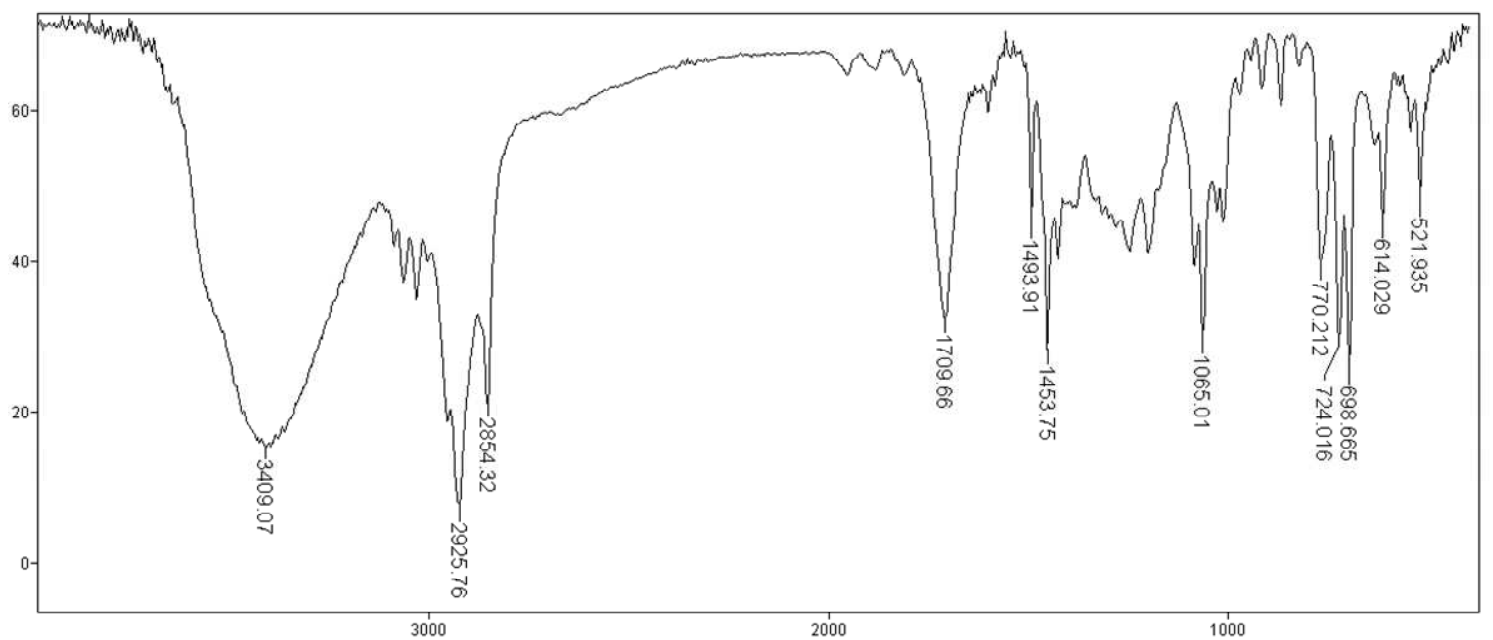

2-cloro-1-feniletanol 


\section{Espectros de Ressonância}

Espectro da mistura do 2-(4-bromofenil)oxirano e 2-bromo-1-(4-bromofenil)etanol Código. lej 17.002

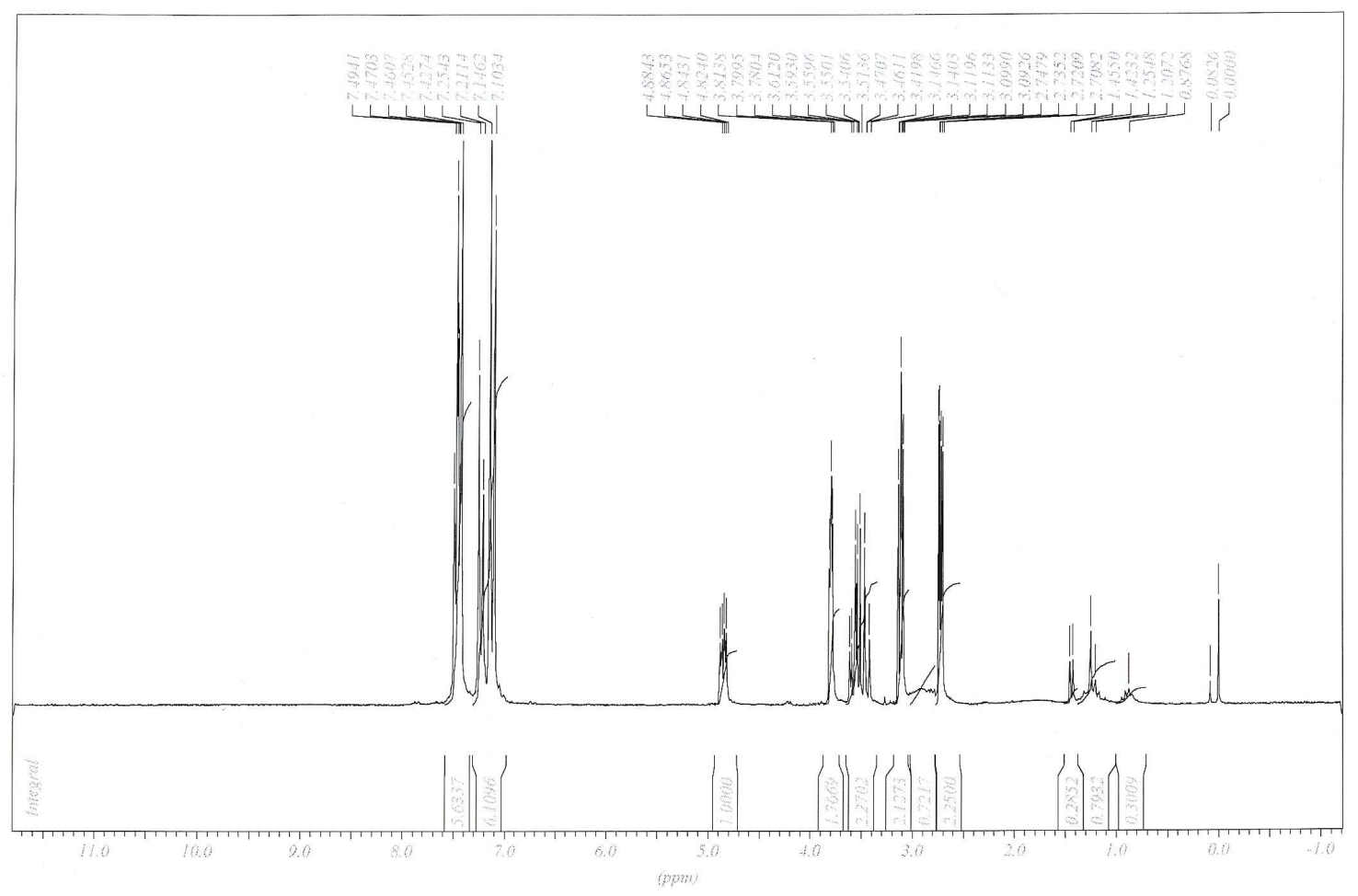

Espectro da mistura do epóxido estireno (2b) e 2-bromo-1-feniletanol (2a) Código. leag 07.001

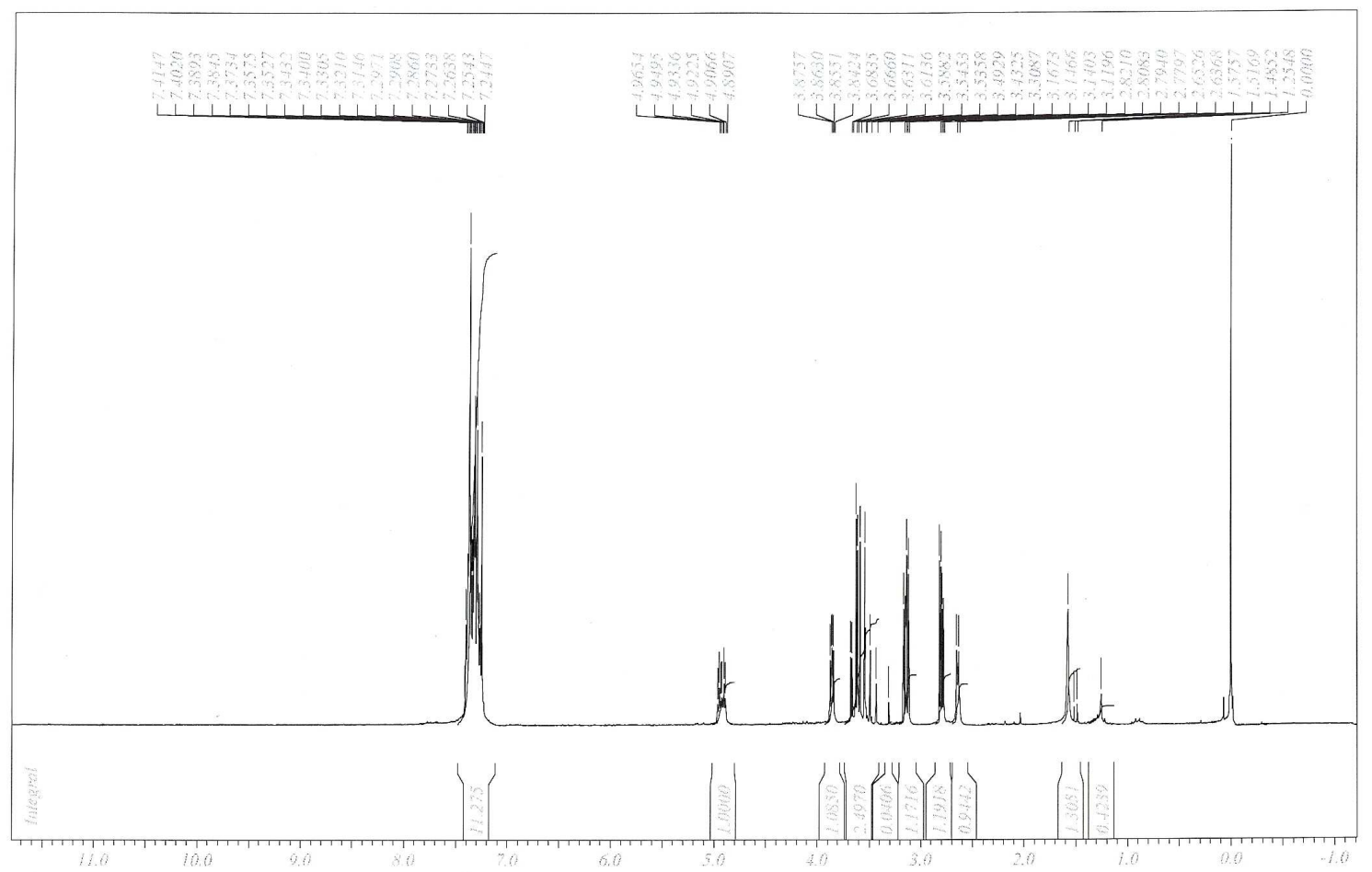




\section{1(2-iodofenil)etanol}

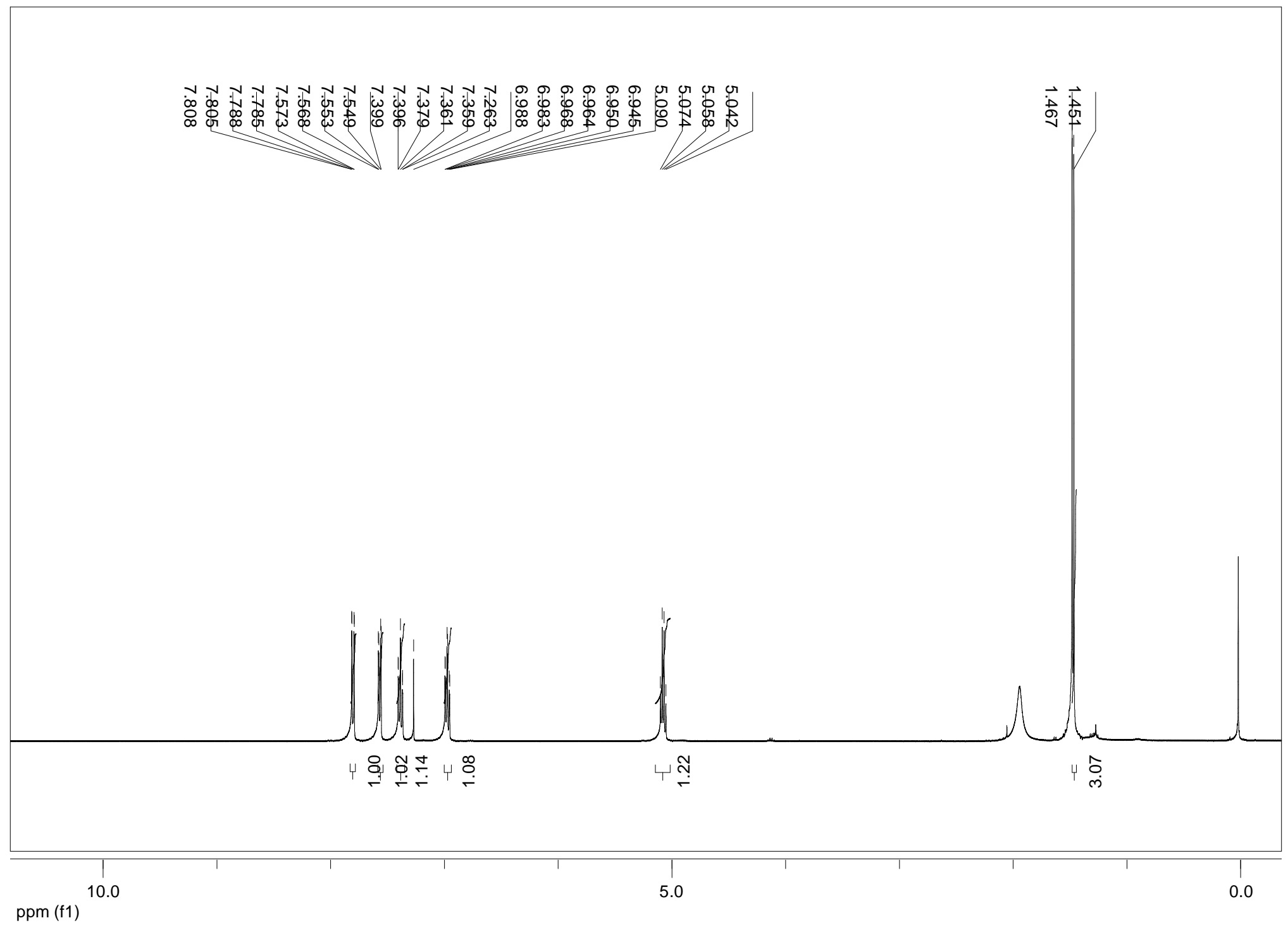



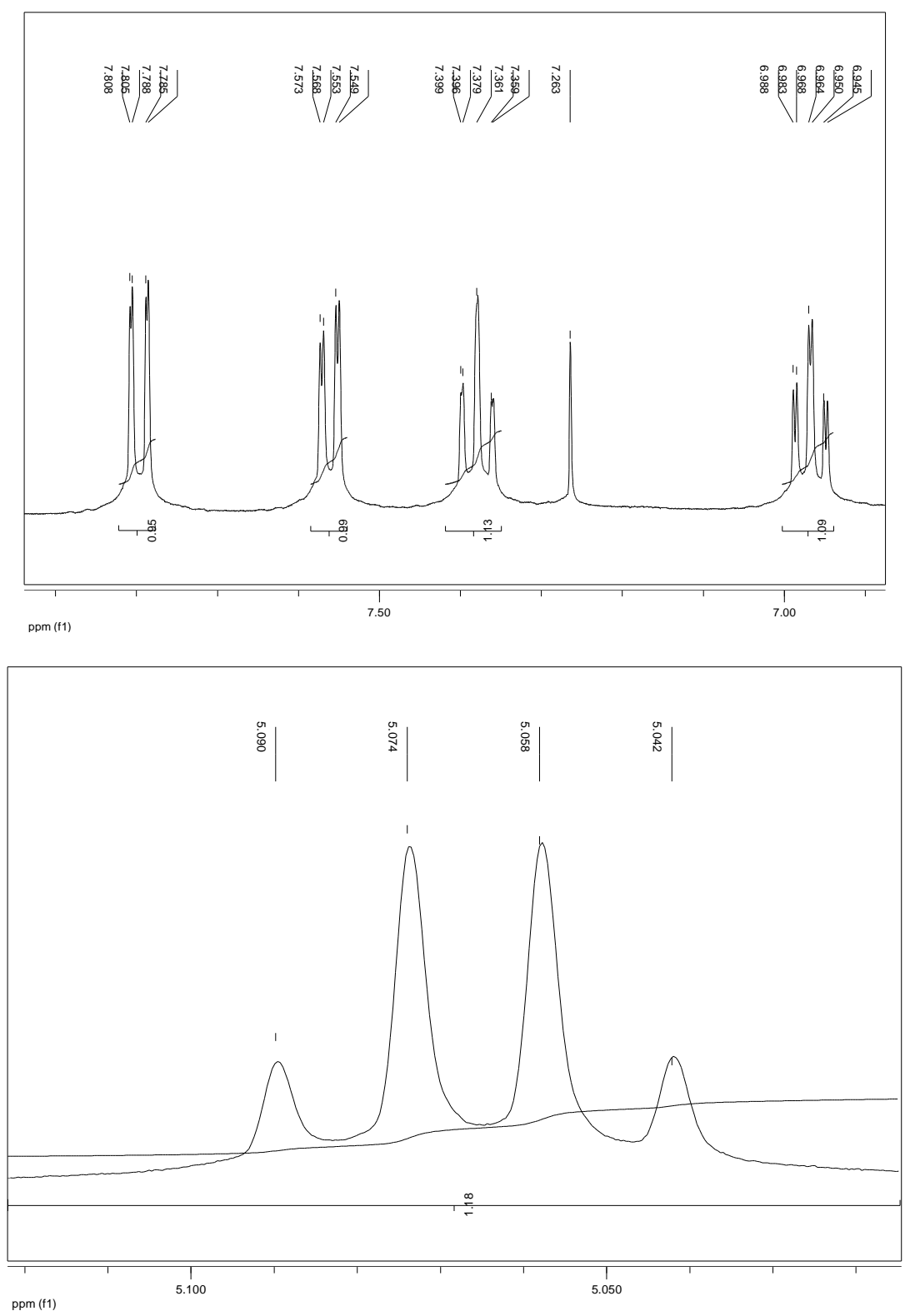


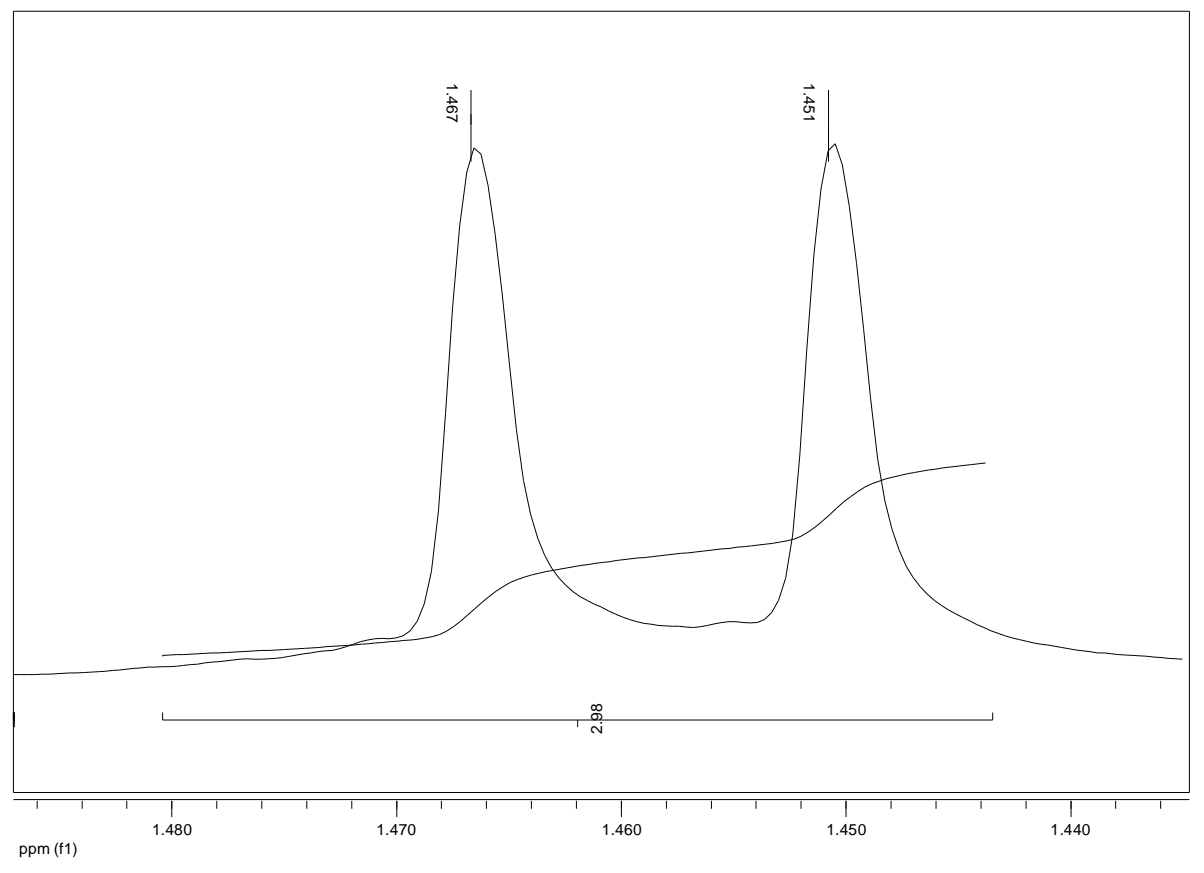


1(3-iodofenil)etanol

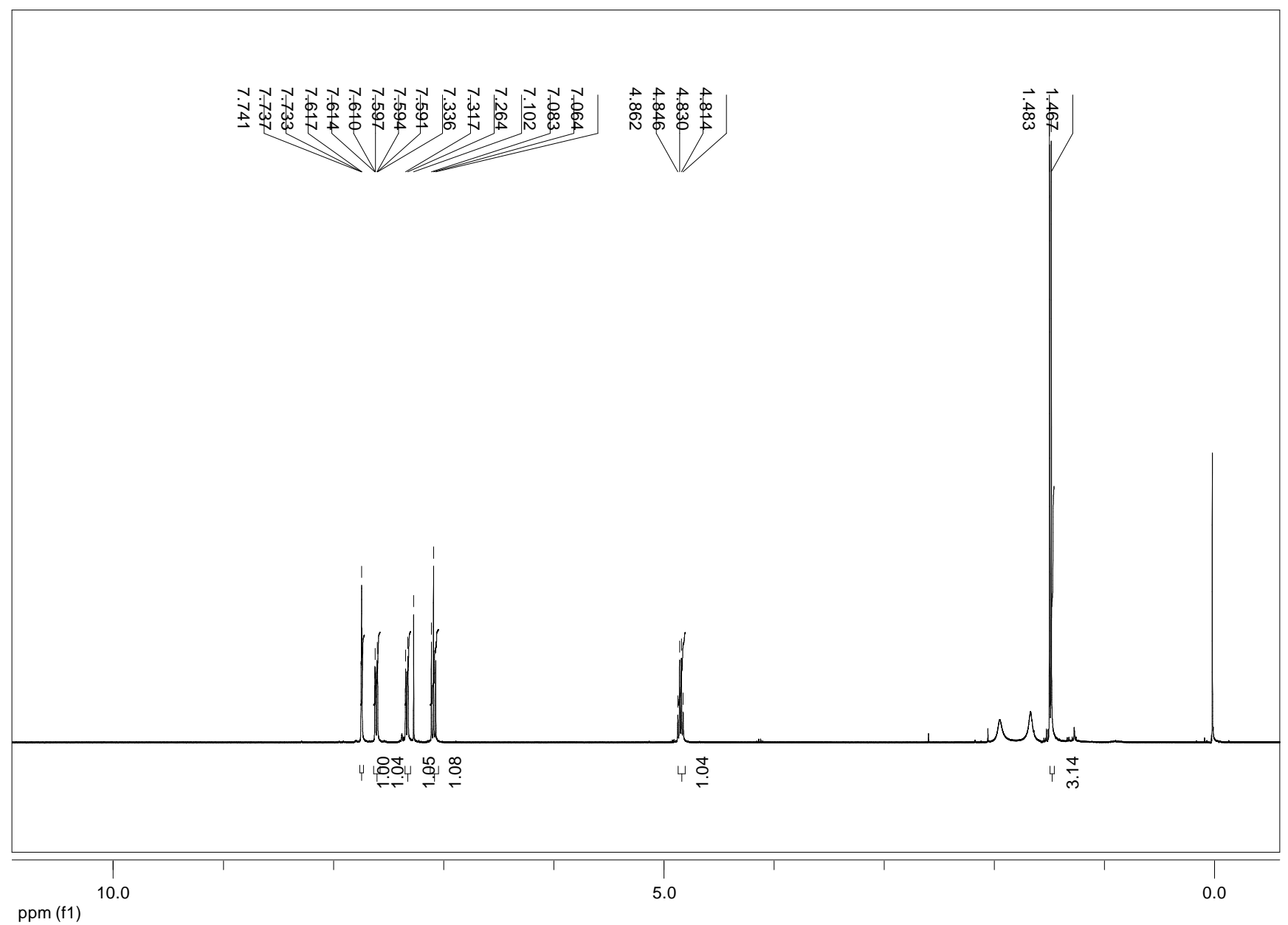



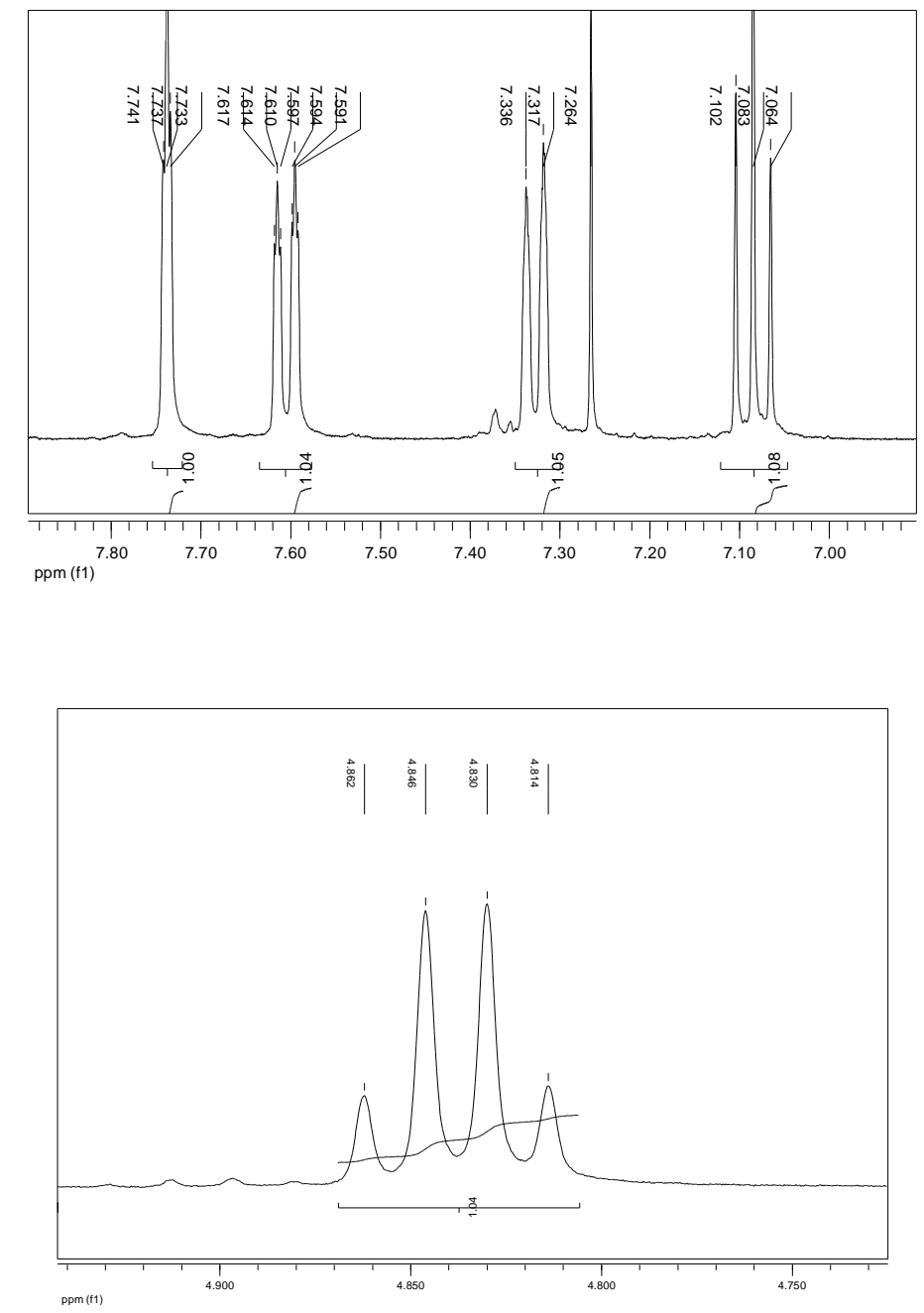


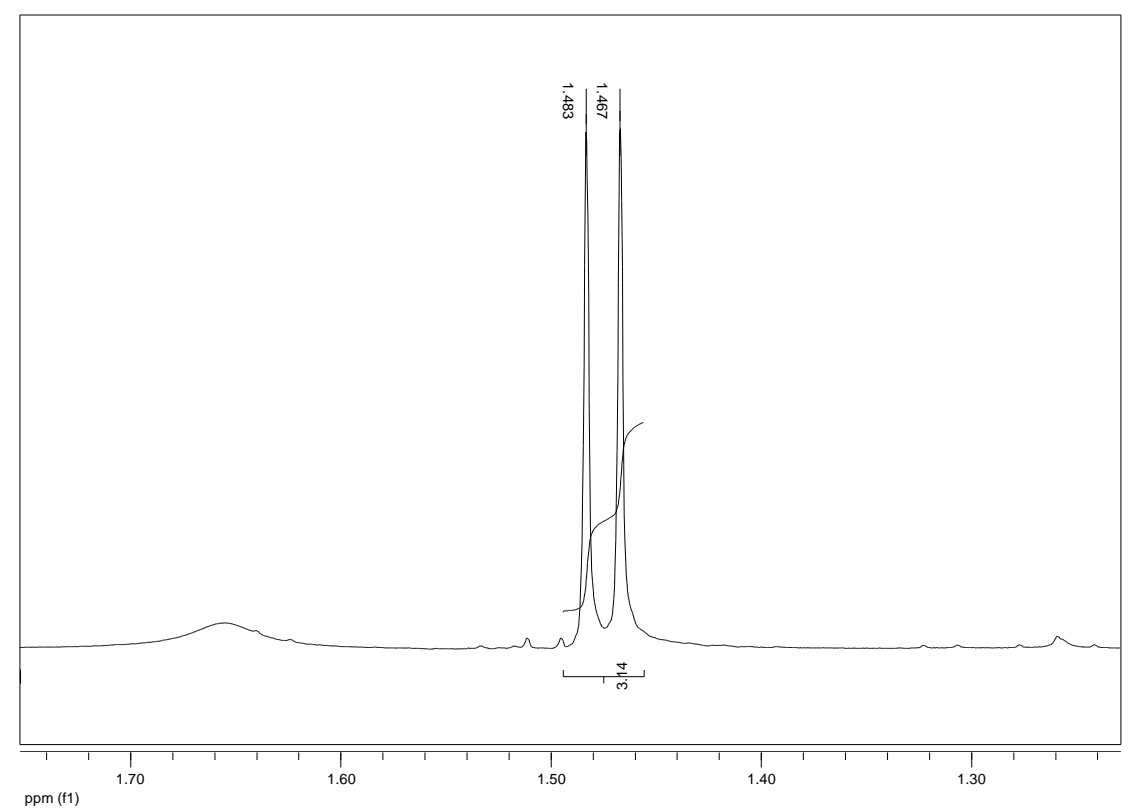


1(4-iodofenil)etanol

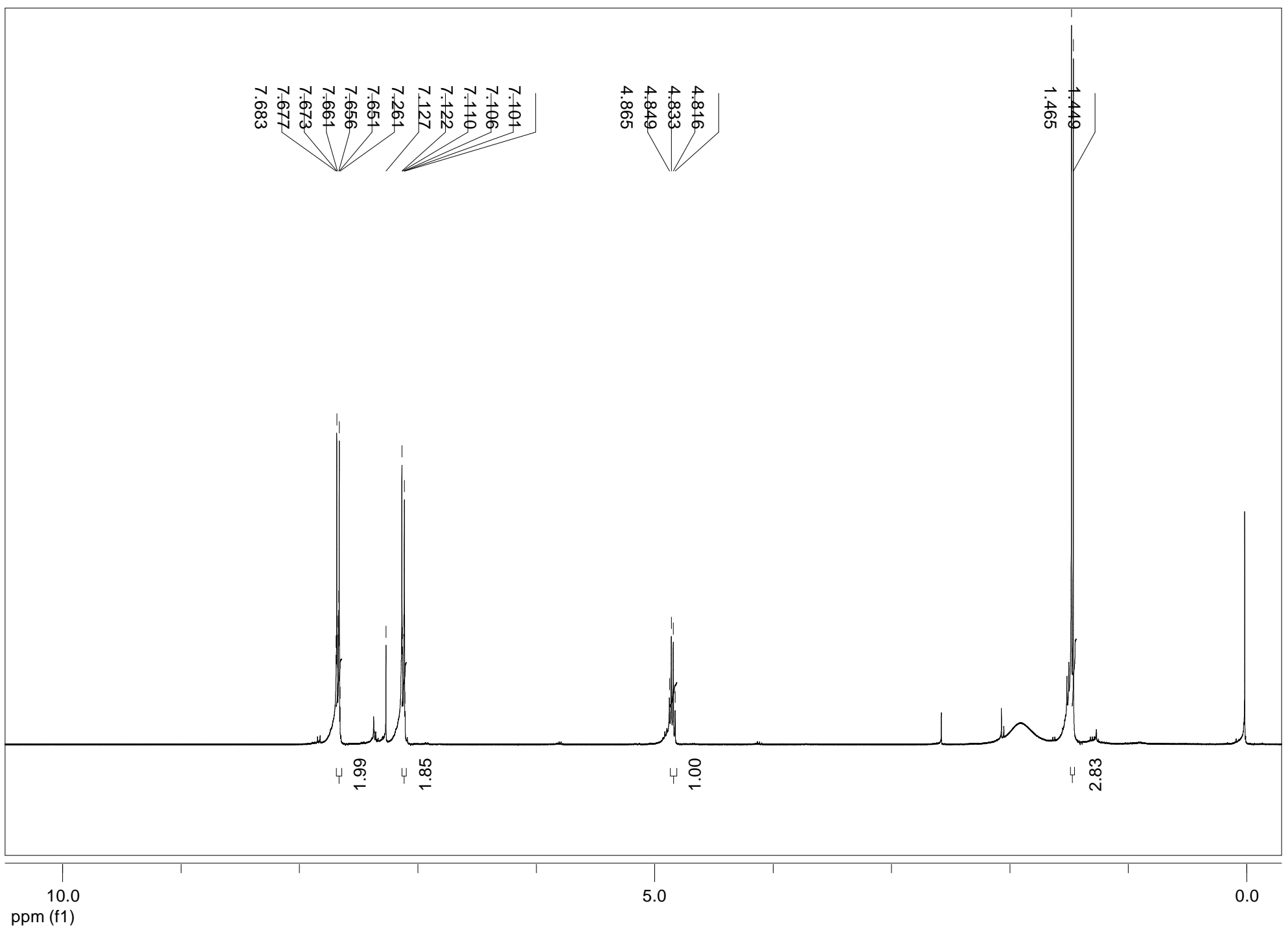



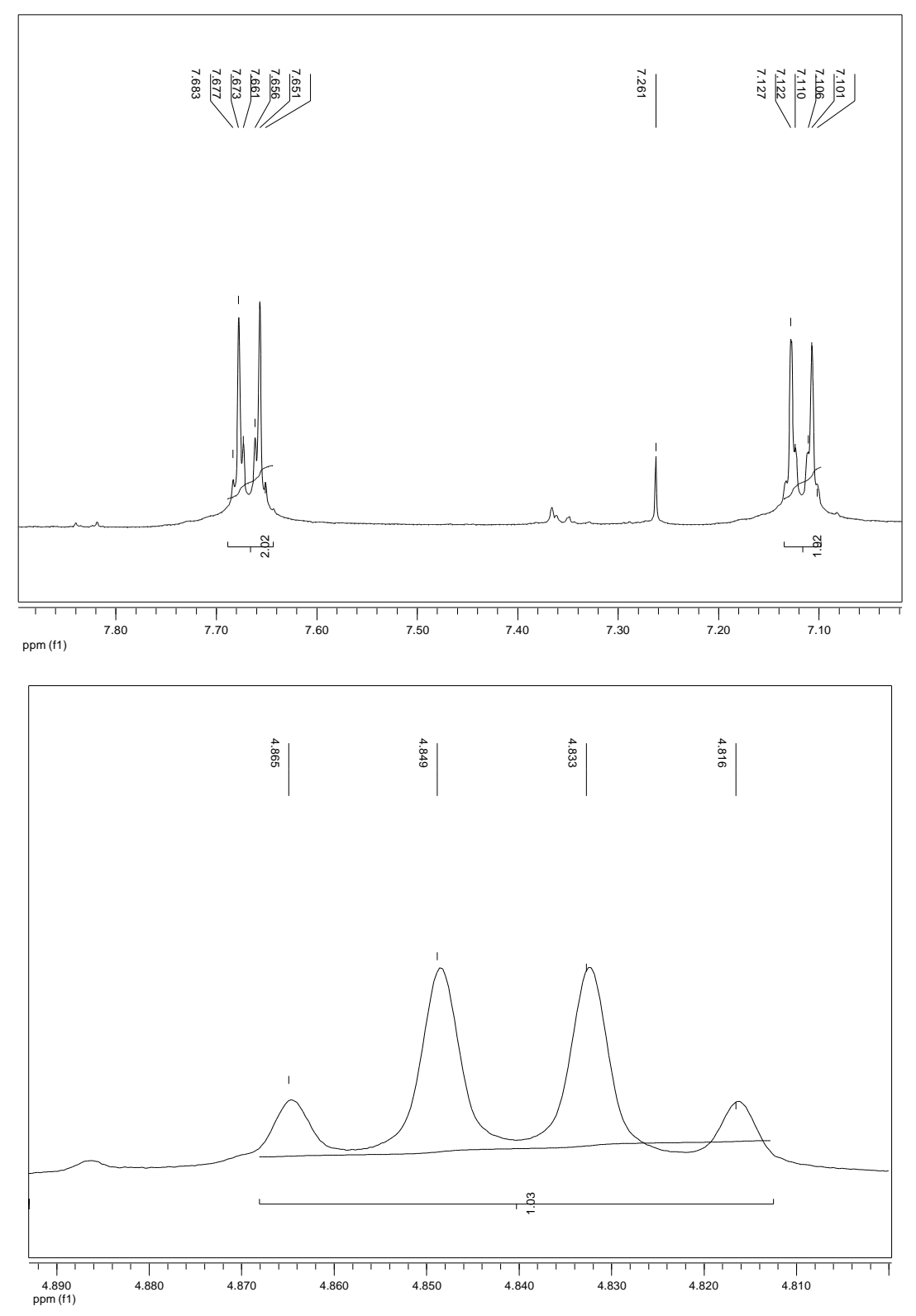


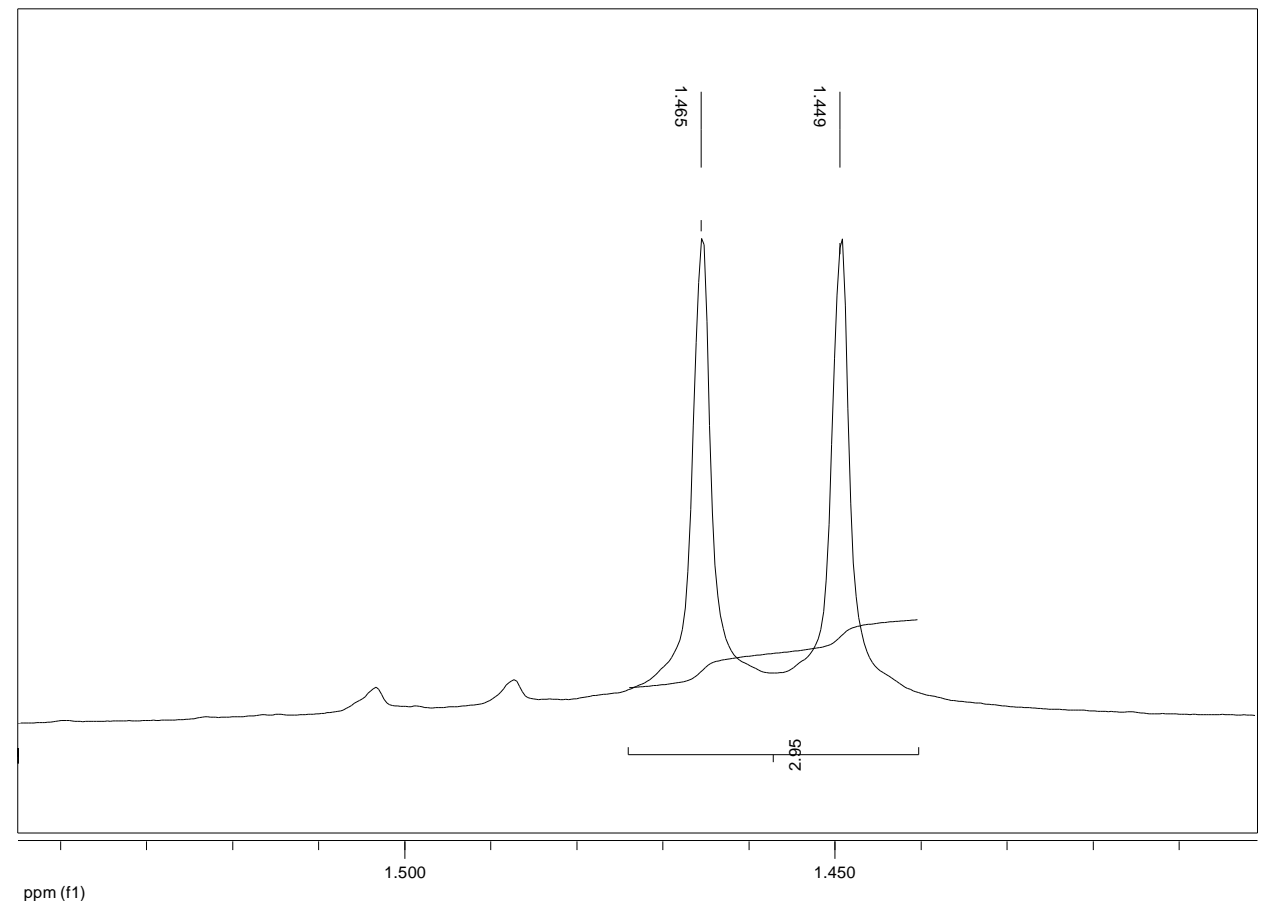


2-cloro-1-feniletanol

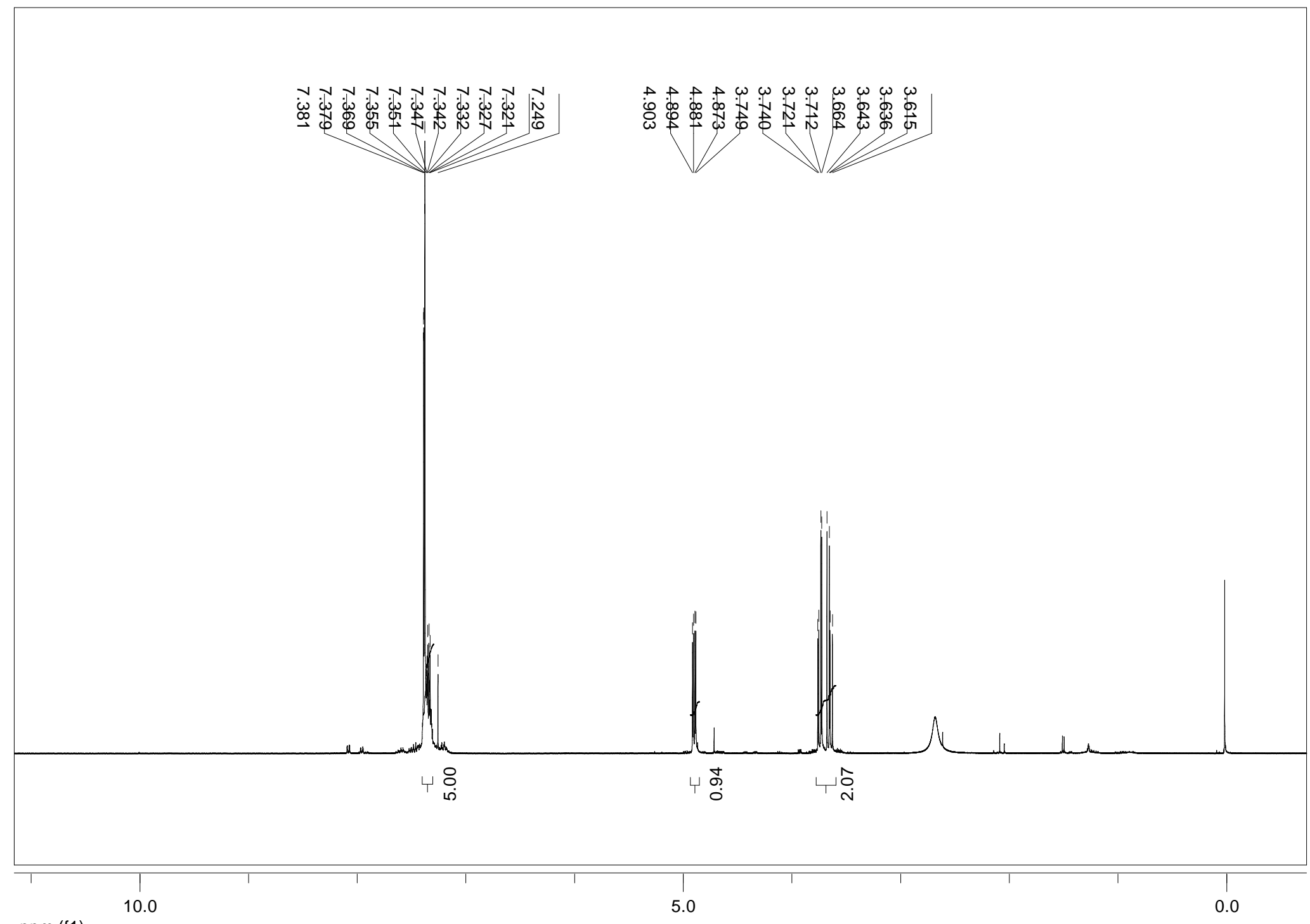

ppm (f1) 


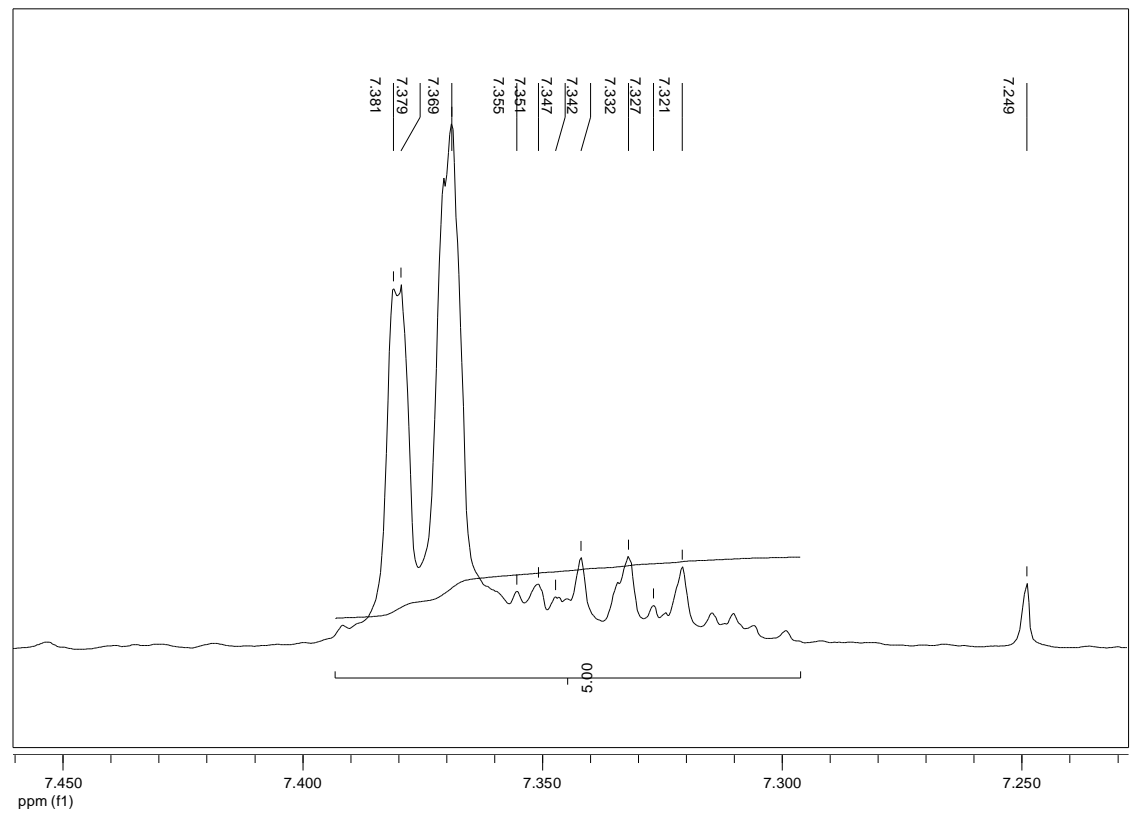




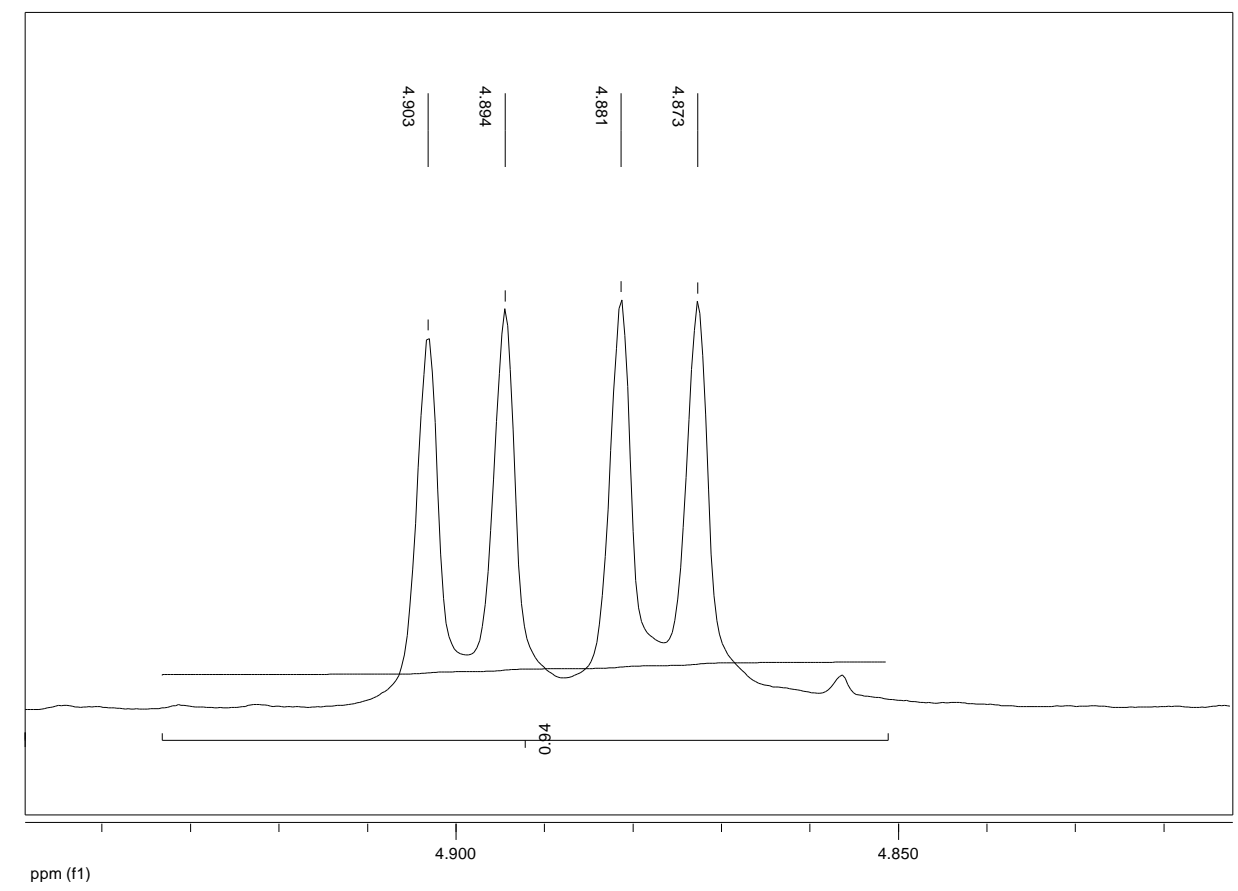




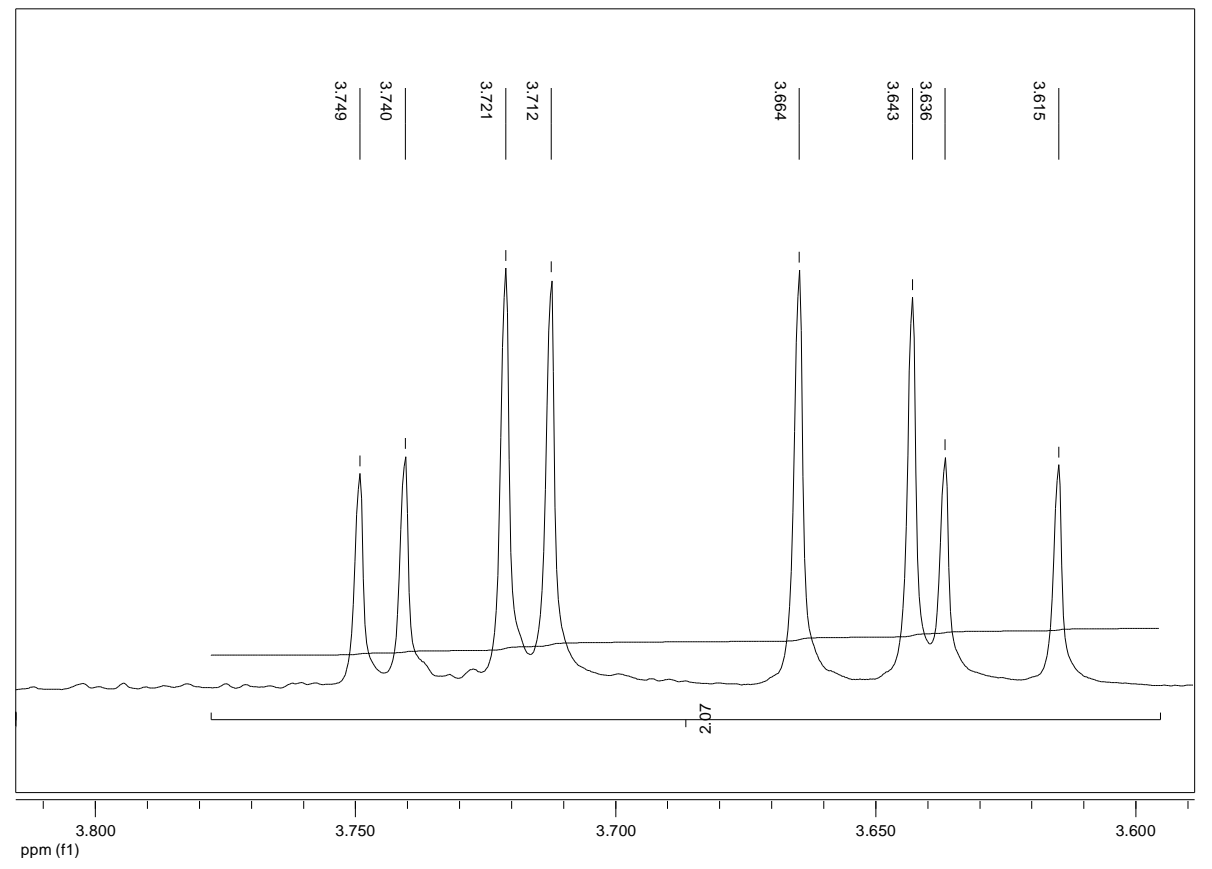

